\title{
XÂY DỰNG MÔ HÌNH \\ PHÁT HIỆN GIAN LẬN TRONG BÁO CÁO TÀI CHÍNH \\ CỦA CÁC CÔNG TY Ở VIẸTT NAM
}

\author{
Mẫn Đức Bình Minh \\ Viện Kinh tế và Kinh doanh Quốc tế, Đại học Ngoại Thương \\ E-mail: manbinhminh99@gmail.com \\ Đinh Văn Cương \\ Khoa Kế toán - Kiểm toán, Đại học Ngoại Thương \\ E-mail: cuongdinh0910@gmail.com
}

Nguyễn Thị Linh Linh

Viện Kinh tế và Kinh doanh Quốc tế, Đại học Ngoại Thương

E-mail: linh.ftu56@gmail.com

\section{ĐỀ TÀI THAM GIA XÉT GIẢI THƯỞNG “SINH VIÊN NGHIÊN CỨU KHOA HỌC” NĂM 2019}

Nguoòi hướng dẫn chính: ThS. Mai Thị Hồng

Hà Nội, Ngày 01-06-2019

Bản hiệu chỉnh 


\section{TRƯỜNG ĐẠI HỌC NGOẠI THƯƠNG}

\section{BÁO CÁO TỔNG KẾT}

ĐỂ TÀI THAM GIA XÉT

GIẢI THƯỞNG “ SINH VIÊN NGHIÊN CỨU KHOA HỌC"

NĂM 2019

XÂY DỰNG MÔ HÌNH

PHÁT HIỆN GIAN LẬN TRONG BÁO CÁO TÀI CHÍNH CỦA CÁC CôNG TY Ở VIẸTT NAM

Thuộc lĩnh vực khoa học và công nghệ: Khoa học Xã hội 


\title{
TRƯỜNG ĐẠI HỌC NGOẠI THỦƠNG
}

\author{
BÁO CÁO TỔNG KẾT \\ ĐỀ TÀI THAM GIA XÉT \\ GIẢI THƯỞNG " SINH VIÊN NGHIÊN CÚU KHOA HỌC" \\ NĂM 2019
}

XÂY DỤ̂NG MÔ HİNH

\section{PHÁT HIỆN GIAN LẬn TRONG BÁO CÁO TÀI CHÍNH \\ CỦA CÁC CÔNG TY Ỏ VIẸT NAM}

\begin{abstract}
Thuộc lĩnh vực khoa học và công nghệ: Khoa học Xã hội
\end{abstract}
Sinh viên thực hiện: Mẫn Đức Bình Minh

manbinhminh99@gmail.com

Dân tộc: Kinh

Lớp, khoa: Anh 01, Viện Kinh tế và Kinh doanh quốc tế

Ngành học : Kinh doanh quốc tế

Sinh viên thực hiện: Đinh Văn Cương

Cuongdinh0910@gmail.com

Dân tộc: Kinh

Lớp, khoa: Anh 03, khoa Kế toán - Kiểm toán

Ngành học: Kế toán - kiểm toán

Sinh viên thực hiện: Nguyễn Thị Linh Linh

Linh.ftu56@gmail.com

Dân tộc: Kinh

Lớp, khoa: Anh 02, Viện Kinh tế và Kinh doanh quốc tế

Ngành học: Thương mại quốc tế

Người hướng dẫn chính: Ths. Mai Thị Hồng
Nam/nữ: Nam

Năm thứ 2/ Số năm đào tạo: 4

Nam/nữ: Nam

Năm thứ 2/ Số năm đào tạo: 4

Nam/nữ: Nữ

Năm thứ 2/ Số năm đào tạo: 4 


\section{MỤC LỤC}

CHƯƠNG 1: Lời mở đầu

1.1. Tính cấp thiết của đề tài.................................................................... 1

1.2. Tổng quan về tình hình nghiên cứu ................................................ 2

1.3. Khoảng trống nghiên cứu và điểm mới của bài nghiên cứu............ 3

1.4. Mục tiêu nghiên cứu ...................................................................... 4

1.5. Đối tượng và phạm vi nghiên cứu ............................................................ 4

1.6. Phương pháp nghiên cứu ............................................................................5 5

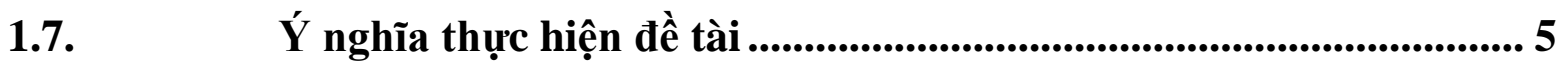

1.8. Cấu trúc nghiên cứu................................................................5 5

$\begin{array}{ll}\text { CHƯƠNG 2: Cơ sở lý luận } & 7\end{array}$

2.1. Khái niệm về gian lận trong báo cáo tài chính .................................... 7

2.2. Các lý thuyết nghiên cứu giải thích hành vi gian lận và đánh giá

khả năng gian lận........................................................................................................ 7

2.3. Một số nghiên cứu về gian lận của các tổ chức, công ty kiểm toán 10

2.4. Các công trình nghiên cứu nhận diện gian lận ................................... 13

2.5. Trách nghiệm của các bên trong phát hiện và ngăn chăn gian lận: 16

2.6. Tổng hợp lý thuyết cơ bản về gian lận................................................. 18

CHƯƠG 3: Thụ̣c trạng gian lận báo cáo tài chính tại Việt Nam 22

3.1. Tình hình gian lận báo cáo tài chính tài Việt Nam ........................... 22

3.2. Hậu quả của gian lận báo cáo tài chính ............................................... 23

3.3. Những biện pháp phổ biến thực hiện gian lận trên báo cáo tài ..... 23

CHƯƠNG 4: Mô hình đề xuất và phương pháp nghiên cứu 26

4.1. Quy trình thực hiện nghiên cứu .................................................................. 26

4.2. Giả thuyết và mô hình nghiên cứu ....................................................... 26

4.3. Tổng thể, mẫu nghiên cứu, mẫu ngoài nghiên cứu và thu thập dữ liệu 32

4.4. Phân tích dữ liệu .............................................................................33

CHƯONG 5: Thảo luận kết quả và giải pháp phòng chống gian lận 55

5.1. Thảo luận về kết quả ......................................................................... 55

5.2. Đề xuất .................................................................................................. 58 
CHƯƠNG 6: Kết luận $\quad 61$

6.1. Kết luận về các kết quả đã nghiên cứu .............................................61

6.2. Đóng góp của nghiên cứu..................................................................... 61

6.3. Hạn chế của nghiên cứu và hướng khắc phục .................................... 61

PHỤ LỤC

REFERENCES 


\section{DANH MỤC BẢNG}

Bảng 1: Báo cáo về gian lận năm 2002 - 2008 (Nguồn ACFE 2008) ..................................... 11

Bảng 2: Bảng mô tả các biến có khả năng ảnh hương đến gian lận báo cáo tài chính........... 32

Bảng 3: Bảng xác định múc trọng yếu theo VACPA ................................................................ 32

Bảng 4: Kết quả phân tích tương quan, kiểm định Jarque-Bera, kiểm định Wilcoxon/Mann-

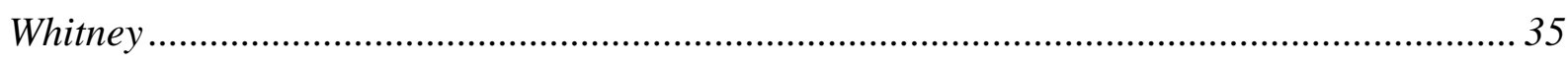

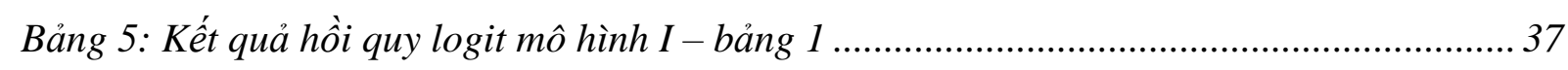

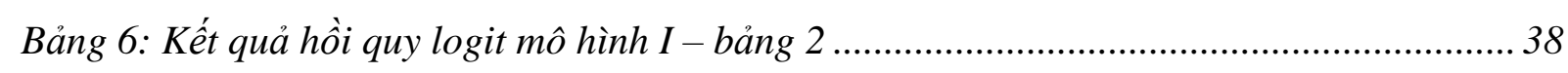

Bảng 7: Kết quả dụ đoán của mô hình I với mẫu nghiên cứu.................................................. 40

Bảng 8: Kết quả dụ đoán của mô hình I với mẫu ngoài nghiên cứu....................................... 40

Bảng 9: Kết quả phân tích tuoong quan,kiểm định Jarque-Bera, kiểm đinh Wilcoxon/Mann-

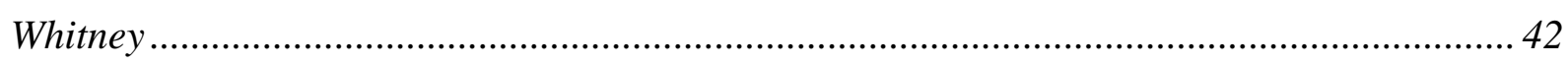

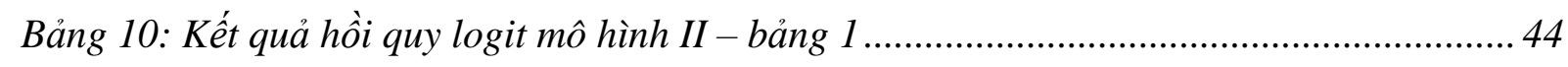

Bảng 11: Kết quả hồi quy logit mô hình II - bảng 2 ............................................................. 45

Bảng 12: Kết quả dụ đoán của mô hình II với mẫu nghiên cúu ............................................... 46

Bảng 13: Kết quả dụ đoán của mô hình II với mẫu ngoài nghiên cứu .................................... 47

Bảng 14: Kết quả phân tích tưong quan, kiểm định Jarque-Bera, kiểm định Wilcoxon/Mann-

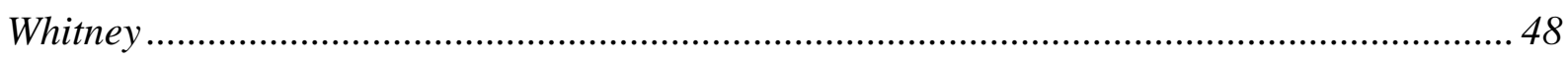

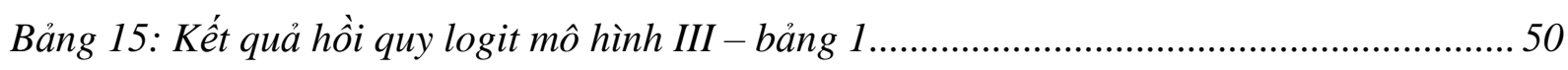

Bảng 16: Kết quả hồi quy logit mô hình III - bảng 2........................................................... 51

Bảng 17: Kết quả dụ đoán của mô hình III với mẫu nghiên cúu .............................................. 52

Bảng 18: Kết quả dụ đoán của mô hình III với mẫu ngoài nghiên cứ .................................... 53 


\section{DANH MỤC HÌNH}

Hình 1: Tam giác gian lận................................................................................. 8

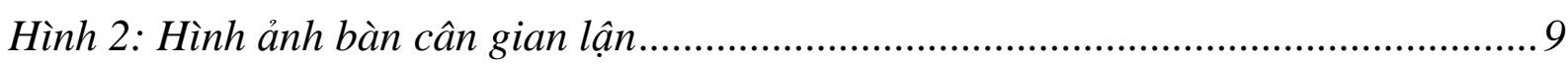

Hình 3: Các loại hình gian lận xảy ra trong 24 tháng qua (Nguồn: PwC: Khảo sát Tội phạm kinh tế và Gian lận toàn cầu 2018) .................................................................. 12

Hình 4: Tổn thất tài chính được báo cáo (Nguồn: PwC: Khảo sát Tội phạm kinh tế và

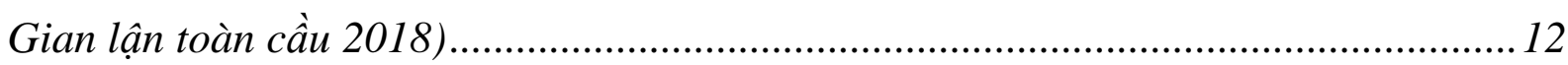

Hình 5: Tỷ lệ phát hiện gian lận kinh tế thông qua kiểm soát nội bộ và đường dây nóng tố giác, theo khu vục (Nguồn: PwC: Khảo sát Tội phạm kinh tế và Gian lận toàn cầu

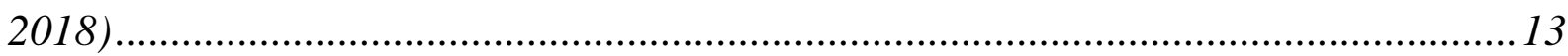

Hình 6: Biểu đồ thể hiện tỉ lệ doanh nghiệp điều chỉnh lợi nhuận (Nguồn Vietstock) 23

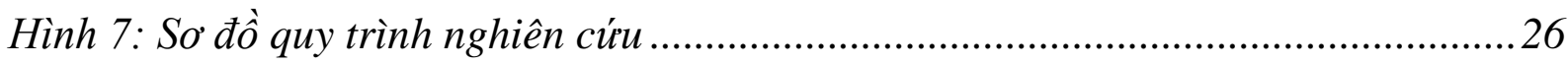




\section{DANH MỤC CÁC TÙ VIÊT TẮT}

\begin{tabular}{|c|c|c|}
\hline Từ viết tắt & Tên đầy đủ (tiếng anh) & Tên đầy đủ (tiếng việt) \\
\hline VSA & Vietnamese Standards on Auditing & Chuẩn mực kiểm toán Việt Nam \\
\hline VACPA & $\begin{array}{l}\text { Vietnam Association of Certified Public } \\
\text { Accountants }\end{array}$ & $\begin{array}{l}\text { Hội kiểm toán viên hành nghề Việt } \\
\text { Nam }\end{array}$ \\
\hline ACFE & Association of Certified Fraud Examminers & $\begin{array}{l}\text { Hiệp hội các nhà điều tra gian lận Hoa } \\
\text { Kỳ }\end{array}$ \\
\hline $\mathrm{PwC}$ & PricewaterhouseCoopers & $\begin{array}{lcc}\text { Công ty } & \text { kiểm } & \text { toán } \\
\text { PricewaterhouseCoopers } & \end{array}$ \\
\hline DSRI & Days Sales in Receivables Index & $\begin{array}{l}\text { Chỉ số phải thu khách hàng so với } \\
\text { doanh thu thuần }\end{array}$ \\
\hline GMI & Gross Margin Index & Chỉ số tỷ lệ lãi gộp \\
\hline AQI & Asset Quality Index & Chỉ số chất lượng tài sản \\
\hline SGI & Sales Growth Index & Chỉ số tăng trưởng doanh thu thuần \\
\hline DEPI & Depreciation Index & $\begin{array}{l}\text { Chỉ số tỷ lệ khấu hao của tài sản cố } \\
\text { đinh hữu hình }\end{array}$ \\
\hline SGAI & $\begin{array}{l}\text { Sales General and Administrative Expenses } \\
\text { Index }\end{array}$ & $\begin{array}{l}\text { Chỉ số chi phí bán hàng và quản lý } \\
\text { doanh nghiệp }\end{array}$ \\
\hline LVGI & Leverage Index & Chỉ số đòn bẩy tài chính \\
\hline TATA & Total Accruals to Total Assets & $\begin{array}{l}\text { Chỉ số biến dồn tích accruals so với } \\
\text { tổng tài sản }\end{array}$ \\
\hline PPE & Property, land \& equipment & Bất động sản, nhà xưởng và thiết bị \\
\hline OP & Operating profit & $\begin{array}{l}\text { Lợi nhuận từ hoạt động sản xuất kinh } \\
\text { doanh }\end{array}$ \\
\hline SAL & Sales & Doanh thu thuần \\
\hline EBT & Earnings before tax & Lợi nhuận trước thuế \\
\hline GA & General and Administrative Expenses & $\begin{array}{l}\text { Chi phí bán hàng và quản lý doanh } \\
\text { nghiệp }\end{array}$ \\
\hline TA & Total assets & Tổng tài sản \\
\hline GP & Gross profit & Lợi nhuận gộp \\
\hline $\mathrm{NI}$ & Net income & Lợi nhuân ròng sau thuế \\
\hline EQ & Equity & Vốn chủ sở hữu \\
\hline $\mathrm{CS}$ & Cost of sale & Giá vốn hàng bán \\
\hline Tac & Total accrual earnings & Các khoản dồn tích trong lợi nhuận \\
\hline $\mathrm{CFO}$ & Cash flow from operating & $\begin{array}{l}\text { Dòng tiền thuần từ hoạt đông sản xuất } \\
\text { kinh doanh }\end{array}$ \\
\hline WC & Working capital & Vốn lưu động \\
\hline CA & Current assets & Tài sản ngắn hạn \\
\hline $\mathrm{CL}$ & Current liabilities & Nợ ngắn hạn \\
\hline $\mathrm{TL}$ & Total liabilities & Tổng nợ \\
\hline INV & Inventories & Hàng tồn kho \\
\hline FA & Fixed assets & Tài sản cố định \\
\hline REC & Receivables & Nợ phải thu \\
\hline REV & Revenue & Doanh thu thuần \\
\hline CEO & Chief Executive Officer & Tổng giám đốc điều hành \\
\hline AUDREPORT & Auditor report & Ý kiến của kiểm toán viên \\
\hline LEV & Leverage & Đòn cân nợ \\
\hline KSNB & & Kiểm soát nội bộ \\
\hline
\end{tabular}




\section{CHƯƠNG 1: LỜI MỞ ĐẦU}

\subsection{Tính cấp thiết của đề tài}

Gian lận báo cáo tài chính trên thế giới ngày càng gia tăng và trở thành vấn đề nghiêm trọng đối với các doanh nghiệp, chính phủ, và các nhà đầu tư. Đặc biệt là tại các quốc gia có thị trường vốn, gian lận báo cáo tài chính đã đe dọa đến niềm tin của công chúng vào thông tin trên thị trường.

Tại Hoa Kỳ, hằng năm thiệt hại do gian lận báo cáo tài chính gây ra ước tính vào khoảng 400 tỉ USD. Các doanh nghiệp trung bình hằng năm bị thất thoát khoảng 5-6\% doanh thu do gian lận báo cáo tài chính. Trường hợp điển hình, một trong những vụ gian lận báo cáo lớn nhất lịch sử-gian lận báo cáo tài chính ở công ty Enron năm 2000 đã gây thiệt hại 80 tỉ USD trên thị trường vốn hóa cho những cá nhân, tổ chức đầu tư vào công ty này.

Tại Việt Nam, những gian lận báo cáo tài chính gần đây của công ty gỗ Trường Thành, công ty thủy sản Hùng Vương, và một loạt các công ty niêm yết trên sàn chứng khoán đã bị phát hiện đã gây ra tâm lý nghi ngờ cho nhà đầu tư, ảnh hưởng tới hoạt động của thị trường vốn.

Trong bối cảnh hiện nay, quá trình sử dụng thông tin đăng tải trên báo cáo tài chính ngày càng thể hiện vai trò quan trọng trong quản lý và đầu tư. Với tâm lí hạn chế rủi ro, các nhà đầu tư muốn biết rõ về dòng tiền mà mình đầu tư sẽ được sử dụng có hiệu quả không. Ở Việt Nam, trong thời gian gần đây, hiện tượng chênh lệch kết quả giữa các báo tài chính trước và sau kiểm toán đã tạo ra những tâm lí nghi ngại. Nhân tố này có tác động tiêu cực đến việc ra quyết định của các nhà đầu tư. Điều này có thể dẫn đến việc hạn chế dòng tiền lưu thông không hiệu quả, gây ra nhiều hệ lụy cho cả nền kinh tế nếu không có những biện pháp cải thiện tình trạng này.

Hiện nay, Bộ tài chính cũng đã ban hành chuẩn mực kiểm toán số 240 (VSA 240) quy định về trách nghiệm của kiểm toán viên liên quan đến gian lận trên báo cáo tài chính, yêu cầu kiểm toán viên phải đánh giá rủi ro sai sót trọng yếu trên báo cáo tài chính dự vào các yếu tố Động cơ/Áp lực, cơ hội và thái độ hoặc khả năng hợp lí hóa (MOF, 2012). Mặc dù vậy, các chuẩn mực này trong quá trình áp dụng vào thực tế còn gặp nhiều khó khăn. Các nhân tố này phụ thuộc lớn vào quyết định suy xét của kiểm toán viên. Đứng về góc độ của nhà đầu tư, chuẩn mực này chưa thực sự hữu ích trong quá trình ra quyết định. Thực tiễn này đòi hỏi một nghiên cứu thực tiễn đưa ra một mô hình có thể dễ dàng tiếp cận và áp dụng hơn đối với các phán đoán về mức độ gian lận trên báo cáo tài chính. Trên cơ sở đó, Nhóm nghiên cứu đề xuất đề tài: “Xây dựng mô hình phát hiện gian lận trên báo cáo tài chính ở Việt Nam”. 


\subsection{Tổng quan về tình hình nghiên cứu}

Trên thế giới hiện nay đã có nhiều nghiên cứu về hành vi gian lận, cũng như xây dựng mô hình phát hiện gian lận trên báo cáo tài chính. Những nghiên cứu này, tạo tiền đề vững chắc giúp cho các nhà quản lí, nhà đầu tư có một sự tham khảo về tổng quan doanh nghiệp, từ đó có những lựa chọn quản lí và đầu tư hiệu quả. Tuy nhiên, số lượng các nghiên cứu về vấn đề này ở Việt Nam còn hạn chế. Bởi vậy, việc sử dụng đồng thời cả hai nguồn tài liệu trong và ngoài nước giúp các tác giả có cái nhìn sâu sắc hơn, đảm bảo cho việc xây dựng một cơ sở lí luận hợp vững chắc cho đề tài này.

\subsubsection{Tổng quan về tình hình nghiên cứu nước ngoài}

Nghiên cứu của Beneish (1999) đã xây dựng mô hình M - score để phát hiện gian lận của các công ty trên $\mathrm{BCTC}$ bằng cách sử dụng mô hình xác suất đơn vị dựa trên tỷ trọng của mẫu ngoại sinh (weighted exogenous sample maximum likelihood probit) cũng như mô hình xác suất không dựa vào tỷ trọng (unweighted probit). Mẫu nghiên cứu gồm 50 công ty có điều chỉnh lợi nhuận và 1708 các công ty trên Compustat với phân loại SIC 2 chữ số của các dữ liệu trong gian đoạn 1982 - 1992. Kết quả nghiên cứu chỉ ra ngưỡng giá trị của mô hình là 1.78, công ty nào có $\mathrm{M}$ - score lớn hơn -1.78 thì có dấu hiệu gian lận lợi nhuận trên BCTC.

Nghiên cứu của Marinakis (2011) đã nghiên cứu lại mô hình M-score riêng để phù hợp với nước Anh. Ông sử dụng 11 biến, trong đó có 8 biến lấy từ mô hình của Beneish. Kết quả nghiên cứu của tác giả cho thấy việc cải thiện mô hình có nhiêu khả năng hơn trong phát hiện gian lận, Marinakis cũng điều chỉnh ngưỡng là -1.31 , lớn hơn ngưỡng $\mathrm{M}$ - score của Beneish.

Nghiên cứu của Dechow et al. (2011) đã nghiên cứu mô hình phát hiện gian lận bóp méo ở cả 3 câp độ và đặt tên là $\mathrm{F}$ - score. Mẫu nghiên cứu bao gồm 2190 công ty niêm yết trong giai đoạn 1982 -2005 trên AAERs (Acoounting Auditing Enforcement Releases). Kết quả nghiên cứu chỉ ra, với ngưỡng giá trị là 1 , khi F-score lớn hơn 1 thì có khoảng xác suất dự án đúng là $65.9 \%$ các công ty trên báo cáo tài chính. Con số này đối là $65.78 \%$ và $66.38 \%$ đối vưới mô hình $\mathrm{F}$ - score 2 và $\mathrm{F}$ - score 3.

Nghiên cứu của Rasa Kanapickiene và Zivile Grundiene (2015) đã nghiên cứu sự ảnh hưởng của các chỉ số tài chính bằng phương pháp hồi quy logistic. Mẫu nghiên cứu được thực hiện bao gồm 125 báo cáo không gian lận và 40 báo cáo tài chính không gian lận. Kết quả nghiên cứu chỉ ra rằng khi xác xuất dự đoán gian lận lớn hơn $50 \%$ thì $84.8 \%$ kết quả được dự đoán là đúng.

Mô hình Mary Jane Leonard đã nghiên cứu sự kết hợp giữa mô hình dự báo phá sản và mô hình dự báo gian lận bằng phương pháp định lượng sử dụng hồi quy logit .Mẫu nghiên 
cứu được thực hiện với quan sát gồm 2 giai đoạn, bao gồm: mẫu quan sát "1990's sample" gồm 26 công ty là sự tổng hợp của 13 công ty gian lận và 13 công ty không gian lận trên compusat trong giai đoạn từ 1996 - 2000 và mẫu quan sát "2000's sample" gồm 34 công ty nhằm xem xét sự phát hiện này, trong đó bao gồm 17 công ty có gian lận lớn (năm 2001) và 17 công ty bất kì thuộc danh sách Fortune 1000 trên cơ sở dữ liệu Edgar Database. Kết quả nghiên cứu chỉ ra các biến trong mô hình phát hiện phá sản cũng chính là những chỉ báo phát hiện gian lận (Leonard \& Alam, 2009).

Trên thực tế đã có rất nhiều nghiên cứu về chủ đề xây dựng mô hình phát hiện gian lận báo cáo tài chính, tuy nhiên các nghiên cứu chủ yếu tập trung việc sử dụng một mô hình duy nhất làm thước đo. Bên cạnh đó, các nghiên cứu cũng chủ yếu dựa trên các thông tin đã được lượng hóa trên báo cáo tài chính mà không chí ý đến sự ảnh hưởng của nhiều biến định danh khác như sự kiêm nhiệm vai trò chủ tịch và giám đốc điều hành, hay kiểm toán viên có uy tín không, ...

\subsubsection{Nghiên cứu trong nước}

Nghiên cứu của Tân et al. (2014) đã nghiên cứu sự ảnh hưởng của tam giác gian lận theo hướng dẫn của chuẩn mực kiểm toán (VSA 240) trong việc phát hiện gian lận các công ty niêm yết trên sàn chứng khoán Hồ Chí Minh (HOSE) bằng phương pháp hồi quy logit. Mô hình sử dụng mẫu nghiên cứu gồm 78 công ty niêm yết trên sàn HOSE trong năm 2012. Kết quả nghiên cứu chỉ ra rằng khả năng gian lận có ý nghĩa thống kê với các mẫu trong tam giác gian lận, và mô hình có khả năng dự đoán đúng 83.33 \% các công ty thuộc mẫu nghiên cứu.

Nghiên cứu của Nguyễn Công Phương và Nguyễn Trần Nguyên Trân (2014) đã nghiên cứu mô hình Beneish khi áp dụng tại thị trường Việt Nam. Các tác giả đã sử dụng mẫu nghiên cứu gồm 30 công ty có sai sót trọng yếu trong báo cáo tài chính năm 2012 do kiểm toán viên phát hiện. Kết quả nghiên cứu cho thấy, khi áp dụng trực tiếp mô hình Beneish tại Việt Nam thì xác suất dự đoán đúng là 53.33 \% các công ty thuộc mẫu nghiên cứu.

Nghiên cứu của Nguyễn Anh Hiền và Phạm Thanh Trung (2015) đã nghiên cứu áp dụng ba mô hình nghiên cứu của các tác giả trên thế giới về hành vi điều chỉnh lợi nhuận, bao gồm mô hình của Jones (1991), mô hình của Jones cải tiến của Dechow et al. (1996) và mô hình của Kothari et al. (2005) khi áp dụng vào thị trường Việt Nam. Mẫu nghiên cứu được thực hiện trên 280 công ty trên cả hai sàn là Hà Nội (HNX) và Hồ Chí Minh (HOSE). Kết quả nghiên cứu chỉ ra mô hình của Dechow et al. (1996) và Kothari et al. (2005) có ý nghĩa trong việc nhận diện hành vi điều chỉnh lợi nhuận của nhà quản lí.

\subsection{Khoảng trống nghiên cứu và điểm mới của bài nghiên cứu}

Các nghiên cứu trước đây chưa đi vào việc quan sát sự biến động tương quan của các chỉ số tài chính trong các năm trước năm phát hiện ra gian lận báo cáo tài chính để từ đó xây 
dựng mô hình nhận diện gian lận báo cáo tài chính, chưa nghiên cứu gian lận trên phạm vi rộng lớn, nên chưa có được đánh giá tổng quan về gian lận.Có thể thấy, các nghiên cứu ở Việt Nam về gian lận hay mô hình dự báo gian lận cũng chưa thật đầy đủ và sâu sắc. Dữ liệu sử dụng trong các nghiên cứu đa phần còn hạn chế và các nghiên cứu chủ yếu tiếp cận thông qua sử dụng trực tiếp mô hình trên thế giới.

Điểm mới trong bài nghiên cứu của nhóm nghiên cứu:

(1) Tích hợp, phân tích, nghiên cứu từ nhiều mô hình, lý thuyết của các tác giả đi trước để có thể xây dựng mô hình tổng quan phù hợp với những đặc điểm riêng của thị trường Việt Nam.

(2) Nhóm nghiên cứu sử dụng nguồn dữ liệu với quy mô lớn hơn, nhằm mang tính dự báo tốt hơn để đành giá gian lận của trên báo cáo tài chính.

(3) Nhóm nghiên cứu cũng sử dụng đa dạng các chỉ số sau khi sàng lọc nhằm tăng hiệu quả dự báo của mô hình.

(4) Nhóm nghiên cứu kết hợp các mô hình lại với nhau nhằm tăng khả năng nhận diện trong báo cáo tài chính tốt hơn, tạo một mô hình có độ chặt cao, giúp các nhà đầu tư có thể tham khảo trong việc thực hiện kế hoạch đầu tư của mình.

\subsection{Mục tiêu nghiên cứu}

Nghiên cứu được thực hiện nhằm hướng tới sự xây dựng mô hình phát hiện gian lận trên báo cáo tài chính ở Việt Nam.

Các mục tiêu được xác định gồm:

Xây dựng lý thuyết về gian lận trong báo cáo tài chính và các mô hình áp dụng trong nhận diện gian lận trong báo cáo tài chính.

Thiết lập quy trình nghiên cứu, giả thuyết, cách chọn mẫu, từ đó xây dựng mô hình phát hiện gian lận.

Trình bày các kết quả, giải thích ý nghĩa và thảo luận về ý nghĩa của kết quả nghiên cứu.

\section{5. Đối tượng và phạm vi nghiên cứu}

Đối tượng: mô hình phát hiện gian lận trên báo cáo tài chính

Phạm vi nghiên cứu bao gồm không gian và thời gian nghiên cứu:

- Không gian: Nhóm nghiên cứu xây dựng mô hình phát hiện gian lận trên báo cáo tài chính của các công ty có niêm yết trên sàn chứng khoán HOSE. Đồng thời, nhóm nghiên cứu cũng dữ liệu thuộc hệ thống Fiinpro,cung cấp bởi công ty StoxPlus, được Đại học Ngoại Thương cung cấp cho Giảng viên và Sinh viên.

- Thời gian: Nhóm nghiên cứu đánh giá thực trạng gian lận trong báo cáo tài chính của các doanh nghiệp trong giai đoạn 2016-2018. 


\subsection{Phương pháp nghiên cứu}

Đầu tiên, nhóm nghiên cứu thực hiện phương pháp nghiên cứu, tìm hiểu và tổng hợp từ các nghiên cứu đi trước để rút kinh nghiệm từ đó tư duy xây dựng mô hình của mình.

Sau đó, nhóm nghiên cứu sử dụng phương pháp nghiên cứu định lượng, thu thập dữ liệu sơ cấp thông qua phần mềm Fiinpro, thu thập từ những website chuyên về đầu tư chứng khoán như vietstock.vn, cafef.vn, và trên các trang web của công ty.

Những thông tin không được lượng hóa trong phần mềm từ các BCTC của doanh nghiệp được công bố. Tiếp theo, nhóm nghiên cứu tổng hợp, phân tích dữ liệu bằng các phần mềm như Excel, Eview.

Ba câu hỏi được đặt ra trong quá trình nghiên cứu là:

Q1: Các trường hợp gian lận báo cáo tài chính tại Việt Nam có được phát hiện thông qua các chỉ số tài chính hay không?

Q2: Nếu các chỉ số chứng minh được khả năng phát hiện gian lận thì sẽ được kết hợp trong mô hình như thế nào, hiệu quả của mô hình ra sao?

Q3: Giải pháp nào để hạn chế tình trạng gian lận báo cáo tài chính ?

\section{7. Ý nghĩa thực hiện đề tài}

Thông qua khảo sát, thống kê kết hợp nghiên cứu tài liệu, bài nghiên cứu xây dựng cơ sở lý thuyết một cách tổng quát về gian lận, chỉ ra thực trạng gian lận,tổng hợp các thủ thuật được sử dụng để làm đẹp báo cáo tài chính của công ty niêm yết xây dựng mô hình nhận diện gian lận.

Đưa ra những đề xuất đối với kiểm toán viên, nhà đầu tư và ban quản lý có thêm hiểu biết về sai sót trọng yếu do gian lận và có định hướng đúng đắn để ứng phó với gian lận trên báo cáo tài chính theo hướng hiệu quả, chính xác và nhanh chóng hơn.

\subsection{Cấu trúc nghiên cứu.}

Bên cạnh lời mở đầu, kết luận, mục lục, danh mục từ viết tắt, danh mục bảng, hình vẽ, danh mục tài liệu tham khảo, và các phụ lục, bài nghiên cứu có kết cấu 6 chương:

Chương 1: Lời mở đầu

Chương 2: Cơ sở lý luận về gian lận trong báo cáo tài chính và các mô hình áp dụng trong nhận diện gian lận trong báo cáo tài chính.

Chương 3: Thực trạng gian lận báo cáo tài chính ở Việt Nam.

Chương 4: Mô hình và phương pháp nghiên cứu: trình bày về quy trình nghiên cứu, giả thuyết, mô hình nghiên cứu, cách chọn mẫu và phân tích dữ liệu.

Chương 5: Kết quả và thảo luận triển khai các kết quả, giải thích ý nghĩa và thảo luận về ý nghĩa của kết quả nghiên cứu. 
Chương 6: Kết luận về bài nghiên cứu, đóng góp, hạn chế và phương hướng khắc phục của nghiên cứu 


\section{CHƯƠNG 2: CƠ SỞ LÝ LUẬN}

\subsection{Khái niệm về gian lận trong báo cáo tài chính}

Theo giải thích thuật ngữ đoạn 11, phần I - Quy định chung của chuẩn mực kiểm toán VSA 240, gian lận là hành vi cố ý do một hay nhiều người trong Ban quản trị, Ban Giám đốc, các nhân viên hoặc bên thứ ba thực hiện bằng các hành vi gian dối để thu lợi bất chính hoặc bất hợp pháp. Các yếu tố dẫn đến rủi ro có gian lận: Là các sự kiện hoặc điều kiện phản ánh một động cơ hoặc áp lực phải thực hiện hành vi gian lận hoặc tạo cơ hội thực hiện hành vi gian lận. Gian lận có thể biểu hiện dưới các dạng tổng quát sau:

- Xuyên tạc, làm giả chứng từ, tạo lập những hợp đồng giả, tạo lập các khách hàng ảo, tài liệu liên quan đến báo cáo tài chính ghi chép các nghiệp vụ kinh tế không đúng sự thật.

- Sửa đổi tài liệu, chứng từ kế toán làm sai lệch báo cáo tài chính, gây ra sai sót trong số liệu kế toán.

- Biển thủ tài sản.

- Cố ý áp dụng sai các chuẩn mực, nguyên tắc, phương pháp và chế độ kế toán, chính sách tài chính.

- Che dấu hoặc cố ý bỏ sót các thông tin, tài liệu hoặc nghiệp vụ kinh tế làm sai lệch báo cáo tài chính.

Mặc dù gian lận là một khái niệm pháp lý rất rộng, nhưng trong nghiên cứu này, nhóm nghiên cứu chỉ quan tâm đến gian lận dẫn đến sai sót trọng yếu trong báo cáo tài chính do lập báo cáo tài chính gây ra.

\subsection{Các lý thuyết nghiên cứu giải thích hành vi gian lận và đánh giá khả năng} gian lận

\subsubsection{Lý thuyết nghiên cứu giải thích hành vi gian lận}

2.2.1.1. Lý thuyết ủ̉y nhiệm của Jensen \& Meckling (1976) và lý thuyết các đối tự̛ng có liên quan của Freeman (1984)

Lý thuyết ủy nhiệm của Jensen \& Meckling (1976) cho rằng bên được ủy nhiệm (nhà quản lý) có thể thực hiện hành vi gian lận báo cáo tài chính để phục vụ lợi ích của cá nhân thay vì phục vụ mục đích của chủ sở hữu. Điều này là do có phân tách giữa quyền sở hữu và quyền điều hành công ty.

Trong khi đó, lý thuyết các đối tượng có liên quan của Freeman (1984) cho rằng một trong những nguyên nhân dẫn tới gian lận là nhằm trục lợi trong cá mối quan hệ với các bên có liên quan tới công ty như chủ nợ, Nhà nước, nhà cung cấp, chủ sở hữu,.. 


\subsubsection{Lý thuyết tam giác gian lận bởi Cressey (1953)}

Theo nghiên cứu của Cressey (1953), có ba yếu tố dẫn tới hành vi gian lận tạo thành một tam giác gian lận. Đó là động cơ hoặc áp lực, cơ hội và thái độ.

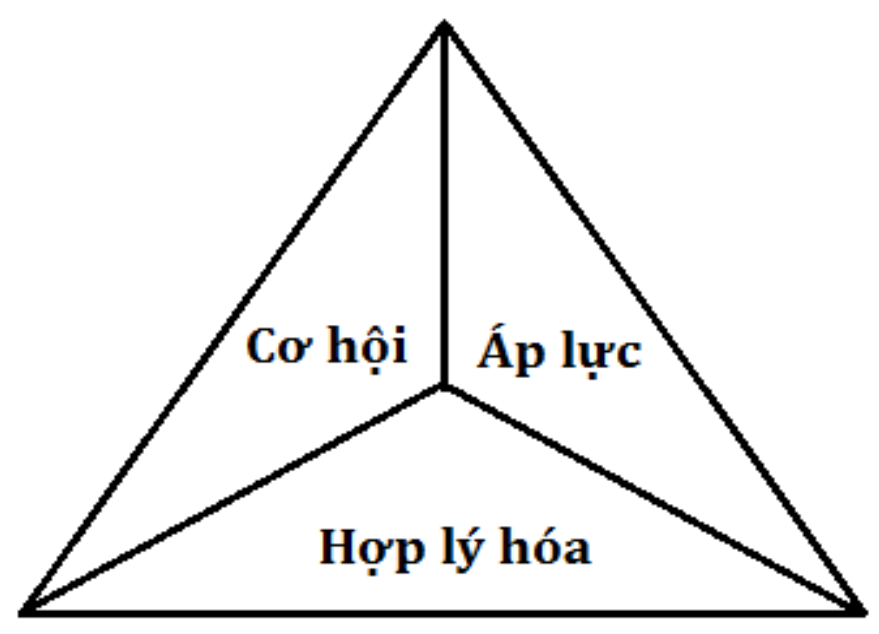

\section{Hình 1: Tam giác gian lận}

Áp lực bao gồm khó khăn về tài chính, hậu quả từ thất bại cá nhân, các khó khăn về kinh doanh, bị cô lập, muốn ngang bằng với người khác hoặc do quan hệ giữa chủ - thợ. Chính những áp lực này tạo nên động cơ gian lận để giảm bớt áp lực cho cá nhân, tổ chức.

Bên cạnh đó để có thể thực hiện hành vi gian lận, các nhân, tổ chức cần phải có những cơ hội cho hành vi gian lận của mình. Cơ hội đến từ việc có khả năng có được các thông tin dẫn tới gian lận, hoặc có khả năng thực hiện các gian lận đó.

Mặc dù có những áp lực, cơ hội để gian lận, tuy nhiên, việc thực hiện hành vi gian lận còn phụ thuộc vào thái độ, sự hợp lý hóa của cá nhân, người quản trị tổ chức. Do đó thái độ của từng cá nhân cũng là yếu tố ảnh hưởng tới gian lận.

Như vậy ta thấy lý thuyết tam giác gian lận của Cressey có khả năng áp dụng để đánh giá gian lận trên báo cáo tài chính.

\subsubsection{Lý thuyết bàn cân gian lận của D.W. Steve Albrecht (1980)}

Nghiên cứu phân tích 212 trường hợp gian lận vào những năm 1980, dưới sự tài trợ của Hiệp hội các nhà sáng lập chuyên nghiên cứu về kiểm toán nội bộ. Tác giả đã xây dựng 50 dấu hiệu gian lận tập trung vào 2 đối tượng là nhân viên và tổ chức. Trong đó, một số dấu hiệu liên quan đến tổ chức:

- Đặt quá nhiều lòng tin vào tổng giám đốc và ban giám đốc với kỳ vọng lợi nhuận đem lại cho công ty cao. 
- Thiếu thủ tục phê chuẩn thích hợp, thiếu các quy định chặt chẽ liên quan tới hành vi gian lận.

- Không yêu cầu công bố đầy đủ thông tin về các mối quan hệ, các khoản đầu tư và thu nhập cá nhân.

- Không tách biệt chức năng bảo quản tài sản và xét duyệt, thiếu kiểm tra hay soát xét độc lập việc thực hiện.

- Các hoạt động kinh doanh của công ty không được giám sát, kiểm duyệt thường xuyên, tạo cơ hội cho ban giám đốc thực hiện hành vi phạm tội.

- Chức năng kế toán không tách biệt chức năng bảo quản tài sản, tạo cơ hôi thực hiện hành vi phạm tội như biên thủ tài sản.

- Không tách biệt một số chức năng về kế toán, điều này rất dễ tạo cơ hội cho gian lận.

- Không có quy định rõ rang về quyền hạn, trách nghiệm và công việc cho mỗi cá nhân trong tổ chức.

- Thiếu kiểm toán nội bộ, kiểm toán nội bộ còn nhiều yếu kém, kiểm toán nội bộ có quan hệ với ban giám đốc.

Mô hình bàn cân gian lận được đưa ra gồm 3 yếu tố là:

- $\quad$ Hoàn cảnh tạo ra:

$+\quad$ Áp lực

$+\quad$ Cơ hội

- Tính trung thực của cá nhân.

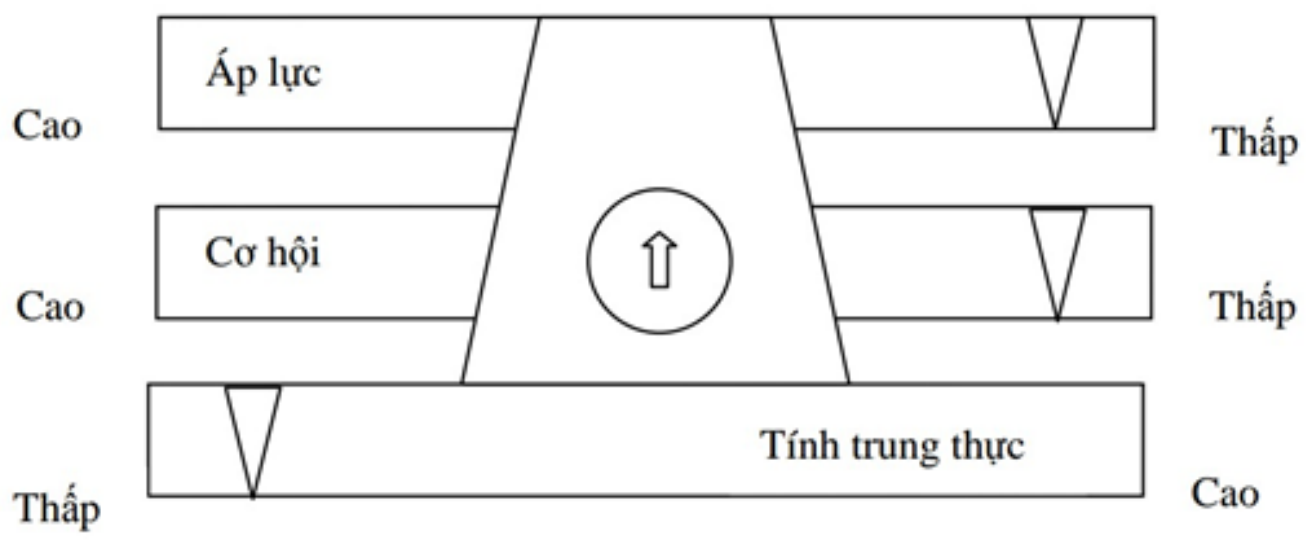

Hình 2: Hình ảnh bàn cân gian lận

Hoàn cảnh tạo cơ hội, áp lực lớn cho cá nhân, tổ chức đi kèm với tính trung thực thấp thì nguy cơ cá nhân, tổ chức đó thực hiện hành vi gian lận cao hơn. Khi hoàn cảnh tạo ra áp 
lực, cơ hội thực hiện gian lận thấp cùng với tính liêm chính cao, nguy cơ xảy ra gian lận là rất thấp.

\subsubsection{Chuẩn mục kiểm toán 240}

Mặc dù không phải là một nghiên cứu chính thức nhưng chuẩn mực kiểm toán VSA 240 đã nêu ra một loạt các ví dụ về các yếu tổ dẫn đến rủi ro có gian lận trong phần phụ lục 1 . Bao gồm rủi ro có gian lận liên quan đến sai sót phát sinh từ việc lập báo cáo tài chính gian lận và rủi ro liên quan đến sai sót do biển thủ tài sản. Nghiên cứu này sẽ chỉ tập trung vào gian lận liên quan đến sai sót phát sinh từ việc lập báo cáo tài chính gian lận.

Theo phần III - Hướng dẫn áp dụng, đoạn A1 đến A6 của chuẩn mực kiểm toán VSA 240, yếu tố dẫn tới rủi ro có gian lận liên quan đến sai sót phát sinh từ việc lập báo cáo tài chính gian lận bao gồm động cơ hoặc áp lực, cơ hội và thái độ hoặc sự biện minh cho hành động. Động cơ hoặc áp lực có thể tới từ việc giữ ổn định tài chính, khả năng sinh lời của doanh nghiệp; hoặc áp lực từ bên thứ ba; hoặc được tạo ra bởi mục tiêu tài chính mà ảnh hưởng tới lợi ích của Ban quản trị hoặc Ban giám đốc. Cơ hội dẫn tới gian lận xuất phát từ đặc điểm của ngành hay đơn vị hoặc do hoạt động của doanh nghiệp không được hiệu quả khiến việc kiểm soát khó khăn. Cuối cùng thái độ hoặc sự biện minh cho hành động.

Như vậy ta có thể thấy các ví dụ về gian lận liên quan đến lập báo cáo tài chính gian lận trong chuẩn mực kiểm toán VSA 240 được đưa ra cùng cơ sở với lý thuyết tam giác gian lận.

\subsection{Một số nghiên cứu về gian lận của các tổ chức, công ty kiểm toán}

\subsubsection{Hiệp hội các nhà điều tra gian lận Hoa Kỳ (ACFE) (1993-2012)}

Nghiên cứu gửi bảng câu hỏi cho các đối tượng nhằm thu thập thông tin về các trường hợp gian lận mà họ từng chứng kiến từ năm 1993 đến năm 2012. Kết quả nghiên cứu đã chỉ ra:

Biển thủ tài sản: là hành vi nhân viên ăn cắp tài sản của tổ chức( biên thủ tiền, vàng, biên thủ hàng tồn kho, biên thủ nguyên vật liệu, công cụ dụng cụ ...)

Tham ô: là hành vi người có quyền sử dung quyền lực của mình để chiếm đoạt tài sản của tổ chức, hành động trái ngược với các nghĩa vụ họ đã cam kết với tổ chức để làm lợi cho bản thân hay một bên thứ ba.

Gian lận trên Báo cáo tài chính: là hành vi làm sai lệch thông tin báo cáo tài chính nhằm cố ý lừa gạt người sử dụng thông tin để giải quyết những áp lực của công ty hoặc làm tư lợi cho ban giám đốc. (Ví dụ khai khống doanh thu, khai giảm nợ phải trả hay chi phí).

Nghiên cứu đã chỉ ra rằng trong các trường hợp khảo sát, gian lận liên quan đến tài sản tuy chiếm khoảng $90 \%$ trường hợp nhưng mức thiệt hại cho nền kinh tế là thấp nhất. Trong 
khi đó, các gian lận trên Báo cáo tài chính, tuy chiếm tỷ lệ thấp nhất nhưng hậu quả gây ra cho nền kinh tế là lớn nhất.

Số lượng nhân viên thực hiện gian lận do nhân viên > nhà quản lý > chủ sở hữu, nhà quản lý cấp cao song mức độ tổn thất do nhân viên thực hiện gian lận < nhà quản lý < chủ sở hữu, nhà quản lý cấp cao.

Các doanh nghiệp nhỏ có tỉ lệ gian lận cào hơn do thiếu nhân lực trong việc quản lý và điều hành, dẫn đến năng lực quản lý yếu kém và khả năng gian lận cao hơn.

Mức lỗ bình quân trong 1 trường hợp gian lận là 140.000 đôla Mỹ, đặc biệt có 1/15 các trường hợp này gây ra lỗ ít nhất 1 triệu đôla Mỹ.

Báo cáo gian lận thường kéo dài bình quân khoảng 18 tháng trước khi bị phát hiện.

Từ bảng 1 cho thấy tỉ lệ tội phạm biên thủ tài sản và tham ô ở mức cao (năm 2008 là $88.7 \%$ và $27.4 \%$ ) tuy nhiên chỉ gây thiệt hại ở mức thấp (năm 2008: 150 ngàn và 375 ngàn USD), trong khi đó tỉ lệ gian lận báo cáo tài chính ở mức thấp (năm 2008 là 10.3\%) nhưng lại gây thiệt hại kinh tế lớn (2000 ngàn USD năm 2008).

\begin{tabular}{|c|c|c|c|c|c|c|c|c|}
\hline \multirow[b]{2}{*}{$\begin{array}{l}\text { Loại } \\
\text { gian lận }\end{array}$} & \multicolumn{2}{|c|}{ Năm 2002} & \multicolumn{2}{|c|}{ Năm 2004} & \multicolumn{2}{|c|}{ Năm 2006} & \multicolumn{2}{|c|}{ Năm 2008} \\
\hline & $\begin{array}{l}\text { Tỷ lệ } \\
(\%)\end{array}$ & $\begin{array}{l}\text { Thiệt } \\
\text { hại } \\
\text { (Ngàn } \\
\text { USD) }\end{array}$ & $\begin{array}{l}\text { Tỷ lệ } \\
(\%)\end{array}$ & $\begin{array}{l}\text { Thiệt } \\
\text { hại } \\
\text { (Ngàn } \\
\text { USD) }\end{array}$ & $\begin{array}{l}\text { Tỷ lệ } \\
(\%)\end{array}$ & $\begin{array}{l}\text { Thiệt } \\
\text { hại } \\
\text { (Ngàn } \\
\text { USD) }\end{array}$ & $\begin{array}{l}\text { Tỷ lệ } \\
(\%)\end{array}$ & $\begin{array}{l}\text { Thiệt } \\
\text { hại } \\
\text { (Ngàn } \\
\text { USD) }\end{array}$ \\
\hline $\begin{array}{l}\text { Biển } \\
\text { thủ, lạm } \\
\text { dụng tài } \\
\text { sản }\end{array}$ & 85,7 & 80 & 92,7 & 93 & 91,5 & 150 & 88,7 & 150 \\
\hline Tham ô & 12,8 & 530 & 30,1 & 250 & 30,8 & 538 & 27,4 & 375 \\
\hline $\begin{array}{l}\text { Gian lận } \\
\text { trên báo } \\
\text { cáo tài } \\
\text { chính }\end{array}$ & 5,1 & 4250 & 7,9 & 1000 & 10,6 & 2000 & 10,3 & 2000 \\
\hline
\end{tabular}

Bảng 1: Báo cáo về gian lận năm 2002 - 2008

(Nguồn: ACFE, 2008) 


\subsubsection{Khảo sát của công ty PriceWaterHouseCoopers (PwC) "Khảo sát về tội phạm}

\section{kinh tế và gian lận toàn cầu 2018 - Đưa hành vi gian lận ra ánh sáng - Góc nhìn}

\section{Việt Nam"}

Khảo sát chỉ ra rằng gian lận liên quan tới kế toán, tham nhũng, biên thủ tài sản chiếm tỉ lệ cao. Trong đó 52\% các doanh nghiệp ở Việt Nam đã và đang đối mặt với tội phạm gian lận, dựa trên kinh nghiệm của $\mathrm{PwC}$ về công tác phòng, chống gian lận, 40\% số người tham gia khảo sát cho biết họ chưa từng đối mặt với tội phạm gian lận, thì rất có thể là do các gian lận này chưa bị phát giác.

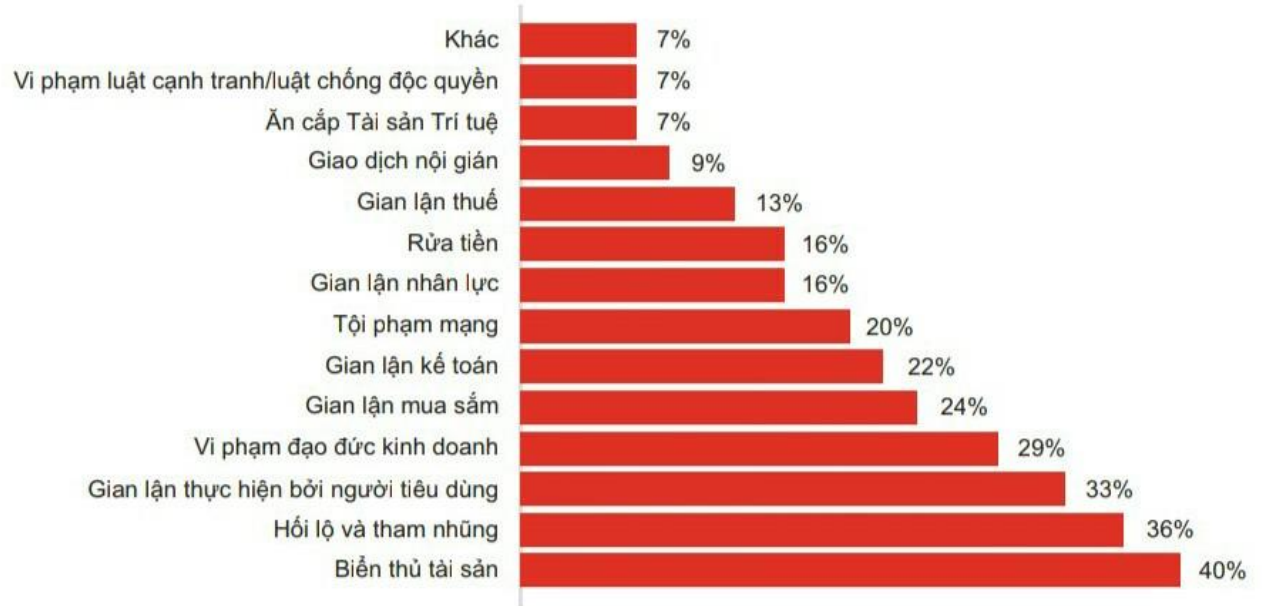

Hình 3: Các loại hình gian lận xảy ra trong 24 tháng qua

(Nguồn: PwC, 2018)

Gian lận kế toán chiếm 22\%, gian lận thuế chiếm 13\%, gian lận mua sắm chiếm $24 \%$, vi phạm đạo đức kinh doanh chiếm 29\%. Các loại gian lận này có liên quan chặt chẽ với gian lận báo cáo tài chính.

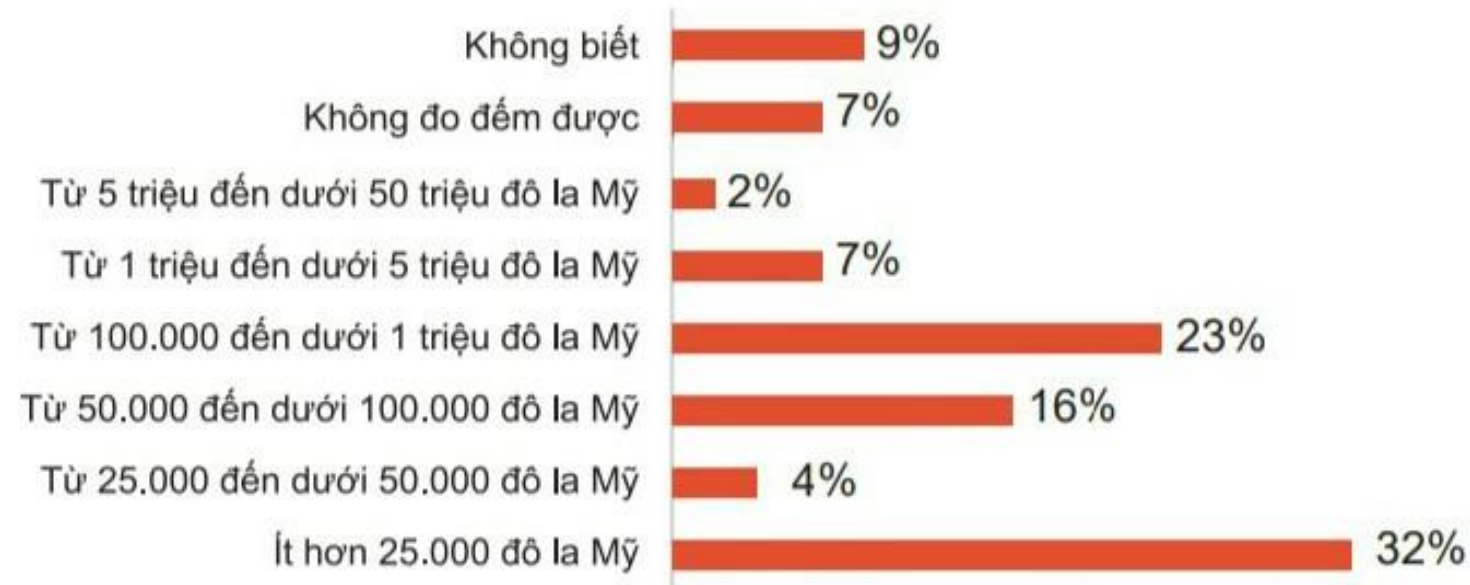

Hình 4: Tổn thất tài chính được báo cáo 
(Nguồn: PwC, 2018)

Khảo sát cũng cho thấy những tổn thất do gian lận gây ra. $53 \%$ các tổ chức tham gia khảo sát cho biết họ chịu tổn thất dưới 100.000 đô la Mỹ (tương đương 2,3 tỷ đồng) trong vòng 2 năm vừa qua. Gần một phần ba $(32 \%)$ số người tham gia khảo sát ước tính họ đã gánh chịu tổn thất hơn 100.000 đô la Mỹ từ các vụ gian lận.

Khảo sát chỉ ra rằng $53 \%$ các vụ gian lận kinh tế có thủ phạm là người trong nội bộ của tổ chức, các sự vụ gian lận do các đối tượng bên ngoài tổ chức chiếm $36 \%$.

Tại Việt Nam, tỉ lệ phát hiện gian lận kinh tê qua kiểm toán nội bộ chiếm tỉ trọng ít là $3 \%$.

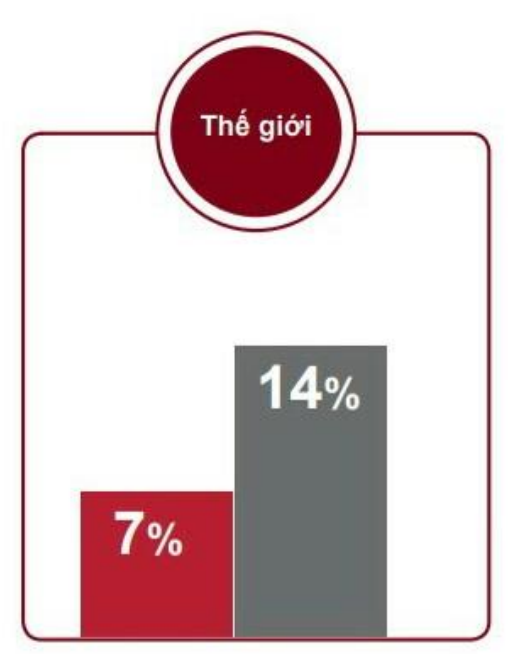

Đường dây nóng tố giác
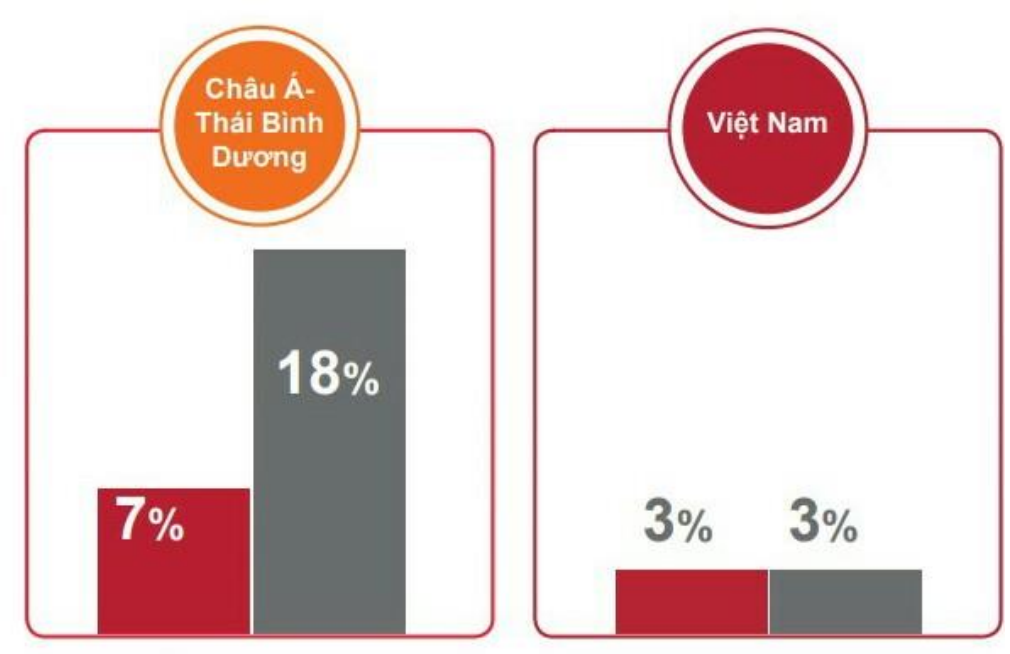

Kiểm toán nội bộ

Hình 5: Tỷ lệ phát hiện gian lận kinh tế thông qua kiểm soát nội bộ và đương dây nóng tố giác, theo khu vục

(Nguồn: PwC, 2018)

Khảo sát cũng chỉ ra rằng tăng cường áp dụng chương trình Đạo đức kinh doanh và tuân thủ, nâng cao chất lượng kiểm toán nội bộ sẽ góp phần ngăn chặn gian lận kinh tế và gian lận báo cáo tài chính.

\subsection{Các công trình nghiên cứu nhận diện gian lận}

\subsubsection{Mô hình M-score của Beneish}

Mô hình M-score của Beneish là một mô hình được sử dụng rộng rãi để phân biệt gian lận trên báo cáo tài chính của các công ty (Beneish \& Press, 1993; Beneish, 1997, 1999).

Theo Beneish (1999) có 8 chỉ số Chỉ số phải thu khách hàng so với doanh thu thuần (DSRI), Chỉ số tỷ lệ lãi gộp (GMI), Chỉ số chất lượng tài sản (AQI), Chỉ số tăng trưởng doanh thu bán hàng (SGI), Chỉ số tỷ lệ khấu hao của TSCĐ hữu hình (DEPI), Chỉ số chi phí 
bán hàng và quản lý doanh nghiệp (SGAI), Chỉ số đòn bẩy tài chính (LVGI) có thể được các công ty vận dụng để thực hiện hành vi gian lận báo cáo tài chính. Trong đó:

DSRI = (Khoản phải thu $\mathrm{t} /$ Doanh thu thuần $\mathrm{t})$ / (Khoản phải thu $\mathrm{t}-1 /$ Doanh thu thuần $\mathrm{t}-1)$

GMI = Tỷ lệ lãi gộp t-1/ Tỷ lệ lãi gộp t = [Lợi nhuận gộp t-1 / Doanh thu t-1] / [Lợi nhuận gộp t / Doanh thu t]

$$
\mathrm{AQI}=[1-(\mathrm{CAt}+\mathrm{PPEt}) / \mathrm{TAt}] /[1 \text { - (CAt-1 + PPEt-1) / TAt-1) }]
$$

PPE: Giá trị còn lại của tài sản dài hạn hữu hình (gồm TSCĐ hữu hình, TSCĐ thuê tài chính, giá trị xây dựng cơ bản dở dang, bất động sản đầu tư) và quyền sử dụng đất; $\mathrm{CA}$ : Tài sản ngắn hạn; TA: Tổng tài sản.

$\mathrm{SGI}=$ Doanh thu $\mathrm{t} /$ Doanh thu $\mathrm{t}-1$

DEPI = [Chi phí khấu hao t-1/ (PPE t-1 + Chi phí khấu hao t-1)]/ [Chi phí khấu hao t/ (PPE $\mathrm{t}+$ Chi phí khấu hao $\mathrm{t})]$

$\mathrm{SGAI}=(\mathrm{SGA} \mathrm{t} /$ Doanh thu $\mathrm{t}) /(\mathrm{SGA} \mathrm{t}-1 /$ Doanh thu $\mathrm{t}-1)$

SGA: Chi phí bán hàng và chi phí quản lý doanh nghiệp

TATA $=($ Lợi nhuận trước thuế $\mathrm{t}$ - Tiền thuần từ sản xuất kinh doanh $\mathrm{t}$ ) / Tổng tài sản t/

LVGI = [Nợ phải trảt / Tổng tài sảnt] / [Nợ phải trảt-1/ Tổng tài sảnt-1]

Từ đó bằng phương pháp hồi quy probit tác giả xây dựng một mô hình gồm các chỉ số tài chính nhằm nhận diện gian lận báo cáo tài chính

$$
\text { M-score }=-4.84+0.92 * \mathrm{DSRI}+0.528 * \mathrm{GMI}+0.404 * \mathrm{AQI}+0.892 * \mathrm{SGI}+
$$
$0.115 *$ DEPI $-0.172 *$ SGAI + 4.679*TATA $-0.327 *$ LVGI

Với M-score lớn hơn $-1,78$ thì BCTC của công ty sẽ được đánh dấu là gian lận

Mô hình Benish được sử dụng rộng rãi để xác đinh các công ty gian lận. Tuy nhiên, tính chính xác của phát hiện gian lận bằng cách sử dụng M-Score là khoảng $50 \%$

\subsubsection{Mô hình của Trần Thị Giang Tân và cộng sự}

Một nghiên cứu khác cũng dựa trên cơ sở các chỉ số trên báo cáo tài chính để đánh giá gian lận đó là nghiên cứu của Tân et al. (2014). Dựa trên lý thuyết về tam giác gian lận của Cressey (1953) và chuẩn mực kiểm toán VSA 240, tác giả xem xét giả thuyết liệu các yếu tố của tam giác gian lận (Động cơ/Áp lực, cơ hội, thái độ) có mối tương quan đối với hành vi gian lận và có thể sử dụng để dự báo gian lận trên báo cáo tài chính tại Việt Nam hay không. Từ đó tác giả đưa ra một mô hình nhằm phát hiện gian lận trên báo cáo tài chính.

Tác giả đưa ra 21 biến thể hiện cho các yếu tổ có khả năng dẫn đến gian lận. Thông qua hồi quy logit tác giả đưa ra mô hình như sau: 


\section{$P(F R A U D=1)$}

$=1 /\left(1+e^{(2,387+0,065 \text { SALAR+3,446 INVTA-3,517 LEV -1,183 BIG4-2,259 AUDREPORT-1,052 RST })}\right)$

Trong đó:

FRAUD là Gian lận trên báo cáo tài chính. FRAUD có giá trị là 1 nếu là mẫu gian lận, ngược lại có giá trị là 0 .

SALAR là Tỷ lẹ doanh thu trên nơ phải thu. SALAR tính bằng Doanh thu thuần năm/Nợ phải thu thuần cuối năm.

INVTA là Tỷ trọng hàng tồn kho trên tổng tài sản. INVTA tính bắng Hàng tồn kho cuối năm/Tổng tài sản cuối năm.

LEV là Đòn cân nợ. LEV tính bằng (Nợ vay ngắn hạn cuối năm + Nợ vay dài hạn cuối năm)/ Tổng tài sản cuối năm.

BIG4 là Kiểm toán viên thuộc nhóm Big 4. BIG4 có giá trị là 1 nếu được kiểm toán bởi công ty thuộc nhóm không phải là Big Four, ngược lại biến có giá trị là 0 .

AUDREPORT là Ý kiến của kiểm toán viên độc lập về báo cáo tài chính. AUDREPORT có giá trị là 1 nếu đơn vị nhận được ý kiến không phải là chấp nhận hoàn toàn về báo cáo tài chính, ngược lại AUDREPORT có giá trị là 0 .

RST là Tiền sư gian lận. RST tính bắng số lần phát sinh chênh lệch lợi nhuận trước và sau kiểm toán trong 3 năm liền trước.

Nghiên cứu cũng chỉ ra mô hình trên có khả năng dự báo rất tốt với tỷ lệ dự báo đúng là $83,33 \%$ cho các công ty trong mẫu nghiên cứu và dự báo đúng $80 \%$ cho mẫu thử ngoài nghiên cứu.

Từ đó tác giả cho rằng kết quả này có thể coi là một bằng chứng cho việc VSA 240 yêu cầu kiểm toán viên đánh giá rủi ro có sai sót trọng yếu của báo cáo tài chính dựa trên tam giác gian lận là hợp lý. Bên cạnh đó cũng nhấn mạnh các yếu tố mà kiểm toán viên cần quan tâm khi xem xét gian lận báo cáo tài chính, đó là Tỷ trọng hàng tồn kho trên tổng tài sản, Tỷ trọng hàng tồn kho trên tổng tài sản, Đòn cân nợ, Kiểm toán viên thuộc nhóm Big 4, Ý kiến của kiểm toán viên độc lập về báo cáo tài chính, Tiền sủ gian lận.

Tóm lại, có thể thấy các chỉ số thể hiện trên báo cáo tài chính là hữu ích để phát hiện gian lận của các công ty.

\subsubsection{Mô hình của Rasa Kanapickiene và Zivile Grundiene}

Dựa trên ý tưởng là liệu các tỷ số tài chính có ý nghĩa trong việc xác định gian lận hay không, Rasa Kanapickiene và Zivile Grundiene (2015) đã đưa ra một nghiên cứu thực nghiệm tại Lithuania chỉ ra một số tỷ số tài chính có khẳ năng phát hiện gian lận. Từ đó xây dựng một mô hình phát hiện gian lận báo cáo tài chính. 
Tác giả đưa ra 51 tỷ số tài chính thể hiện cho các yếu tố có khả năng dẫn đến gian lận. Thông qua hồi quy logit tác giả đưa ra mô hình như sau:

$P(F R A U D=1)=1 /\left(1+e^{-(5,768-4,263 I N V / T A-0,029 S A L / F A-4,766 T L / T A-1,936 C A C H / C L)}\right)$

Trong đó:

FRAUD là Gian lận trên báo cáo tài chính. FRAUD có giá trị là 1 nếu là mẫu gian lận, ngược lại có giá trị là 0 .

INV/TA là Tỷ số hàng tồn kho trên tổng tài sản. INV tính bằng Hàng tồn kho/Tổng tài sản.

SAL/FA là Tỷ số doanh thu trên tài sản cố định. SAL/FA tính bằng Doanh thu/Tài sản cố định.

TL/TA là Tỷ số tổng nợ trên tổng tài sản. TL/TA tính bằng Tổng nợ/Tổng tài sản.

$\mathrm{CACH} / \mathrm{CL}$ là Tỷ số tiền và tương đương tiền trên nơ ngắn hạn. CACH/CL tính bằng Tiền và tương đương tiền/Nợ ngắn hạn.

Kết quả cho thấy mô hình dự đoán chính xác $84,8 \%$ đối với mẫu nghiên cứu.

Tóm lại, các tỷ số tài chính có ý nghĩa trong việc phát hiện khả năng gian lận báo cáo tài chính của các công ty.

\subsection{Trách nghiệm của các bên trong phát hiện và ngăn chăn gian lận:}

\subsubsection{Trách nhiệm của ban giám đốc}

Trách nghiệm trong ngă ngừa và phát hiện của ban giám đốc được VSA 240 quy định cụ thể tại phần I, đoạn 4 :

“04.Việc ngăn ngừa và phát hiện gian lận trước hết thuộc về trách nhiệm của Ban quản trị và Ban Giám đốc đơn vị được kiểm toán. Điều quan trọng là Ban Giám đốc, với sự giám sát của Ban quản trị, phải đặc biệt chú ý đến việc ngăn ngừa gian lận nhằm làm giảm bớt các cơ hội thực hiện hành vi gian lận và phát hiện gian lận qua đó thuyết phục các cá nhân không thực hiện hành vi gian lận vì khả năng bị phát hiện và xử phạt. Trách nhiệm này bao gồm việc cam kết tạo ra văn hóa trung thực và hành vi có đạo đức mà có thể được tăng cường bằng hoạt động giám sát tích cực của Ban quản trị. Trong khi thực hiện trách nhiệm giám sát của mình, Ban quản trị phải xem xét khả năng xảy ra hành vi khống chế kiểm soát hoặc hành động gây ảnh hưởng không thích hợp đến quy trình lập và trình bày báo cáo tài chính, ví dụ việc Ban Giám đốc cố gắng điều chỉnh kết quả kinh doanh để các nhà phân tích hiểu không đúng về hiệu quả hoạt động và khả năng sinh lời của đơn vị được kiểm toán"

\subsubsection{Trách nghiệm của hệ thống kiểm soát nội bộ:}

Theo Chuẩn mực Kiểm toán VN số 400 (MOF, 2001), hệ thống KSNB là các quy định và các thủ tục kiểm soát do đơn vị được kiểm toán xây dựng và áp dụng nhằm đảm bảo cho 
đơn vị tuân thủ pháp luật và các quy định, để kiểm tra kiểm soát, ngăn ngừa và phát hiện gian lận và sai sót; để lập báo cáo tài chính trung thực và hợp lý; nhằm bảo vệ, quản lý và sử dụng có hiệu quả tài sản của đơn vị.

Theo Ủy ban Treadway (Hoa Kỳ), hệ thống kiểm soát nội bộ một quá trình do hội đồng quản trị, Ban giám đốc và các nhân viên khác triển khai thực hiện, được thiết kế nhằm đưa ra mức độ đảm bảo hợp lý về việc đạt được mục tiêu trong các khía cạnh sau đây:

- Bảo toàn tài sản

- Hiệu quả, hiệu suất của các hoạt động

- Mức độ tin cậy của công tác báo cáo tài chính

- Tuân thủ các luật lệ, quy định áp dụng

Từ định nghĩa trên, hệ thống kiểm soát nội bộ có vai trò và trách nghiêm trong việc ngăn ngừa và phát hiện gian lận báo cáo tài chính:

- Đảm bảo số liệu trên sổ sách kế toán và trong báo cáo tài chính của công ty phản ánh trung thực, hợp lý, thận trọng tình trạng sản xuất kinh doanh của doanh nghiệp

- Giảm bớt rủi ro gian lận, trộm cắp tài sản của công ty.

- Giúp công ty thực hiện đúng chính sách, pháp luật của nhà nước, tuân thủ nghiêm ngặt các nguyên tắc kế toán, chuẩn mực kế toán, chế độ kế toán

- Ngăn ngừa các rủi ro khác ảnh hưởng xấu tới doanh nghiệp

\subsubsection{Trách nhiệm của kiểm toán viên}

Trách nghiệm của kiểm toán viên được trong phát hiện gian lận báo cáo tài chính được quy định rất rõ ràng, cụ thể tại phần I, đoạn 5 đến 9 (MOF, 2012):

“05. Khi thực hiện kiểm toán theo các chuẩn mực kiểm toán Việt Nam, kiểm toán viên chịu trách nhiệm đạt được sự đảm bảo hợp lý rằng liệu báo cáo tài chính, xét trên phương diện tổng thể, có còn sai sót trọng yếu do gian lận hoặc nhầm lẫn hay không. Do những hạn chế vốn có của kiểm toán, nên có rủi ro không thể tránh khỏi là kiểm toán viên không phát hiện được một số sai sót làm ảnh hưởng trọng yếu đến báo cáo tài chính, kể cả khi cuộc kiểm toán đã được lập kế hoạch và thực hiện theo các chuẩn mực kiểm toán Việt Nam (xem đoạn A51 Chuẩn mực kiểm toán Việt Nam số 200).

06.Như đã đề cập tại đoạn A51 Chuẩn mực kiểm toán Việt Nam số 200, ảnh hưởng của các hạn chế vốn có là đặc biệt nghiêm trọng đối với các sai sót do gian lận. Rủi ro có sai sót trọng yếu do gian lận cao hơn rủi ro có sai sót trọng yếu do nhầm lẫn. Đó là do gian lận có thể được thực hiện thông qua các mánh khóe tinh vi và được tổ chức chặt chẽ nhằm che giấu 
hành vi gian lận, như giả mạo hồ sơ, cố ý không ghi chép các giao dịch, hoặc cố ý cung cấp các giải trình sai cho kiểm toán viên. Hành động che giấu còn có thể khó phát hiện hơn khi có sự thông đồng thực hiện hành vi gian lận. Sự thông đồng có thể làm cho kiểm toán viên tin rằng bằng chứng kiểm toán là thuyết phục trong khi thực tế đó là những bằng chứng giả. Khả năng phát hiện gian lận của kiểm toán viên phụ thuộc vào các yếu tố như kỹ năng của thủ phạm, tần suất và mức độ của hành vi thao túng, mức độ thông đồng, giá trị của khoản tiền bị thao túng, cấp bậc của những cá nhân có hành vi gian lận. Mặc dù kiểm toán viên có thể xác định được các cơ hội thực hiện hành vi gian lận, nhưng rất khó để có thể xác định được các sai sót trong các lĩnh vực mà họ xem xét, như các ước tính kế toán, là do gian lận hay nhầm lẫn.

07. Ngoài ra, rủi ro về việc kiểm toán viên không phát hiện hết sai sót trọng yếu xuất phát từ hành vi gian lận của Ban Giám đốc là cao hơn so với việc phát hiện sai sót do gian lận của nhân viên, bởi vì Ban Giám đốc thường xuyên có điều kiện trực tiếp hoặc gián tiếp thao túng việc ghi sổ kế toán, trình bày các thông tin tài chính gian lận hoặc khống chế các thủ tục kiểm soát được thiết lập nhằm ngăn ngừa các hành vi gian lận tương tự của các nhân viên khác

08. Để đạt được sự đảm bảo hợp lý, kiểm toán viên phải duy trì thái độ hoài nghi nghề nghiệp trong suốt quá trình kiểm toán, phải cân nhắc khả năng Ban Giám đốc có thể khống chế kiểm soát và phải nhận thức được thực tế là các thủ tục kiểm toán nhằm phát hiện nhầm lẫn một cách hiệu quả có thể không hiệu quả trong việc phát hiện gian lận. Các quy định của chuẩn mực kiểm toán này nhằm hỗ trợ kiểm toán viên trong việc xác định và đánh giá các rủi ro có sai sót trọng yếu do gian lận và thiết lập các thủ tục nhằm phát hiện sai sót đó.

09. Kiểm toán viên và doanh nghiệp kiểm toán phải tuân thủ các quy định của Chuẩn mực này trong quá trình thực hiện kiểm toán báo cáo tài chính.

Đơn vị được kiểm toán (khách hàng) và các bên sử dụng kết quả kiểm toán phải có những hiểu biết cần thiết về những quy định trong Chuẩn mực này để phối hợp công việc với doanh nghiệp kiểm toán và kiểm toán viên cũng như quản lý các mối quan hệ liên quan đến các thông tin đã được kiểm toán.”

\subsection{Tổng hợp lý thuyết cơ bản về gian lận}

Từ những lý thuyết gian lận trên, nhóm nghiên cứu đã tổng hợp và nêu ra một số ý kiến mới về gian lận báo cáo tài chính. Khái niệm về gian lận theo VSA 240 đoạn 11 cho biết: Biểu hiện của gian lận báo cáo tài chính bao gồm: 
- Xuyên tạc, làm giả chứng từ, tạo lập những hợp đồng giả, tạo lập các khách hàng ảo, tài liệu liên quan đến báo cáo tài chính, ghi chép các nghiệp vụ kinh tế không đúng sự thật.

- Sửa đổi tài liệu, chứng từ kế toán làm sai lệch báo cáo tài chính, gây ra sai sót trong số liệu kế toán.

- Cố ý áp dụng sai các chuẩn mực, nguyên tắc, phương pháp và chế độ kế toán, chính sách tài chính.

- Che dấu hoặc cố ý bỏ sót các thông tin, tài liệu hoặc nghiệp vụ kinh tế làm sai lệch báo cáo tài chính.

Đặc điểm của gian lận bao gồm:

- Gian lận báo cáo tài chính co xu hướng gian tăng với mức độ tinh vi, phức tạp, quy mô lớn và gây thiêt hịa ngày cằng nghiêm trọng

- Số lượng nhân viên thực hiện gian lận do nhân viên > nhà quản lý > chủ sở hữu, nhà quản lý cấp cao song mức độ tổn thất do nhân viên thực hiện gian lận < nhà quản lý < chủ sở hữu, nhà quản lý cấp cao.(Theo khảo sát của ACFE (1993-2012))

- Gian lận trên Báo cáo tài chính, tuy chiếm tỷ lệ thấp nhất nhưng hậu quả gây ra cho nền kinh tế là lớn.(Theo khảo sát của ACFE (1993-2012))

- CEO và $\mathrm{CFO}$ có khả năng liên quan đến gian lận báo cáo tài chính

- Báo cáo gian lận thường kéo dài có thê xuyên qua nhiều năm kế toán

- Các chỉ số tài chính trong báo cáo tài chính có thê phát hiện gian lận

Động cơ hoặc áp lực thực hiện gian lận bao gồm:

- Lợi ích của ban giám đốc thu được khi tình hình kinh doanh tốt

- Ổn định tài chính( theo VSA 240, phụ lục 1 đoạn A1)

- Khả năng sinh lời của doanh nghiệp

- Áp lực từ bên thứ ba (theo VSA 240 phụ lục 1 đoạn A1)

- Mục tiêu tài chính mà ảnh hưởng tới lợi ích của Ban quản trị hoặc Ban giám đốc

- Ban giám đốc thực hiện gian lận nhằm trục lợi trong cá mối quan hệ với các bên có liên quan tới công ty (lý thuyết các đối tượng liên quan của Freeman (1984))

- Đặt quá nhiều lòng tin vào tổng giám đốc và ban giám đốc với kỳ vọng lợi nhuận đem lại cho công ty cao (lý thuyết bàn cân gian lận D.W.Steve Albrecht (1980))

- Môi trường kinh doanh của doanh nghiệp có nhiều thay đổi gây bất lợi cho doanh nghiệp.

Cơ hội: 
- Có phân tách giữa quyền sở hữu và quyền điều hành công ty. (Lý thuyết ủy nhiệm của Jensen \& Meckling (1976))

- Việc giám sát hoạt động của Ban Giám đốc không hiệu quả (VSA 240, phần phụ luc đoạn A2)

- Đặc điểm của ngành hay các hoạt động của đơn vị ( theo VSA 240, phần phụ luc đoạn A2)

- Cơ cấu tổ chức phức tạp hoặc không ổn định (theo VSA 240, phần phụ luc đoạn A2)

- Do hoạt động của doanh nghiệp không được hiệu quả khiến việc kiểm soát khó khăn

- Thiếu thủ tục phê chuẩn thích hợp, thiếu các quy định chặt chẽ liên quan tới hành vi gian lận. (lý thuyết bàn cân gian lận D.W.Steve Albrecht (1980))

- Không yêu cầu công bố đầy đủ thông tin về các mối quan hệ,các khoản đầu tư và thu nhập cá nhân (lý thuyết bàn cân gian lận D.W.Steve Albrecht (1980))

- Các hoạt động kinh doanh của công ty không được giám sát, kiểm duyệt thường xuyên, tạo cơ hội cho ban giám đốc thực hiện hành vi phạm tội (lý thuyết bàn cân gian lận D.W.Steve Albrecht (1980))

- Thiếu kiểm toán nội bộ, kiểm toán nội bộ còn nhiều yếu kém, kiểm toán nội bộ có quan hệ với ban giám đốc. (VSA 240, phầnn phụ luc đoạn A2)

- Hệ thống thông tin không đủ chi tiết và không được báo cáo thường xuyên

Thái độ:

- Tính trung thực, yếu kém về đạo đức trong thành viên Ban Giám đốc (VSA 240, phần phụ luc đoạn A2)

- Cấp quản lý truyền đạt, thực hiện, hỗ trợ hoặc yêu cầu thực hiện văn hoá doanh nghiệp hoặc tiêu chuẩn đạo đức nghề nghiệp không phù hợp và không hiệu quả (VSA 240, phần phụ luc đoạn A2)

- Ban giám đốc có tính độc đoán/và chuyên quyền

- Ban giám đốc tham vọng quá mức về kế hoạch kinh doanh

- Ban giám đốc có lối sống xa hoa, vượt quá thu nhập chính thống từ doanh nghiệp/tổ chức

- Ban Giám đốc cam kết với các chuyên gia phân tích, các chủ nợ và bên thứ ba sẽ đạt được những mức dự báo quá cao hoặc không thực tế (VSA 240, phần phụ luc đoạn A2)

- Năng lực điều hành của ban giám đốc khi gặp áp lực 
- Công ty gian lận có khả năng thay đổi kiểm toán giữa kỳ báo cáo tài chính sạch và báo cáo tài chính gian lận hoặc thay đổi kiểm toán trong suốt thời kỳ gian lận

Trách nghiệm của các bên trong phát hiện và ngăn chăn gian lận:

- Ban giám đốc Theo VSA 240, phần I, đoạn 4.

- Kiểm soát nội bộ: Có vai trò quan trọng trong phòng chống,phát hiện gian lận

- Kiểm toán viên: Theo VSA 240, phần I, đoạn 5 đến 9

\section{Kết luận chương 2}

Trong chương 2, nhóm nghiên cứu đã trình bày rõ về khái niệm gian lận báo cáo tài chính theo VSA 240, nêu ra những lý thuyết giải thích hành vi gian lận báo cáo tài chính: Lý thuyết ủy nhiệm của Jensen \& Meckling (1976), lý thuyết các đối tượng có liên quan của Freeman (1984), Lý thuyết tam giác gian lận bởi Cressey (1953), Lý thuyết bàn cân gian lận của D.W.Steve Albrecht (1980); trình bày kết quả nghiện cứu của Hiệp hội các nhà điều tra gian lận Hoa Kỳ (ACFE) (1993-2012) về các loại hình gian lận trong tổ chức, khảo sát về tội phạm kinh tế và gian lận ở Việt Nam năm 2018 của PwC có những số liệu sát thực về gian lận, làm rõ mối quan hệ giữa gian lận và các yếu tố trong và ngoài công ty, những người có khả năng gây ra gian lận báo cáo tài chính và mức độ ảnh hưởng của gian lận báo cáo tài chính; làm rõ trách nghiệm của các bên trong phát hiện và ngăn chăn gian lận báo cáo tài chính.Đồng thời, nhóm nghiên cứu cũng trình bày công trình nghiên cứu của Beneish (1999), Tân et al. (2014), Kanapickienẻ (2015), tổng hợp lý thuyết cơ bản về gian lận để tao tiền đề xây dựng các biến và mô hình nhận diện gian lận. 


\section{CHƯƠNG 3: THỤC TRẠNG GIẠN LẬN BÁO CÁO TÀI CHÍNH Ở VIỆT NAM}

\subsection{Tình hình gian lận báo cáo tài chính tài Việt Nam}

Trong những năm gần đây, hàng loạt vụ gian lận báo cáo tài chính bị phát hiện gây chấn động khiến cho nhà đầu tư lo ngại. Có rất nhiều công ty niêm yết trên sàn chứng khoán có sự chênh lệch lớn giữa lợi nhuận sau thuế trước và sau kiểm toán. Nhiều doanh nghiệp đã chuyển từ kết quả lãi sang kết quả lỗ nặng sau kiểm toán. Điển hình là công ty gỗ Trường Thành: trong báo cáo hợp nhất soát xét đầu năm, công ty công bố lỗ 1073 tỉ đồng, trong khi lãi cùng kỳ năm trước là 133 tỷ đồng, 980 tỷ đồng hàng tồn kho bị thiếu hụt khi kiểm kê; năm 2017 lợi nhuân sau thuế sau kiểm toán của công ty là 2.5 tỷ đồng, giảm hơn $91 \%$ so với trước kiểm toán. Cũng trong năm 2016, công ty Đầu tư hạ tầng và Đô thị dầu khí (PTL), lợi nhuận sau thuế trước kiểm toán là 1.45 tỉ đồng, sau kiểm toán giảm xuống chỉ còn 5.5 triệu. Trong năm 2017, công ty Hùng Vương bị phát hiện gian lận: trong báo cáo tài chính hợp nhất kiển toán năm 2017, lợi nhuận sau thuế của công ty là -705 tỉ đồng, khác xa con số -63 tỉ đồng trong báo cáo trước kiểm toán. Các vụ gian lận này gây tổn thất rất lớn cho doanh nghiêp và các bên liên quan, gây tâm lý hoang mang, lo ngại, đánh mất niềm tin của nhà đầu tư, gây ảnh hưởng lớn tới nền kinh tế. Có rất nhiều doanh nghiệp niêm yết (DNNY) trên sàn chứng khoán có sự chênh lệch lớn giữa lợi nhuận sau thuế trước và sau kiểm toán. Nhiều doanh nghiệp đã chuyển từ kết quả lãi sang kết quả lỗ nặng sau kiểm toán, ảnh hưởng rất lớn đến lợi ích của nhà đầu tư. Theo giải trình của các doanh nghiệp, sự chênh lệch này là do sự yếu kém của kế toán, do sự khác biệt trong phương thức kế toán của doanh nghiệp và kiểm toán.

Theo thống kê của Vietstock năm 2013, chỉ xét riêng về các khoản mục trên bảng kết

quả hoạt động kinh doanh, mà quan trọng nhất là khoản mục lợi nhuận sau thuế cho thấy có đến $80 \%$ kết quả có chênh lệch trước và sau kiểm toán. 


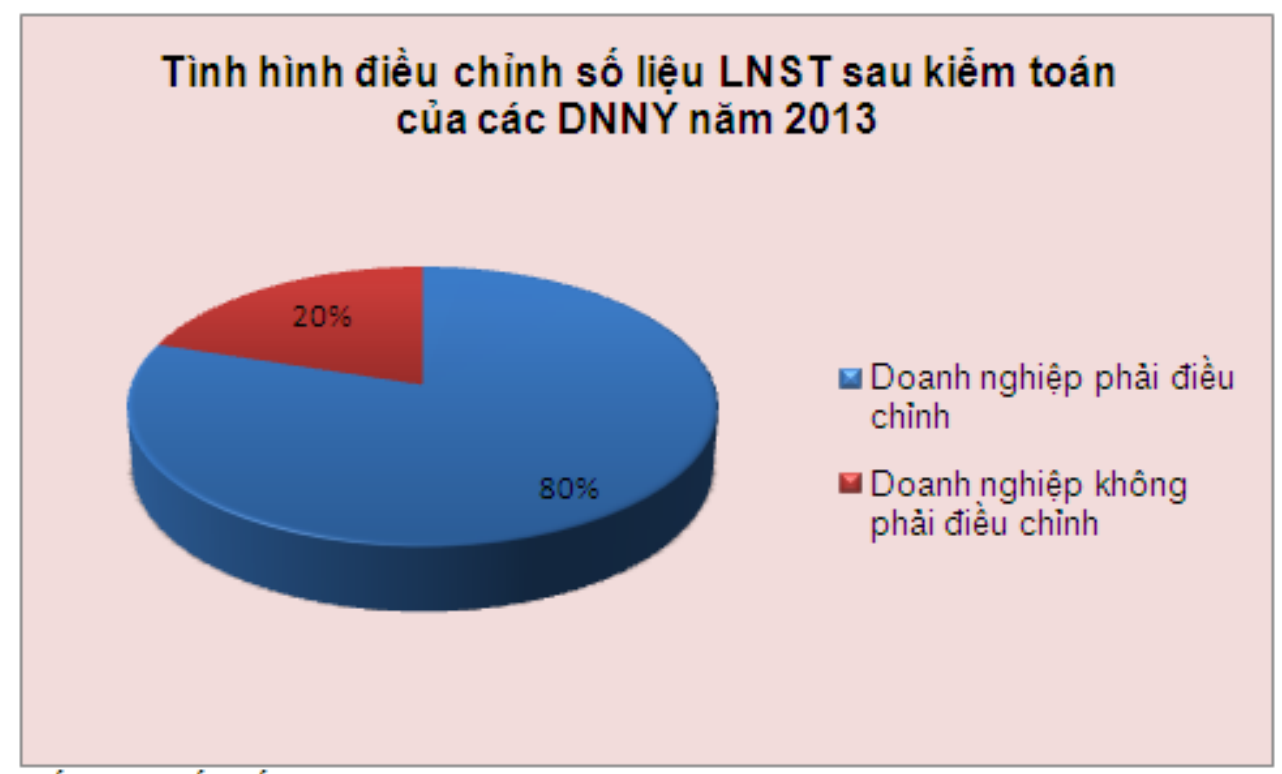

Số liệu chốt đến ngày 10/04/2014

Hình 6: Biểu đồ thể hiện tỉ lệ doanh nghiệp điều chỉnh lợi nhuận

(Nguồn Vietstock)

\subsection{Hậu quả của gian lận báo cáo tài chính}

Gian lận báo cáo tài chính có thể đem lại những hậu quả khó lường cho doanh nghiệp và các bên liên quan:

(1) Làm suy giảm độ trung thực của báo cáo tài chính.

(2) Làm suy giảm tính trung thực, khách quan của ngành nghề kế toán, gây sự không tin tưởng vào kế toán và ban giám đốc.

(3) Làm mất đi niềm tin khi đầu tư vào thị trường tài chính, làm cho thị trường vốn kém hiệu quả.

(4) Gây ảnh hưởng xấu tới sự phát triển của nền kinh tế, gây thiệt hịa kinh tế cho công ty và các bện liên quan với công ty.

(5) Phá hủy sự nghiệp của các cá nhân liên quan đến hành vi gian lận.

(6) Đòi hỏi có những quy định chặt chẽ hơn liên quan tới gian lận báo cáo tài chính.

(7) Gây ảnh hưởng xấu tới hoạt động của thi trường tài chính, ảnh hưởng tới quá trình hoạt động sản xuất kinh doanh của công ty bị cáo buộc gian lận.

\subsection{Những biện pháp phổ biến thực hiện gian lận trên báo cáo tài}

A. Ghi nhận doanh thu ảo: ghi nhận vào sổ sách một nghiệp vụ bán hàng hoá hay cung cấp dịch vụ không có thực. Phương pháp thông thường để tạo ra những khoản doanh thu ảo là: tạo khách hàng giả mạo, tạo lâp hóa đơn giả mạo, ghi tăng số lượng hàng hóa, ghi tăng giá vốn trên hóa đơn bán hàng... hoặc ghi nhận doanh thu khi quá trình giao hàng chưa hoàn tất, 
bên bán chưa hoàn thành nghĩa vụ chuyển giao hàng hóa và dịch vụ, chưa chuyển giao quyền và nghĩa vụ đối với hàng hóa cho bên mua.

B. Ghi nhận sai niên độ, sai thời điểm: Gian lận báo cán tài chính có thể được thực hiện bởi kỹ thuật ghi nhận sai thời điểm trong đó, doanh thu hoặc chi phí được ghi nhận không đúng với thời điểm được phép ghi nhân doanh thu và chi phí theo nguyên tắc cơ sở dồn tích của kế toán. Doanh nghiệp có thể thực hiên gian lận bằng cách chuyển doanh thu, chi phí của kỳ sau về kỳ này, chuyển doanh thu,chi phí của kỳ trước về kỳ này và ngược lại để đạt được mục đích gian lận của mình.

C. Giấu công nợ và chi phí: phương pháp này thực hiện nhằm mục đích thổi phồng lợi nhuận. Lợi nhuận trước thuế sẽ tăng tương ứng với số chi phí hay công nợ bị che dấu, dẫn đến lợi nhuân sau thuế cũng tăng lên. Đây là một phương pháp dễ dàng có thể thực hiện, trong khi việc phát hiện ra nó rất khó khăn. Gian lận về nợ công và chi phí thường được thực hiện phổ biến thông qua những phương pháp sau:

- Không ghi nhận công nợ và chi phí;

- Vốn hoá chi phí;

- Không ghi nhận hàng bán trả lại, các khoản giảm trừ, các khoản dự phòng và bảo hành;

D. Không khai báo đầy đủ thông tin gây khó khăn cho những người sử dụng báo cáo tài chính, hạn chế khả năng phân tích tài chính của người sử dụng, che dấu những dấu hiệu sai phạm của công ty.

E. Định giá sai tài sản: Đây là một kỹ thuật gian lận phổ biến nhằm gia tăng khối lượng tài sản của công ty, đáp ứng những yêu cầu vay nơ, đầu tư,...Phương pháp này được thực hiện chủ yếu với các khoản mục: hàng tồn kho, các loại chứng khoán do công ty nắm giữ, các loại tài sản cố định, các khoản phải thu, các loại vàng bạc,đá quý của doanh nghiệp,... 


\section{Kết luận chương 3:}

Trong chương 3, nhóm nghiên cứu đã làm rõ những tác động tiêu cực to lớn của gian lận báo cáo tài chính về mặt lý thuyết và thực tế, đề cập đến những phương thức gian lận chủ yếu của các doanh nghiêp Việt Nam.Qua đó cho thấy rõ tầm quan trọng của việc nhận diện, ngăn chặn gian lận báo cáo tài chính. Cần thiết phải có những công cụ phát hiện gian lận hữu ích và có những chính sách, biện pháp hiệu quả để giảm thiểu gian lận báo cáo tài chính. 


\section{CHƯƠNG 4: MÔ HÌNH ĐỀ XUẤT VÀ PHƯƠNG PHÁP NGHIÊN CỨU}

\subsection{Quy trình thực hiện nghiên cứu}

Sơ đồ thể hiện quy trình nghiên cứu:

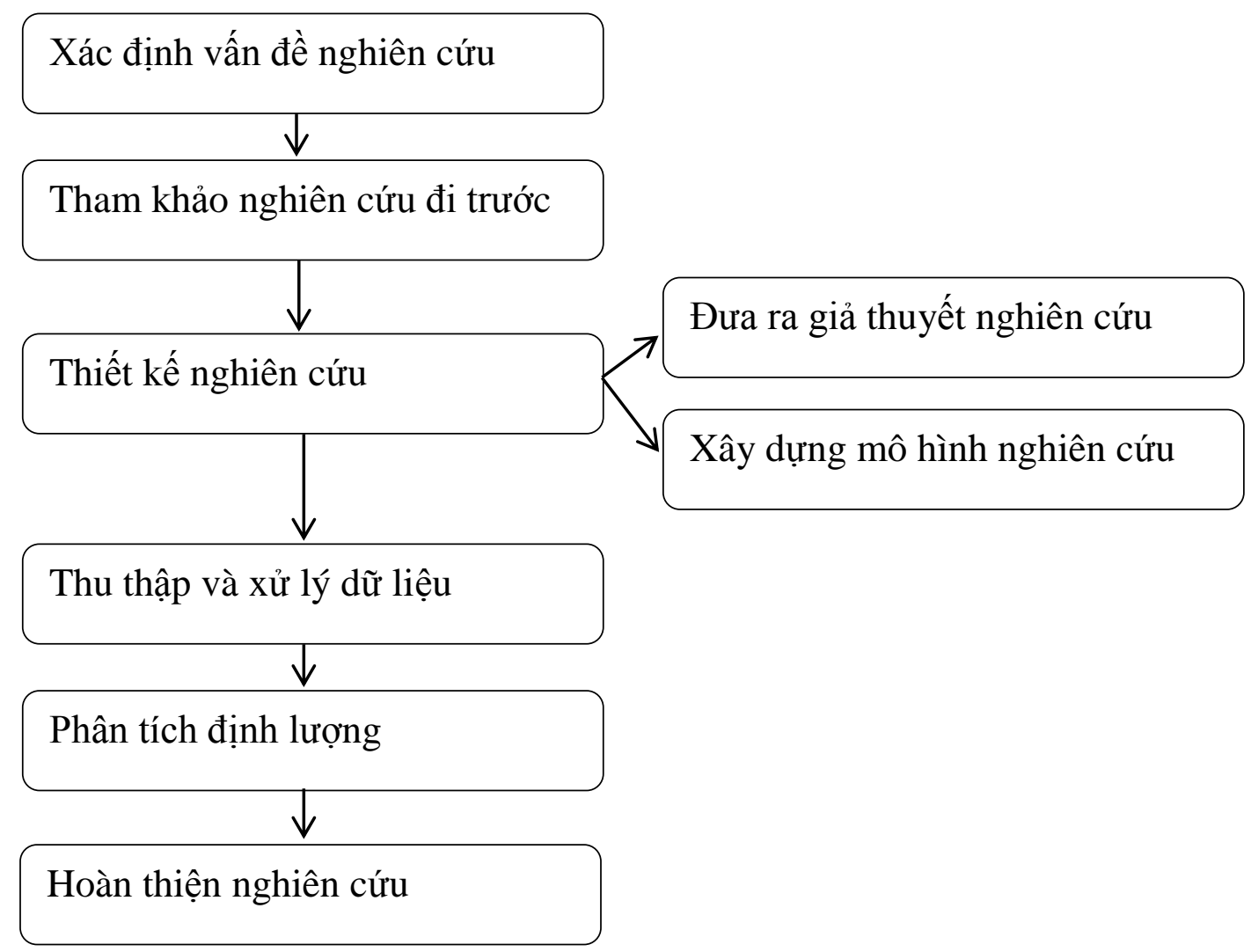

\section{Hình 7: So đồ quy trình nghiên cúu}

\subsection{Giả thuyết và mô hình nghiên cứu}

\subsubsection{Giả thuyết}

Các yếu tố của tam giác gian lận (Động cơ/Áp lực, cơ hội, thái độ) có mối tương quan đối với hành vi gian lận, và có thể được sử dụng để dự báo gian lận trên báo cáo tài chính tại Việt Nam.

\subsubsection{Các biến có khả năng ảnh hưởng}

\subsubsection{Yếu tố động co\% áp lục:}

Áp lực là những yếu tố tác động bên ngoài hoặc bên trong làm cho người quản lý có xu hướng làm sai lệch báo cáo tài chính. Nghiên cứu mới đây chỉ ra hoạt động của các công ty Việt Nam phụ thuộc rất nhiều vào nguồn nhân công rẻ, trong khi cải tiến công nghệ không nhiều mặc dù dư thừa nguồn lực (Vu et al., 2019). Vì vậy, nhà quản lý thường chịu áp lực từ chính bản thân họ, áp lực từ nhà đầu tư, áp lực từ các đối tác liên quan, áp lực do đánh mất khách hàng, do sự giảm sút doanh thu, lợi nhuận... Những áp lực này tạo động cơ để ban 
giám đốc gian lận báo cáo tài chính để có thể thu hút nhà đầu tư, tăng giá cổ phiếu, đáp ứng các điều kiện vay nợ của ngân hàng,...

\section{(a) Sự ổn định tài chính}

Các công ty gian lận báo cáo tài chính thường có lợi nhuận thấp hơn kỳ vọng của chủ sở hữu, do đó các công ty này có xu hướng gia tăng lợi ảo nhuận thông qua việc thổi phồng doanh thu (ghi nhân doanh thu ảo, ghi nhân doanh thu sai thời điểm) hoặc gian lận về chi phí (được thực hiện chủ yếu bằng che dấu công nợ, vốn hóa chi phí và không nhận hàng bán bị trả lại). Do đó các chỉ số đo lường mức độ sinh lời có thể được sử dụng để phát hiện các công ty gian lận: OP/SAL (lợi nhuận hoạt động sản suất kinh doanh trên tổng tài sản, Kanapickiene \& Grundienė (2015)), EBT/TA (lợi nhuận trước thuế trên tổng tài sản, Kanapickiene \& Grundienė (2015)), GP/FA (lợi nhuận gộp trên tổng tài sản), NI/CS (lợi nhuân sau thuế trên giá vốn hàng bán), GP/SAL (lợi nhuận gộp trên doanh thu thuần, Kanapickiene \& Grundienè (2015)), GP/TA (lợi nhuận gộp trên tổng tài sản, Kanapickiene \& Grundienè (2015)), NI/EQ (lợi nhuân gộp trên tổng tài sản, Kanapickiene \& Grundienè (2015)), CS/GP( giá vống hầng bán trên lợi nhuận gộp), CS/GP,GP/CS( lợi nhuận gôp trên giá vốn hàng bán), NI/TA( lơi nhuận gộp trên tổng tài sản, Kanapickiene \& Grundienẻ (2015), Persons (1995)), OP/GP( lợi nhuận hoạt động trên lợi nhuận gộp), NI/SAL (lợi nhuận sau thuế trên doanh thu thuần, Kanapickiene \& Grundienè (2015)).

\section{(b) Dòng tiền trong doanh nghiệp}

Do các công ty gian lận có xu hướng thổi phồng lợi nhuận nên dẫn đến việc tỉ lệ lợi nhuận thực tế thu được thấp hơn các công ty không gian lận, nên các chỉ số $\mathrm{CFO} / \mathrm{SAL}$ ( dòng tiền thuần từ sản xuất kinh doanh trên doanh thu thuần), TAc/TA(tổng biến dồn tích trên tổng tài sản), $\mathrm{CFO} / \mathrm{CS}$ (dòng tiền thuần từ sản xuất kinh doanh trên giá vốn hàng bán), NI/CFO (lợi nhuận sau thuế trên dòng tiền thuần từ sản xuất kinh doanh), $\mathrm{CFO} / \mathrm{TA}$ (dòng tiền thuần từ sản xuất kinh doanh trên tổng tài sản), $\mathrm{CFO} / \mathrm{NI}$ (dòng tiền thuần từ sản xuất kinh doanh trên lợi nhuận sau thuế) có thể phân biệt các công ty gian lận và không gian lận.

\section{(c) Áp lự tù̀ bên thứ ba}

Các công ty còn chịu áp lực từ bên thứ ba - áp lực từ phía chủ nợ. Nghiên cứu của Dechow et al. (1996) chỉ ra rằng các công ty có đòn bẩy tài chính cao cùng với các điều khoản đảm bảo an toàn nợ vay sẽ có động cơ thực hiện hành vi chi phối thu nhập. Mức vay nợ càng cao thì doanh nghiệp càng có xu hướng thổi phồng lợi nhuận thông qua các ước tính kế toán. Do đó, các chỉ số về khả năng thanh toán,trả nợ,cơ cấu nợ, cơ cấu nguồn vốn của doanh nghiệp có thể được sử dụng để phát hiện các công ty có gian lận báo cáo tài chính: WC/TA (vốn lựu động trên tổng tài sản, Kanapickiene \& Grundienè (2015)), CASH/CL (tổng tiền và 
tương đương tiền trên tổng nợ, Kanapickiene \& Grundienè (2015)), CASH/TA (tổng tiền và tương đương tiền trên tổng tài sản, Kanapickiene \& Grundienè (2015)), CASH/CA (tổng tiền và tương đương tiền trên tài sản ngắn hạn,Kanapickiene \& Grundienè (2015)), CA/CL (tài sản ngắn hạn trên nợ ngắn hạn, Kanapickiene \& Grundienè (2015)), CL/TL(nợ ngắn hạn trên tổng nợ), $\mathrm{EQ} / \mathrm{TL}$ (vốn chủ sở hữu trên tổng nợ), $\mathrm{CA} / \mathrm{TL}$ (tài sản ngắn hạn trên tổng nợ), $\mathrm{CFO} / \mathrm{TL}$ (dòng tiền thuần từ hoạt động sản xuất kinh doanh trên tổng nợ, Mary Jane Lenard, Pervaiz Alam(2009)), EQ/TA( vốn chủ sở hữu trên tổng tài sản), EQ/LA( vốn chủ sở hữu trên tài sản dài hạn), (CA-INV)/CL (hệ số thanh toán nhanh, Kanapickiene \& Grundienè (2015)), LEV( đòn cân nợ)

\section{(d) Khả năng tạo ra doanh thu}

Theo nghiên cứu của Kanapickiene \& Grundienė (2015), các doanh nghiệp có khả năng tạo ra doanh thu của doanh nghiệp thấp cũng có khả năng gian lận cao hơn. Do đó có thể sử dụng chỉ số $\mathrm{SAL} / \mathrm{FA}$ (doanh thu thuần trên tài sản cố đinh), SAL/TA (doanh thu thuần trên tổng tài sản,Kanapickiene \& Grundienė (2015) ) SAL/CS(doanh thu thuần trên giá vốn hàng bán), SAL/COST(doanh thu thuần trên tổng chi phí cơ bản), SAL/GA (doanh thu thuần trên tổng chi phí bán hàng và quản lý doanh nghiệp)để phân biệt các công ty gian lận và không gian lận. Cũng trong nghiên cứu trên, chỉ số cơ cấu tài sản FA/TA (tài sản cố định trên tổng tài sản) cũng có ý nghĩa trong việc phát hiện các công ty gian lận. Tỷ lệ này ở mức cao, phản ánh doanh nghiệp đang nỗ lực đầu tư cho một chiến lược dài hơn nhằm tìm kiếm lợi nhuận ổn định lâu dài trong tương lai.

\subsubsection{Yếu tố co hội}

Cơ hội là những điều kiện để cho người quản lý thực hiện hành vi gian lận của mình. Các cơ hội được cho là có thể dẫn tới gian lận báo cáo tài chính bao gồm: sự yếu kếm của kiểm soát nội bộ, sự phức tạp trong các hoạt động kinh tế, không có sự giám sát chặt chẽ hoạt động cảu ban giám đốc ...

(a) Đặc điểm của ngành hay các hoạt động của doanh nghiệp

Doanh nghiệp có thể thực hiện gian lận thông qua việc lập các ước tính kế toán thông qua hàng tồn kho; ghi nhận chi phí và nợ phải thu. Do đó có thể sử dụng các chỉ số: INV/TA (hàng tồn kho trên tổng tài sản) Kanapickiene \& Grundienè (2015)), INV/CA (hàng tồn kho trên tài sản ngắn hạn), INV/CS (hàng tổng kho trên giá vốn hàng bán), REC/REV (nợ phải thu trên doanh thu thuần)

\section{(b) Giám sát của ban Giám đốc không hiệu quả}

Theo Loebbecke, Eining \& Willingham (1989), Beasley (1996), Abbott, Park và Parker (2000) và Dunn (2004) đã kết luận khi giám đốc điều hành nắm giữ nhiều chức vụ thì 
người này sẽ thống trị quá trình ra quyết định tại doanh nghiệp. Như vậy, việc kiểm soát quá trình ra quyết định sẽ là cơ hội để họ thực hiện hành vi gian lận, do đó việc kiêm nhiệm chức danh giám đốc điều hành và chủ tịch hội đồng quản trị (CEO) là dấu hiệu của gian lận. Ngoài ra, kết quả nghiên cứu của Farber (2005) đã chỉ ra quản trị doanh nghiệp yếu kém có mối quan hệ với việc ít sử dụng công ty kiểm toán thuộc nhóm Big4.

\subsubsection{Yếu tố thái độ}

Việc nhà quản lý có thực hiện hành vi gian lận khi phải chịu áp lực lớn từ các bến hay không còn phụ thuộc vào đạo đức và tính trung thực của nhà quản lý. Nếu tính trung thực của nhà quản lý không tốt thì có khả năng thực hiện hành vi gian lận cao hơn khi gặp phải những áp lực từ các bên liên quan.

Theo nghiên cứu của Lou \& Wang (2011), số lần phát sinh chênh lệch lợi nhuận trước và sau kiểm toán (RST) trong quá khứ là biến đại diện cho sự chính trực của nhà quản lí.

Ngoài ra, theo nghiên cứu của Skousen, Smith, \& Wright (2009), ý kiến của kiểm toán viên độc lập không phải chấp nhận toàn phần (AUDREPORT) là dấu hiệu đáng ngờ về tính chính trực của nhà quản lí.

\begin{tabular}{|c|c|c|}
\hline Mã biến & Tên biến & Phương pháp tính \\
\hline \multicolumn{3}{|c|}{ BIẾN PHỤ THUỘC } \\
\hline FRAUD & Gian lận trên báo cáo tài chính & $\begin{array}{l}\text { Biến định danh. FRAUD có giá trị là } 1 \text { nếu là mẫu gian } \\
\text { lận, ngược lại có giá trị là } 0\end{array}$ \\
\hline \multicolumn{3}{|c|}{ BIẾN ĐỘC LẬP } \\
\hline \multicolumn{3}{|c|}{ Động co/Áp lực } \\
\hline \multicolumn{3}{|c|}{ Sụ ổn định tài chính } \\
\hline $\mathrm{OP} / \mathrm{SAL}$ & $\begin{array}{l}\text { Lợi nhuận từ hoạt động sản xuất } \\
\text { kinh doanh trên doanh thu thuần }\end{array}$ & $\begin{array}{l}\text { Lợi nhuận từ hoạt động sản xuất kinh doanh t/Doanh } \\
\text { thu thuần } \mathrm{t}\end{array}$ \\
\hline $\mathrm{EBT} / \mathrm{TA}$ & $\begin{array}{l}\text { Lợi nhuận trước thuế trên tổng tài } \\
\text { sản }\end{array}$ & Lợi nhuận trước thuế t/Tổng tài sản $\mathrm{t}$ \\
\hline GP/FA & Lợi nhuận gộp trên tài sản cố định & Lợi nhuận gộp t/Tài sản cố định t \\
\hline $\mathrm{NI} / \mathrm{CS}$ & $\begin{array}{l}\text { Lợi nhuận sau thuế trên giá vốn } \\
\text { hàng bán }\end{array}$ & Lợi nhuận sau thuế t/Giá vốn hàng bán $\mathrm{t}$ \\
\hline GP/SAL & $\begin{array}{l}\text { Lợi nhuận gộp trên doanh thu } \\
\text { thuần }\end{array}$ & Lợi nhuận gộp t/Doanh thu thuần t \\
\hline GP/TA & Lợi nhuận gộp trên tổng tài sản & Lợi nhuận gộp t/Tổng tài sản $\mathrm{t}$ \\
\hline NI/EQ & $\begin{array}{l}\text { Lợi nhuận sau thuế trên vốn chủ } \\
\text { sở hữu }\end{array}$ & Lợi nhuận sau thuế t/Vốn chủ sở hữu $\mathrm{t}$ \\
\hline
\end{tabular}




\begin{tabular}{|c|c|c|}
\hline $\mathrm{CS} / \mathrm{GP}$ & $\begin{array}{l}\text { Giá vốn hàng bán trên lợi nhuận } \\
\text { gộp }\end{array}$ & Giá vốn hàng bán t/Lợi nhuận gộp t \\
\hline GP/CS & $\begin{array}{l}\text { Lợi nhuận gộp trên giá vốn hàng } \\
\text { bán }\end{array}$ & Lợi nhuận gộp t/Giá vốn hàng bán t \\
\hline NI/TA & $\begin{array}{l}\text { Lợi nhuận sau thuế trên tổng tài } \\
\text { sản }\end{array}$ & Lợi nhuận sau thuế t/Tổng tài sản t \\
\hline OP/GP & $\begin{array}{l}\text { Lợi nhuận từ hoạt động sản xuất } \\
\text { kinh doanh trên lợi nhuận gộp }\end{array}$ & $\begin{array}{l}\text { Lợi nhuận từ hoạt động sản xuất kinh doanh t/Lợi } \\
\text { nhuận gộp t }\end{array}$ \\
\hline NI/SAL & $\begin{array}{l}\text { Lợi nhuận sau thuế trên doanh thu } \\
\text { thuần }\end{array}$ & Lợi nhuận sau thuế t/Doanh thu thuần $\mathrm{t}$ \\
\hline
\end{tabular}

\section{Dòng tiền trong doanh nghiệp}

\begin{tabular}{|c|c|c|}
\hline TAc/TA & $\begin{array}{l}\text { Tổng biến dồn tích trên tổng tài } \\
\text { sản }\end{array}$ & $\begin{array}{l}\text { (lợi nhuận sau thuế t- dòng tiền thuần từ hd sxkd } \\
\text { t)/tổng tài sản } t\end{array}$ \\
\hline $\mathrm{CFO} / \mathrm{CS}$ & $\begin{array}{l}\text { Dòng tiền thuần từ hoạt động sản } \\
\text { xuất kinh doanh trên giá vốn hàng } \\
\text { bán }\end{array}$ & $\begin{array}{l}\text { Dòng tiền thuần từ hoạt động sản xuất kinh doanh } \\
\text { t/Giá vốn hàng bán } \mathrm{t}\end{array}$ \\
\hline $\mathrm{CFO} / \mathrm{SAL}$ & $\begin{array}{l}\text { Dòng tiền thuần từ hoạt động sản } \\
\text { xuất kinh doanh trên doanh thu } \\
\text { thuần }\end{array}$ & $\begin{array}{l}\text { Dòng tiền thuần từ hoạt động sản xuất kinh doanh } \\
\text { t/doanh thu thuần } \mathrm{t}\end{array}$ \\
\hline NI/CFO & $\begin{array}{l}\text { Lợi nhuận sau thuế trên dòng tiền } \\
\text { thuần từ hoạt động sản xuất kinh } \\
\text { doanh }\end{array}$ & $\begin{array}{l}\text { Lợi nhuận sau thuế t/Dòng tiền thuần từ hoạt động sản } \\
\text { xuất kinh doanh } \mathrm{t}\end{array}$ \\
\hline $\mathrm{CFO} / \mathrm{TA}$ & $\begin{array}{l}\text { Dòng tiền thuần từ hoạt động sản } \\
\text { xuất kinh doanh trên tổng tài sản }\end{array}$ & $\begin{array}{l}\text { Dòng tiền thuần từ hoạt động sản xuất kinh doanh } \\
\text { t/Tổng tài sản } t\end{array}$ \\
\hline $\mathrm{CFO} / \mathrm{NI}$ & $\begin{array}{l}\text { Dòng tiền thuần từ hoạt động sản } \\
\text { xuất kinh doanh trên lợi nhuận } \\
\text { sau thuế }\end{array}$ & $\begin{array}{l}\text { Dòng tiền thuần từ hoạt động sản xuất kinh doanh t/Lợi } \\
\text { nhuận sau thuế } \mathrm{t}\end{array}$ \\
\hline
\end{tabular}

\begin{tabular}{|c|c|c|}
\hline \multicolumn{3}{|c|}{ Áp lục tù̀ bên thú ba } \\
\hline LEV & Đòn cân nợ & ợ t/ Tổng tài sản t \\
\hline $\mathrm{WC} / \mathrm{TA}$ & Vốn lưu động trên tổng tài sản & (Tài sản ngắn hạn $\mathrm{t}$ - Nợ ngắn hạn $\mathrm{t}$ )/Tổng tài sản $\mathrm{t}$ \\
\hline $\mathrm{CASH} / \mathrm{CL}$ & $\begin{array}{l}\text { Tiền và tương đương tiền trên nợ } \\
\text { ngắn hạn }\end{array}$ & Tiền và tương đương tiền t/Nợ ngắn hạn t \\
\hline $\mathrm{CASH} / \mathrm{CA}$ & $\begin{array}{l}\text { Tiền và tương đương tiền trên tài } \\
\text { sản ngắn hạn }\end{array}$ & Tiền và tương đương tiền t/Tài sản ngắn hạn t \\
\hline $\mathrm{CASH} / \mathrm{TA}$ & $\begin{array}{l}\text { Tiền và tương đương tiền trên } \\
\text { tồng tài sản }\end{array}$ & Tiền và tương đương tiền $\mathrm{t} /$ tổng tài sản $\mathrm{t}$ \\
\hline $\mathrm{CA} / \mathrm{CL}$ & Tài sản ngắn hạn trên nợ ngắn hạn & Tài sản ngắn hạn t/Nợ ngắn hạn t \\
\hline $\mathrm{CL} / \mathrm{TL}$ & Nợ ngắn hạn trên tổng nợ & Nợ ngắn hạn t/Tổng nợ t \\
\hline $\mathrm{EQ} / \mathrm{TL}$ & Vốn chủ sở hữu trên tổng nợ & Vốn chủ sở hữu t/Tổng nợ t \\
\hline $\mathrm{CA} / \mathrm{TL}$ & Tài sản ngắn hạn trên tổng nợ & Tài sản ngắn hạn t/Tổng nợ t \\
\hline
\end{tabular}




\begin{tabular}{|c|c|c|}
\hline $\mathrm{CFO} / \mathrm{TL}$ & $\begin{array}{l}\text { Dòng tiền thuần từ hoạt động sản } \\
\text { xuất kinh doanh trên tổng nợ }\end{array}$ & $\begin{array}{l}\text { Dòng tiền thuần từ hoạt động sản xuất kinh doanh } \\
\text { t/Tổng nợ } t\end{array}$ \\
\hline $\mathrm{EQ} / \mathrm{TA}$ & Vốn chủ sở hữu trên tổng tài sản & Vốn chủ sở hữu t/Tổng tài sản $\mathrm{t}$ \\
\hline EQ/LA & $\begin{array}{l}\text { Vốn chủ sở hữu trên tài sản dài } \\
\text { hạn }\end{array}$ & Vốn chủ sở hữu t/(Tổng tài sản t - Tài sản ngắn hạn t) \\
\hline$(\mathrm{CA}-\mathrm{INV}) / \mathrm{CL}$ & $\begin{array}{l}\text { Hệ số thanh toán } \\
\text { Nhanh }\end{array}$ & (Tài sản ngắn hạn $\mathrm{t}$ - Hàng tồn kho t)/Nợ ngắn hạn t \\
\hline
\end{tabular}

\begin{tabular}{|c|c|c|}
\hline \multicolumn{3}{|c|}{ Khả năng tạo doanh thu } \\
\hline SAL/FA & $\begin{array}{l}\text { Doanh thu thuần trên tài sản cố } \\
\text { định }\end{array}$ & Doanh thu thuần t/Tài sản cố định t \\
\hline $\mathrm{SAL} / \mathrm{TA}$ & Doanh thu thuần trên tổng tài sản & Doanh thu thuần $\mathrm{t} / \mathrm{T}$ ổng tài sản $\mathrm{t}$ \\
\hline FA/TA & Tài sản cố định trên tổng tài sản & Tài sản cố định t/Tổng tài sản $\mathrm{t}$ \\
\hline SAL/CS & $\begin{array}{l}\text { Tỉ lệ doanh thu thuần trên giá } \\
\text { vốn hàng bán }\end{array}$ & $\begin{array}{l}\text { (Doanh thu thuần t/Giá vốn hàng bán } \mathrm{t} \text { )/(Doanh thu } \\
\text { thuần } \mathrm{t}-1 / \text { Giá vốn hàng bán } \mathrm{t}-1 \text { ) }\end{array}$ \\
\hline SAL/COST & $\begin{array}{l}\text { Tỉ lệ doanh thu thuần trên tổng } \\
\text { chi phí cơ bản }\end{array}$ & $\begin{array}{l}\text { (Doanh thu thuần } \mathrm{t} /(\text { Giá vốn hàng bán } \mathrm{t}+\text { Chi phí bán } \\
\text { hàng } \mathrm{t}+\mathrm{Chi} \text { phí quản lý doanh nghiệp } \mathrm{t}) \text { )/(Doanh thu } \\
\text { thuần } \mathrm{t}-1 /(\text { Giá vốn hàng bán } \mathrm{t}-1+\text { Chi phí bán hàng } \mathrm{t}-1 \\
+ \text { Chi phí quản lý doanh nghiệp } \mathrm{t}-1) \text { ) }\end{array}$ \\
\hline SAL/GA & $\begin{array}{l}\text { Tỉ lệ doanh thu thuần trên chi phí } \\
\text { bán hàng và quản lý doanh nghiệp }\end{array}$ & $\begin{array}{l}\text { (Doanh thu thuần } \mathrm{t} /(\text { Chi phí bán hàng } \mathrm{t}+\text { Chi phí quản } \\
\text { lý doanh nghiệp } \mathrm{t}) \text { )/Doanh thu thuần } \mathrm{t}-1 /(\text { Doanh thu } \\
\text { thuần } \mathrm{t}-1 /(\text { Chi phí bán hàng } \mathrm{t}-1+\text { Chi phí quản lý } \\
\text { doanh nghiệp } \mathrm{t}-1))\end{array}$ \\
\hline
\end{tabular}

\begin{tabular}{|c|c|c|}
\hline \multicolumn{3}{|l|}{ Cơ hội } \\
\hline \multicolumn{3}{|c|}{ Đặc điểm của ngành hay các hoạt động của doanh nghiệp } \\
\hline INV/TA & Hàng tồn kho trên tổng tài sản & Hàng tồn kho t/Tổng tài sản $\mathrm{t}$ \\
\hline INV/CA & $\begin{array}{l}\text { Hàng tồn kho trên tài sản ngắn } \\
\text { hạn }\end{array}$ & Hàng tồn kho t/Tài sản ngắn hạn t \\
\hline INV/CS & $\begin{array}{l}\text { Hàng tồn kho trên giá vốn hàng } \\
\text { bán }\end{array}$ & Hàng tồn kho t/Giá vốn hàng bán t \\
\hline REC/REV & Tỉ lệ nợ phải thu trên doanh thu & $\begin{array}{l}\text { (Phải thu khách hàng ngắn hạn } \mathrm{t}-\text { Dự phòng nợ khó } \\
\text { đòi } \mathrm{t}+\text { Phải thu khách hàng dài hạn } \mathrm{t}-\text { Dự phòng phải } \\
\text { thu dài hạn } \mathrm{t} \text { )/Doanh thu thuần } \mathrm{t}\end{array}$ \\
\hline \multicolumn{3}{|c|}{ Giám sát của Ban giám đốc không hiểu quả } \\
\hline CEO & $\begin{array}{l}\text { Sự kiêm nhiệm giữa chức danh } \\
\text { chủ t ịch hội đồng quản trị và gám } \\
\text { đốc điều hành }\end{array}$ & $\begin{array}{l}\text { Biến định danh. CEO có giá trị là } 1 \text { nếu chủ } t \text { ịch hội } \\
\text { đồng quản trị kiêm nhiệm giám đốc điều hành, ngược } \\
\text { lại, biến có giá trị là } 0\end{array}$ \\
\hline BIG4 & Kiểm toán viên thuộc nhóm Big 4 & $\begin{array}{l}\text { Biến định danh. BIG4 có giá trị là } 1 \text { nếu được kiểm } \\
\text { toán bởi công ty thuộc nhóm không phải là Big Four, }\end{array}$ \\
\hline
\end{tabular}


ngược lại biến có giá trị là 0

\begin{tabular}{|c|c|c|}
\hline Thái độ & & \\
\hline RST & Tiền sử gian lận & $\begin{array}{l}\text { Số lần phát sinh chênh lệch lợi nhuận trước và sau } \\
\text { kiểm toán trong } 2 \text { năm liền trước }\end{array}$ \\
\hline AUDREPORT & $\begin{array}{l}\text { Ý kiến của kiểm toán viên độc lập } \\
\text { về báo cáo tài chính }\end{array}$ & $\begin{array}{l}\text { Biến định danh. AUDREPORT có giá trị là } 1 \text { nếu đơn } \\
\text { vị nhận được ý kiến không phải là chấp nhận hoàn toàn } \\
\text { về báo cáo tài chính, ngược lại AUDREPORT có giá } \\
\text { trị là } 0\end{array}$ \\
\hline
\end{tabular}

\section{Bảng 2: Bảng mô tả các biến có khả năng ảnh huơong đến} gian lận báo cáo tài chính

\subsection{Tổng thể, mẫu nghiên cứu, mẫu ngoài nghiên cứu và thu thập dữ liệu}

\subsubsection{Tổng thể}

Tổng thể nghiên cứu là các doanh nghiệp tại Việt Nam trừ các doanh nghiệp thuộc lĩnh vực tài chính như ngân hàng, bảo hiểm, chứng khoán, chứng chỉ quỹ, công ty quản lý quỹ, tổ chức tài chính khác.

\subsubsection{Mẫu nghiên cứu}

Mẫu nghiên cứu là các công ty gian lận và không gian lận. Theo VACPA, mức trọng yếu của báo cáo tài chính được xác định như sau:

\begin{tabular}{|l|l|}
\hline Cơ sở ước lượng & Tỷ lệ ước lượng \\
\hline Lợi nhuận trước thuế & $5-10 \%$ \\
\hline Doanh thu & $0,5-3 \%$ \\
\hline Tổng tài sản & $2 \%$ \\
\hline Vốn chủ sở hữu & $2 \%$ \\
\hline
\end{tabular}

Bảng 3: Bảng xác định mức trọng yếu theo VACPA

Ta có:

Chênh lệch lợi nhuận

$=\left|\frac{\text { lợi } n h u \text { ận trước thuế trước kiểm toán - lợi nhuận trước thuế sau kiểm toán }}{\text { lơi nhuận trước thuế sau kiểm toán }}\right|$

Từ bảng trên ta có những công ty có mức chênh lệch lợi nhuận trước thuế dưới $5 \%$ được xem là không có gian lận, các công ty có mức độ chênh lệch lợi nhuận từ $5 \%$ trở lên là các công ty có khả năng gian lận. Lợi nhuận trên báo cáo tài chính sau kiểm toán được xem là lợi nhuận thực tế của công ty (do được kiểm toán viện chấp nhận). Công thức trên nhằm tính mức độ gian lận trên giá trị lợi nhuận đúng. Nhóm nghiên cứu sử dụng giá trị tuyệt đối vì 
không phân biệt chênh lệch dương (thổi phồng lợi nhuận) hay chênh lệch âm (che dấu lợi nhuận).

Để có sự sự khác biệt rõ ràng giữa các công ty gian lận và không gian lận, cần có mức độ phân biệt rõ ràng tỉ lệ chênh lệch lợi nhuận giữa các công ty gian lận và không gian lận. Xét các công ty có mức chênh lệch dưới $5 \%$, ta thấy $90 \%$ công ty có tỉ lệ chênh lệch lợi nhuân trước thuế dưới $3 \%$. Xét các công ty có mức chênh lệch lợi nhuân trước thuế trên $5 \%$, ta thấy có hơn $90 \%$ các công ty có tỉ lệ chênh lêch lợi nhuân lớn hơn $6 \%$. Do đó, chọn các công ty mức chênh lệch dưới $3 \%$ là không gian lận và các công ty có mức chêch lệch lợi nhuân trên $6 \%$ là các công ty gian lận.

Xét mẫu nghiên cứu gồm 230 công ty cổ phần thường trên sàn HOSE trong giai đoạn 2016 đến 2018 với 434 quan sát trong đó có 374 quan sát là các báo cáo tài chính không có gian lận và 60 quan sát là các báo cáo tài chính có gian lận.

\subsubsection{Mẫu ngoài nghiên cứu}

Mẫu ngoài nghiên cứu gồm 110 quan sát trong đó có 90 quan sát là các báo cáo tài chính không gian lận và 20 quan sát là các báo cáo tài chính có gian lận.

\subsubsection{Cách thu thập và xử lý dữ liệu}

Số liệu được lấy trên báo cáo tài chính của các công ty được lấy từ nguồn của phần mềm FiinPro và do tác giả tự thu thập.

Dữ liệu được xử lý từ các số liệu thu thập được thông qua phần mềm Excel.

\subsection{Phân tích dữ liệu}

\subsubsection{Mô hình I}

Nhóm nghiên cứu sử dụng các biến độc lập: AUDREPORT, BIG4 ,CA/CL,CA/TL, CASH/CA, CASH/CL, CASH/TA, TAc/TA, CEO, CFO/CL, CL/TL,EQ/TL, FA/TA, GP/SAL, GP/TA, INV/CS, INV/TA ,LEV,OP/GP, REC/REV, NI/TA, NI/EQ, RST, SAL/COST, SAL/CS, SAL/GA, SAL/FA, SAL/TA, WC/TA và biến phụ thuộc là FRAUD (Xem bảng 2).

\subsubsection{Phân tích tương quan}

\section{(a) Kiểm tra hệ số turơng quan}

Nhóm nghiên cứu sử dụng phần mềm Eview 8 để kiểm tra phân tích tương quan giữa các biến độc lập với với biến phụ thuộc FRAUD. Các biến có ít tương quan với FRAUD (pvalue $\geq 0.2$ ) đều được loại ra khỏi mô hình. Kết quả phân tích tương quan (Correlation Analysis) cho thấy phần lớn các biến độc lập có tương quan với FRAUD với mức ý nghĩa bé hơn 0.2 (ngoại trừ các biến BIG4, TAc/TA, CL/TL, EQ/TL, INV/CS, INV/TA, NI/EQ, $\mathrm{SAL} / \mathrm{CS})$. 


\section{(b) Kiểm tra đa cộng tuyến}

Nhóm nghiên cứu sử dụng phần mềm Eview 8 để kiểm tra phân tích tương quan giữa các biến độc lập với nhau. Các biến có hệ số tương quan $\geq 0.8$ được xem là có đa cộng tuyến cao, ngược lại các biến có hệ số tương quan < 0.8 được xem là có đa cộng tuyến không đáng kể. Kết quả phân tích cho thấy biến $\mathrm{CA} / \mathrm{CL}$ tương quan cao với $\mathrm{CA} / \mathrm{TL}, \mathrm{CASH} / \mathrm{TA}$ tương quan cao với $\mathrm{CASH} / \mathrm{CA}, \mathrm{EQ} / \mathrm{TL}$ tương quan cao với $\mathrm{CA} / \mathrm{TL}$. Trong số các cặp có tương quan cao với nhau, nhóm nghiên cứu sẽ loại bỏ các biến có ít nghĩa thống kê hơn sau khi hồi quy mô hình đầu tiên. 


\begin{tabular}{|c|c|c|c|c|c|c|}
\hline & \multicolumn{2}{|c|}{ Tương quan vói Fraud } & \multicolumn{2}{|l|}{ Jarque-Bera } & \multicolumn{2}{|c|}{ Wilcoxon/Mann-Whitney } \\
\hline & Corr. & P-value & $\mathbf{J B}$ & $\operatorname{Pr}>|\mathbf{J B}|$ & Z-value & $\operatorname{Pr}>|Z|$ \\
\hline AUDREPORT & 0.2330 & 0.0000 & 2480.9050 & 0 & 2.1294 & 0.0332 \\
\hline BIG4 & 0.0542 & 0.2595 & 73.3223 & 0 & 0.9496 & 0.3423 \\
\hline $\mathrm{CA} / \mathrm{CL}$ & -0.0755 & 0.1162 & 8900.9170 & 0 & 1.6271 & 0.1037 \\
\hline CA/TL & -0.1057 & 0.0277 & 16886.6300 & 0 & 1.6027 & 0.1090 \\
\hline $\mathrm{CASH} / \mathrm{CA}$ & -0.1476 & 0.0020 & 300.6935 & 0 & 4.0785 & 0 \\
\hline CASH/CL & -0.0989 & 0.0395 & 19523.2900 & 0 & 4.6551 & 0 \\
\hline $\mathrm{CASH} / \mathrm{TA}$ & -0.1559 & 0.0011 & 1147.4670 & 0 & 4.3169 & 0 \\
\hline TAc/TA & 0.0010 & 0.9828 & 700821.6000 & 0 & 0.5017 & 0.6159 \\
\hline CEO & 0.0624 & 0.1943 & 134.1337 & 0 & 0.9297 & 0.3525 \\
\hline $\mathrm{CFO} / \mathrm{TL}$ & -0.1026 & 0.0327 & 9972.1150 & 0 & 4.4455 & 0 \\
\hline CL/TL & -0.0444 & 0.3563 & 57.3110 & 0 & 1.4325 & 0.1520 \\
\hline $\mathrm{EQ} / \mathrm{TL}$ & -0.0568 & 0.2379 & 17298.9900 & 0 & 2.4099 & 0.0160 \\
\hline FA/TA & -0.1638 & 0.0006 & 132.8984 & 0 & 4.1750 & 0 \\
\hline GP/SAL & -0.1758 & 0.0002 & 168.0209 & 0 & 3.4532 & 0.0006 \\
\hline GP/TA & -0.2800 & 0.0000 & 200.3026 & 0 & 7.4347 & 0 \\
\hline INV/CS & 0.0452 & 0.3480 & 2191141.0000 & 0 & 3.1228 & 0.0018 \\
\hline INV/TA & 0.0601 & 0.2114 & 80.5814 & 0 & 0.7922 & 0.4282 \\
\hline LEV & 0.1179 & 0.0140 & 12.9422 & 0.0015 & 2.4232 & 0.0154 \\
\hline OP/GP & -0.0654 & 0.1740 & 1447384.0000 & 0 & 4.3025 & 0 \\
\hline REC/REV & 0.2360 & 0.0000 & 100734.5000 & 0 & 4.9478 & 0 \\
\hline NI/TA & -0.2619 & 0.0000 & 9912.2190 & 0 & 8.3849 & 0 \\
\hline NI/EQ & 0.0288 & 0.5502 & 1457104.0000 & 0 & 7.6066 & 0 \\
\hline RST & 0.4245 & 0.0000 & 289.1251 & 0 & 6.3077 & 0 \\
\hline SAL/COST & -0.0798 & 0.0968 & 17278.8300 & 0 & 1.9342 & 0.0531 \\
\hline SAL/CS & -0.0052 & 0.9148 & 34915.3100 & 0 & 0.2012 & 0.8405 \\
\hline SAL/GA & 0.0756 & 0.1158 & 1312430.0000 & 0 & 2.2303 & 0.0257 \\
\hline SAL/FA & 0.1296 & 0.0069 & 2881418.0000 & 0 & 0.6381 & 0.5234 \\
\hline SAL/TA & -0.1587 & 0.0009 & 2483.5000 & 0 & 5.1152 & 0 \\
\hline WC/TA & -0.0829 & 0.0847 & 5.7432 & 0.0566 & 1.6094 & 0.1075 \\
\hline
\end{tabular}

Bảng 4: Kết quả phân tích tuơng quan, kiểm định Jarque-Bera, kiểm định Wilcoxon/Mann-Whitney

\subsubsection{Kiểm định phân phối của các biến và kiểm đinh khả năng phát hiên} gian lận của các biến

(a) Kiểm định phân phối chuẩn

Nhóm nghiên cứu sử dụng phần mềm Eview8 thực hiện kiểm đinh Jarque-Bera để kiểm tra hai giả thuyết:

- Ho: các biến không tuân theo quy luật phân phối chuẩn $(\mathrm{p}<0.1)$

- H1: các biến tuân theo quy luật phân phối chuẩn (p $\geq 0.1)$ 
Kết quả kiểm định cho thấy tất cả các các biến đều không tuân theo quy luật phân phối chuẩn.

(b) Kiểm định khả năng phát hiên gian lận của các biến:

Nhóm nghiên cứu sử dụng kiểm định Mann-Whitney U test để kiểm tra khả năng phân biệt các báo cáo gian lận và không gian lận của các biến không tuân theo quy luật phân phối chuẩn:

- Ho: các biến có khả năng phân biệt các báo cáo gian lận và không gian lận $(\mathrm{p}<0.2)$.

- H1: các biến không có khả năng phân biệt các báo cáo tài chính gian lận và không gian lận ( $\mathrm{p} \geq 0.2)$.

Kết quả kiểm định cho thấy đa số các biến đều có khả năng phân biệt các báo cáo tài chính gian lận và không gian lận ngoại trừ các biến $\mathrm{CEO}, \mathrm{SAL} / \mathrm{FA}$. Các biến này bị loại khỏi mô hình.

\subsubsection{Hồi quy logit}

Mô hình hồi quy logit 19 biến sau khi đã loại các biến không phù hợp có dạng như sau:

FRAUD $=\beta_{0}+\quad \beta_{1} A U D R E P O R T+\quad \beta_{2} \mathrm{CA} / \mathrm{CL}+\quad \beta_{3} \mathrm{CA} / \mathrm{TL}+\quad \beta_{4} \mathrm{CASH} / \mathrm{CA}+$ $\beta_{5} \mathrm{CASH} / \mathrm{CL}+\beta_{6} \mathrm{CASH} / \mathrm{TA}+\beta_{7} \mathrm{CFO} / \mathrm{TL}+\beta_{8} \mathrm{FA} / \mathrm{TA}+\beta_{9} \mathrm{GP} / \mathrm{SAL}+\beta_{10} \mathrm{GP} / \mathrm{TA}+\beta_{11 \mathrm{LEV}}+$ $\beta_{12} \mathrm{OP} / \mathrm{GP}+\beta_{13 \mathrm{REC} / \mathrm{REV}+}+\beta_{14 \mathrm{NI} / \mathrm{TA}+}+\beta_{15} \mathrm{RST}+\beta_{16} \mathrm{SAL} / \mathrm{COST}+\beta_{17} \mathrm{SAL} / \mathrm{GA}+$

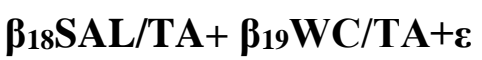

Kết quả hồi quy mô hình theo phương pháp logit được trình bày trong bảng sau: 


\begin{tabular}{|c|c|c|c|c|c|c|c|c|c|c|}
\hline \multirow[b]{2}{*}{ FRAUD } & \multicolumn{2}{|l|}{ Mô hình 1} & \multicolumn{2}{|c|}{$\begin{array}{l}\text { Mô hình } 2 \\
\text { (từ mô hình 1, loại } \\
\text { CA/CL, CASH/CA, } \\
\text { CASH/CL, SAL/TA) }\end{array}$} & \multicolumn{2}{|c|}{$\begin{array}{l}\text { Mô hình } 3 \\
\text { (từ mô hình 2, loại } \\
\text { GP/SAL) }\end{array}$} & \multicolumn{2}{|c|}{$\begin{array}{l}\text { Mô hình } 4 \\
\text { (từ mô hình } 3 \text {, loại } \\
\text { CFO/TL) }\end{array}$} & \multicolumn{2}{|c|}{$\begin{array}{l}\text { Mô hình } 5 \\
\text { (từ mô hình 4, loại } \\
\text { CASH/TA, NI/TA) }\end{array}$} \\
\hline & Coef. & $\mathrm{P}>\mathrm{Z}$ & Coef. & $\mathrm{P}>\mathrm{Z}$ & Coef. & $\mathrm{P}>\mathrm{Z}$ & Coef. & $\mathrm{P}>\mathrm{Z}$ & Coef. & $\mathrm{P}>\mathrm{Z}$ \\
\hline AUDREPORT & 0.673909 & 0.2434 & 0.671642 & 0.239 & 0.674262 & 0.2366 & 0.651509 & 0.2511 & 0.621132 & 0.2723 \\
\hline $\mathrm{CA} / \mathrm{CL}$ & 0.080171 & 0.6609 & & & & & & & & \\
\hline $\mathrm{CA} / \mathrm{TL}$ & -0.384284 & 0.2336 & -0.37854 & 0.2777 & -0.34338 & 0.2809 & -0.3056 & 0.325 & -0.32295 & 0.3073 \\
\hline CASH/CA & 0.722402 & 0.7794 & & & & & & & & \\
\hline $\mathrm{CASH} / \mathrm{CL}$ & 0.121761 & 0.856 & & & & & & & & \\
\hline CASH/TA & -4.023454 & 0.4777 & -1.97466 & 0.5015 & -1.85399 & 0.5237 & -1.55459 & 0.5756 & & \\
\hline $\mathrm{CFO} / \mathrm{TL}$ & 0.163263 & 0.6945 & 0.166917 & 0.6869 & 0.171068 & 0.6777 & & & & \\
\hline FA/TA & -2.95578 & 0.0106 & -2.76708 & 0.0138 & -2.82112 & 0.0111 & -2.80833 & 0.0116 & -2.82413 & 0.0117 \\
\hline GP/SAL & -0.936849 & 0.6087 & -0.56203 & 0.6999 & & & & & & \\
\hline GP/TA & -5.059148 & 0.1195 & -5.86673 & 0.0278 & -6.24075 & 0.0124 & -6.28305 & 0.012 & -6.05509 & 0.0067 \\
\hline LEV & -1.198834 & 0.3338 & -1.45002 & 0.2182 & -1.33173 & 0.2338 & -1.41397 & 0.2016 & -1.45197 & 0.1946 \\
\hline OP/GP & -0.775239 & 0.0195 & -0.72376 & 0.0236 & -0.73389 & 0.0212 & -0.73289 & 0.0217 & -0.65429 & 0.0074 \\
\hline REC/REV & 0.640495 & 0.0935 & 0.572946 & 0.1139 & 0.575512 & 0.1079 & 0.573721 & 0.1099 & 0.615805 & 0.083 \\
\hline NI/TA & 1.587721 & 0.5831 & 1.450412 & 0.6071 & 1.604642 & 0.5653 & 1.595562 & 0.5688 & & \\
\hline $\mathrm{RST}$ & 1.215402 & 0 & 1.179299 & 0 & 1.180207 & 0 & 1.185426 & 0 & 1.17375 & 0 \\
\hline SAL/COST & -3.464898 & 0.0783 & -3.51648 & 0.065 & -3.72111 & 0.0418 & -3.69879 & 0.043 & -3.16778 & 0.0491 \\
\hline SAL/GA & 0.066502 & 0.5756 & 0.065975 & 0.5735 & 0.068984 & 0.5626 & 0.070633 & 0.5503 & 0.070692 & 0.5472 \\
\hline SAL/TA & -0.027682 & 0.932 & & & & & & & & \\
\hline WC/TA & -0.969119 & 0.4822 & -0.6156 & 0.6411 & -0.72368 & 0.5695 & -0.86507 & 0.4839 & -0.82076 & 0.5015 \\
\hline Cons & 3.711985 & 0.0809 & 3.969973 & 0.0518 & 4.026582 & 0.0469 & 4.028023 & 0.0474 & 3.425618 & 0.056 \\
\hline LR stat & \multicolumn{2}{|l|}{119.3964} & \multicolumn{2}{|l|}{\begin{tabular}{|l|}
117.909 \\
\end{tabular}} & \multicolumn{2}{|l|}{117.7569} & \multicolumn{2}{|l|}{117.5857} & \multicolumn{2}{|l|}{116.9434} \\
\hline Prob > chi2 & \multicolumn{2}{|l|}{0} & \multicolumn{2}{|l|}{0} & \multicolumn{2}{|l|}{0} & \multicolumn{2}{|c|}{0} & \multicolumn{2}{|l|}{0} \\
\hline Pseudo R2 & \multicolumn{2}{|l|}{0.342367} & \multicolumn{2}{|l|}{0.338102} & \multicolumn{2}{|l|}{0.337666} & \multicolumn{2}{|l|}{0.337175} & \multicolumn{2}{|l|}{0.335333} \\
\hline
\end{tabular}

Bảng 5: Kết quả hồi quy logit mô hình I - bảng 1 


\begin{tabular}{|c|c|c|c|c|c|c|c|c|c|c|}
\hline \multirow[b]{2}{*}{ FRAUD } & \multicolumn{2}{|c|}{$\begin{array}{l}\text { Mô hình } 6 \\
\text { (từ mô hình 5, loại } \\
\text { SAL/GA) }\end{array}$} & \multicolumn{2}{|c|}{$\begin{array}{l}\text { Mô hình } 7 \\
\text { (từ mô hình 6, loại } \\
\text { WC/TA) }\end{array}$} & \multicolumn{2}{|c|}{$\begin{array}{l}\text { Mô hình } 8 \\
\text { (từ mô hình 7, loại } \\
\text { AUDREPORT) }\end{array}$} & \multicolumn{2}{|c|}{$\begin{array}{l}\text { Mô hình } 9 \\
\text { (từ mô hình 8, loại LEV) }\end{array}$} & \multicolumn{2}{|c|}{$\begin{array}{l}\text { Mô hình } 10 \\
\text { (từ mô hình 9, loại } \\
\text { CA/TL) }\end{array}$} \\
\hline & Coef. & $\mathrm{P}>\mathrm{z}$ & Coef. & $\mathrm{P}>\mathrm{z}$ & Coef. & $\mathrm{P}>\mathrm{Z}$ & Coef. & $\mathrm{P}>\mathrm{z}$ & Coef. & $\mathrm{P}>\mathrm{z}$ \\
\hline AUDREPORT & 0.670457 & 0.2285 & 0.681712 & 0.2223 & & & & & & \\
\hline \multicolumn{11}{|l|}{$\mathrm{CA} / \mathrm{CL}$} \\
\hline $\mathrm{CA} / \mathrm{TL}$ & -0.31486 & 0.3129 & -0.4286 & 0.1329 & -0.40957 & 0.1447 & -0.23855 & 0.2176 & & \\
\hline \multicolumn{11}{|l|}{$\mathrm{CASH} / \mathrm{CA}$} \\
\hline \multicolumn{11}{|l|}{$\mathrm{CASH} / \mathrm{CL}$} \\
\hline \multicolumn{11}{|l|}{ CASH/TA } \\
\hline \multicolumn{11}{|l|}{$\mathrm{CFO} / \mathrm{TL}$} \\
\hline FA/TA & -2.79655 & 0.0126 & -2.60782 & 0.0158 & -2.68241 & 0.0122 & -2.3801 & 0.0188 & -2.02104 & 0.0383 \\
\hline \multicolumn{11}{|l|}{ GP/SAL } \\
\hline GP/TA & -6.16519 & 0.0058 & -6.12146 & 0.0062 & -6.30073 & 0.0052 & -6.46297 & 0.0041 & -6.92946 & 0.0017 \\
\hline LEV & -1.35603 & 0.2212 & -1.40417 & 0.214 & -1.20702 & 0.2776 & & & & \\
\hline OP/GP & -0.66211 & 0.0066 & -0.67632 & 0.0058 & -0.70686 & 0.0036 & -0.68113 & 0.0037 & -0.72145 & 0.0018 \\
\hline REC/REV & 0.618997 & 0.0788 & 0.601848 & 0.0872 & 0.598166 & 0.1037 & 0.590034 & 0.0954 & 0.6039 & 0.0937 \\
\hline \multicolumn{11}{|l|}{ NI/TA } \\
\hline RST & 1.166998 & 0 & 1.168697 & 0 & 1.217137 & 0 & 1.207541 & 0 & 1.209523 & 0 \\
\hline SAL/COST & -3.01589 & 0.0612 & -3.06048 & 0.0555 & -2.91872 & 0.0642 & -3.11803 & 0.0505 & -2.88343 & 0.0631 \\
\hline \multicolumn{11}{|l|}{ SAL/GA } \\
\hline \multicolumn{11}{|l|}{ SAL/TA } \\
\hline WC/TA & -0.75803 & 0.532 & & & & & & & & \\
\hline Cons & 3.290976 & 0.0662 & 3.31915 & 0.0668 & 3.142198 & 0.0789 & 2.455855 & 0.1408 & 1.868825 & 0.2373 \\
\hline LR stat & \multicolumn{2}{|l|}{116.3615} & \multicolumn{2}{|l|}{115.9754} & \multicolumn{2}{|l|}{114.5104} & \multicolumn{2}{|l|}{113.3129} & \multicolumn{2}{|l|}{110.4236} \\
\hline Prob $>$ chi 2 & \multicolumn{2}{|c|}{0} & \multicolumn{2}{|l|}{0} & \multicolumn{2}{|l|}{0} & \multicolumn{2}{|l|}{0} & \multicolumn{2}{|l|}{0} \\
\hline Pseudo $\mathrm{R}^{2}$ & \multicolumn{2}{|l|}{0.333665} & \multicolumn{2}{|l|}{0.332557} & \multicolumn{2}{|l|}{0.328356} & \multicolumn{2}{|l|}{0.324923} & \multicolumn{2}{|l|}{0.316638} \\
\hline
\end{tabular}

Bảng 6: Kết quả hồi quy logit mô hình I- bảng 2 
Tất cả các mô hình đều có hệ số LR Chi2 cao (từ 110.4236 đến 117.909) với p-value (Prob>chi2) là 0,000 cho thấy các mô hình này là phù hợp để nghiên cứu gian lận. Các hệ số Pseudo R2 cao hơn mức tối thiểu là 0.2 theo yêu cầu của McFadden (1974). Trong bảng trên, mô hình số 10 được xem là tối ưu để dự đoán gian lận vì có ít biến, thuận tiện khi sử dụng, các biến có ý nghĩa thống kê cao.

Phương trình hồi quy logit mô hình 10 được viết lại như sau:

FRAUD $=1.868825-2.021039$ FA/TA -6.929463 GP/TA -0.721449 OP/GP + 0.6039 REC/REV + 1.209523 RST - 2.883432 SAL/COST

\subsubsection{Lụa chọn giá trị phân biệt p, đối chiếu mẫu ngoài nghiên cứu}

(a) Lựa chọn giá trị phân biệt $p$

Do cả kiểm toán viên và nhà đầu tư đều yêu cầu tỉ lệ phân loại chính xác cao giữa các báo cáo tài chính gian lận và không gian lận, nên nhóm nghiên cứu lựa chọn giá trị p có thể phân loại chính xác cao nhất giữa báo cáo tài chính gian lận và không gian lận thông qua tỉ lệ chính xác trung bình (Ep). Phải lựa chọn giá trị p có tỉ lệ phân loại chính xác trung bình cao nhất và có tính đại diện cao. Tính đại diện của Ep cao thể hiện qua hệ số biến thiên của $\mathrm{Ep}(\mathrm{CV})$. Hệ số biến thiên càng thấp, tính đại diện càng cao và ngược lại.

$\mathrm{CV}=\frac{\sqrt{\operatorname{Var}}(E p)}{E p}$. Trong đó $\operatorname{Var}(\mathrm{Ep})=(E p-p 1)^{2} \mathrm{P} 1+(E p-p 2)^{2} \mathrm{P} 2$

p1: tỉ lệ phần trăm dự đoán đúng các báo cáo không gian lận

P1: tỉ lệ phần trăm các báo cáo không gian lận trong mẫu nhiên cứu

p2: tî̉ lệ phần trăm dự đoán đúng các báo cáo gian lận

P2: tỉ lệ phần trăm các báo cáo gian lận trong mẫu nghiên cứu 


\begin{tabular}{|c|c|c|c|c|c|}
\hline \multirow{7}{*}{$\begin{array}{l}\text { Mẫu } \\
\text { nghiên cứu }\end{array}$} & & $\mathrm{p}=10 \%$ & $\mathrm{p}=13 \%$ & $\mathrm{p}=16 \%$ & $\mathrm{p}=19 \%$ \\
\hline & $\begin{array}{l}\text { Số dự báo chính xác báo cáo } \\
\text { không gian lận }\end{array}$ & 270 & 304 & 316 & 326 \\
\hline & $\begin{array}{l}\text { Tỉ lệ phần trăm dụ báo chính xác } \\
\text { báo cáo không gian lận }\end{array}$ & $72.19 \%$ & $81.28 \%$ & $84.49 \%$ & $87.17 \%$ \\
\hline & $\begin{array}{l}\text { Số dự báo chính xác báo cáo gian } \\
\text { lận }\end{array}$ & 51 & 47 & 44 & 42 \\
\hline & $\begin{array}{l}\text { Tỉ lệ phần trăm dụ báo chính xác } \\
\text { báo cáo gian lận }\end{array}$ & $85 \%$ & $78.33 \%$ & $73.33 \%$ & $70 \%$ \\
\hline & Tỉ lệ dụ báo chính xác trung bình & $73.96 \%$ & $80.88 \%$ & $82.95 \%$ & $84.79 \%$ \\
\hline & CV & $5.98 \%$ & $1.26 \%$ & $4.64 \%$ & $6.99 \%$ \\
\hline
\end{tabular}

Bảng 7: Kết quả dụ đoán của mô hình I với mẫu nghiên cứu

Ta thấy với $\mathrm{p}$ cao, tỉ lệ phần trăm dự đoán chính xác báo cáo không gian lận càng cao, tỉ lệ dự đoán chính xác báo cáo gian lận càng thấp và ngược lại. Để CV thấp, p1 và p2 có giá trị gần nhau.

Từ bảng 7 , nhóm nghiên cứu chọn giá trị $\mathrm{p}=13 \%$.

(b) Đối chiếu mẫu ngoài nghiên cưu

\begin{tabular}{|l|l|c|}
\hline \multirow{4}{*}{$\begin{array}{l}\text { Mẫu ngoài } \\
\text { nghiên cứu }\end{array}$} & $\begin{array}{l}\text { Sî́ dự báo chính xác báo cáo khồng gian lận } \\
\text { gian lận }\end{array}$ & $\mathrm{p}=13 \%$ \\
\cline { 2 - 3 } & Số dụ̣ báo chính xạ́c báo chính xác báo cáo không & 73 \\
\cline { 2 - 3 } & Tỉ lệ phần trăm dụ̂ bậo chính xác báo cáo gian lận & $81.11 \%$ \\
\cline { 2 - 3 } & Tỉ lệ dự báo chính xác trung bình & 17 \\
\hline
\end{tabular}

Bảng 8: Kết quả dụ đoán của mô hình I với mâ̂u ngoài nghiên cúu

\subsubsection{5. Đề xuất các mô hình mới dụa vào kết quả}

Dựa vào kết quả của mô hình đầu tiên, nhóm nghiên cứu loại bỏ các biến không phân biệt được báo cáo tài chính gian lận và không gian lận (CEO, SAL/FA), loại bỏ các biến ít có tương quan với biến phụ thuộc (BIG4, CA/TA, CL/TL, EQ/TL, INV/CS, INV/TA, NI/EQ, $\mathrm{SAL} / \mathrm{CS}$ ) và các biến $\mathrm{CA} / \mathrm{TL}, \mathrm{CA} / \mathrm{CL}, \mathrm{LEV}$ do không có ý nghĩa trong mô hình hồi quy đầu tiên, loại bỏ biến $\mathrm{OP} / \mathrm{GP}$, thay vào đó, nhóm nghiên cứu them các biến $\mathrm{CFO} / \mathrm{NI}, \mathrm{CFO} / \mathrm{TA}$, CS/GP, EQ/TA, INV/CA, NI/SAL để tiến hành hồi quy mô hình thứ 2. 


\subsubsection{Mô hình II}

\subsubsection{Phân tích tương quan}

(a) Kiểm tra hệ số tương quan

Nhóm nghiên cứu sử dụng phần mềm Eview 8 để kiểm tra phân tích tương quan giữa các biến độc lập với với biến phụ thuộc Fraud. Các biến có ít tương quan với Fraud(p-value $\geq$ 0.2) đều được loại ra khỏi mô hình. Kết quả phân tích tương quan (Correlation Analysis) cho thấy đa số các biến độc lập có tương quan với FRAUD với mức ý nghĩa bé hơn 0.2 (trừ CS/GP, INV/CA).

\section{(b) Kiểm tra đa cộng tuyến}

Nhóm nghiên cứu sử dụng phần mềm Eview 8 để kiểm tra phân tích tương quan giữa các biến độc lập với nhau. Các biến có hệ số tương quan $\geq 0.8$ được xem là có đa cộng tuyến cao, ngược lại các biến có hệ số tương quan $<0.8$ được xem là có đa cộng tuyến không đáng kể. Kết quả phân tích cho thấy biến biến đều không có tượng quan cao với nhau. 


\begin{tabular}{|c|c|c|c|c|c|c|}
\hline & \multicolumn{2}{|c|}{ Tương quan với Fraud } & \multicolumn{2}{|l|}{ Jarque-Bera } & \multicolumn{2}{|c|}{ Wilcoxon/Mann-Whitney } \\
\hline & Corr. & P-value & $\mathbf{J B}$ & $\mathbf{P r}>|\mathbf{J B}|$ & Z-value & $\operatorname{Pr}>|Z|$ \\
\hline AUDREPORT & 0.2330 & 0 & 2480.9050 & 0 & 2.1294 & 0.0332 \\
\hline $\mathrm{CASH} / \mathrm{CA}$ & -0.1476 & 0.002 & 300.6935 & 0 & 4.0785 & 0 \\
\hline $\mathrm{CASH} / \mathrm{CL}$ & -0.0989 & 0.0395 & 19523.2900 & 0 & 4.6551 & 0 \\
\hline CASH/TA & -0.1559 & 0.0011 & 1147.4670 & 0 & 4.3169 & 0 \\
\hline $\mathrm{CFO} / \mathrm{NI}$ & -0.0970 & 0.0435 & 280047.8000 & 0 & 1.9708 & 0.0487 \\
\hline $\mathrm{CFO} / \mathrm{TA}$ & -0.1575 & 0.001 & 310.3738 & 0 & 4.0874 & 0 \\
\hline $\mathrm{CFO} / \mathrm{TL}$ & -0.1026 & 0.0327 & 9972.1150 & 0 & 4.4455 & 0 \\
\hline CS/GP & 0.0615 & 0.201 & 1915691.0000 & 0 & 2.9565 & 0.0031 \\
\hline $\mathrm{EQ} / \mathrm{TA}$ & -0.1163 & 0.0153 & 12.6915 & 0.0018 & 2.3877 & 0.017 \\
\hline FA/TA & -0.1638 & 0.0006 & 132.8984 & 0 & 4.1750 & 0 \\
\hline GP/SAL & -0.1758 & 0.0002 & 168.0209 & 0 & 3.4532 & 0.0006 \\
\hline GP/TA & -0.2800 & 0 & 200.3026 & 0 & 7.4347 & 0 \\
\hline INV/CA & 0.0451 & 0.3484 & 29.6454 & 0 & 0.8111 & 0.4173 \\
\hline $\mathrm{NI} / \mathrm{SAL}$ & -0.1455 & 0.0024 & 20589.1800 & 0 & 4.9434 & 0 \\
\hline $\mathrm{REC} / \mathrm{REV}$ & 0.2360 & 0 & 100734.5000 & 0 & 4.9478 & 0 \\
\hline RST & 0.4245 & 0 & 289.1251 & 0 & 8.3849 & 0 \\
\hline NI/TA & -0.2619 & 0 & 9912.2190 & 0 & 6.3077 & 0 \\
\hline SAL/COST & -0.0798 & 0.0968 & 17278.8300 & 0 & 1.9342 & 0.0531 \\
\hline SAL/GA & 0.0756 & 0.1158 & 1312430.0000 & 0 & 2.2303 & 0.0257 \\
\hline SAL/TA & -0.1587 & 0.0009 & 2483.5000 & 0 & 5.1152 & 0 \\
\hline WC/TA & -0.0829 & 0.0847 & 5.7432 & 0.0566 & 1.6094 & 0.1075 \\
\hline
\end{tabular}

Bảng 9: Kết quả phân tích tuơng quan,kiểm định Jarque-Bera, kiểm đinh Wilcoxon/Mann-Whitney

\subsubsection{Kiểm định phân phối của các biến với kiểm đinh khả năng phát hiên} gian lận của các biến

(a) Kiểm định phân phối chuẩn

Nhóm nghiên cứu sử dụng phần mềm Eview8 thực hiện kiểm đinh Jarque-Bera để kiểm tra hai giả thuyết:

- Ho: các biến không tuân theo quy luật phân phối chuẩn $(\mathrm{p}<0.1)$

- H1: các biến tuân theo quy luật phân phối chuẩn $(\mathrm{p} \geq 0.1)$

Kết quả kiểm định cho thấy tất cả các các biến đều không tuân theo quy luật phân phối chuẩn. 


\section{(b) Kiểm định khả năng phát hiện gian lận của biến}

Nhóm nghiên cứu sử dụng kiểm định Mann-Whitney U test để kiểm tra khả năng phân biệt các báo cáo gian lận và không gian lận của các biến không tuân theo quy luật phân phối chuẩn:

- Ho: các biến có khả năng phân biệt các báo cáo gian lận và không gian lận $(\mathrm{p}<0.2)$.

- H1: các biến không có khả năng phân biệt các báo cáo tài chính gian lận và không gian lận $(\mathrm{p} \geq 0.2)$.

Kết quả kiểm định cho thấy đa số các biến đều có khả năng phân biệt các báo cáo tài chính gian lận và không gian lận ngoại trừ biến INV/CA.

\subsubsection{Hồi quy logit:}

Mô hình hồi quy logit 20 biến sau khi loại trừ các biến không phù hơp có dạng như sau

FRAUD $=\beta_{0}+\quad \beta_{1}$ AUDREPORT $+\quad \beta_{2} \mathrm{CFO} / \mathrm{NI}+\beta_{3} \mathrm{CFO} / \mathrm{TA}+\beta_{4} \mathrm{CASH} / \mathrm{CA}+$ $\beta_{5} \mathrm{CASH} / \mathrm{CL}+\beta_{6} \mathrm{CASH} / \mathrm{TA}+\beta_{7} \mathrm{CFO} / \mathrm{TL}+\beta_{8} \mathrm{CS} / \mathrm{GP}+\beta_{9} \mathrm{EQ} / \mathrm{TA}+\beta_{10} \mathrm{FA} / \mathrm{TA}+\beta_{11} \mathrm{GP} / \mathrm{SAL}+$ $\beta_{12} \mathrm{GP} / \mathrm{TA}+\beta_{13} \mathrm{NI} / \mathrm{SAL}+\beta_{14} \mathrm{NI} / \mathrm{TA}+\beta_{15} \mathrm{RST}+\beta_{16} \mathrm{SAL} / \mathrm{COST}+\beta_{17} \mathrm{SAL} / \mathrm{GA}+\beta_{18} \mathrm{SAL} / \mathrm{TA}+$ $\beta 19 \mathrm{WC} / \mathrm{TA}+\beta_{20} \mathrm{REC} / \mathrm{REV}+\varepsilon$

Kết quả hồi quy mô hình theo phương pháp logit được trình bày trong bảng sau: 


\begin{tabular}{|c|c|c|c|c|c|c|c|c|c|c|}
\hline \multirow[b]{2}{*}{ FRAUD } & \multicolumn{2}{|c|}{ Mô hình 1} & \multicolumn{2}{|c|}{$\begin{array}{l}\text { Mô hình } 2 \\
\text { (từ mô hình 1, loại } \\
\text { CASH/CA, CFO/CL, } \\
\text { SAL/TA) }\end{array}$} & \multicolumn{2}{|c|}{$\begin{array}{l}\text { Mô hình } 3 \\
\text { Từ mô hình 2, loại } \\
\text { CASH/CL, GP/SAL) }\end{array}$} & \multicolumn{2}{|c|}{$\begin{array}{l}\text { Mô hình } 4 \\
\text { (từ mô hình 3, loại } \\
\text { CFO/TA, NI/SAL) }\end{array}$} & \multicolumn{2}{|c|}{$\begin{array}{l}\text { Mô hình } 5 \\
\text { (từ mô hình 4, loại } \\
\text { EQ/TA, SAL/GA) }\end{array}$} \\
\hline & Coef. & $\mathrm{P}>\mathrm{Z}$ & Coef. & $\mathrm{P}>\mathrm{Z}$ & Coef. & $\mathrm{P}>\mathrm{Z}$ & Coef. & $\mathrm{P}>\mathrm{Z}$ & Coef. & $\mathrm{P}>\mathrm{Z}$ \\
\hline AUDREPORT & 0.700216 & 0.2078 & 0.683665 & 0.2163 & 0.686446 & 0.2137 & 0.671513 & 0.2222 & 0.682413 & 0.1985 \\
\hline CASH/CA & 1.727804 & 0.4579 & & & & & & & & \\
\hline CASH/CL & 0.076639 & 0.8016 & 0.104283 & 0.6978 & & & & & & \\
\hline $\mathrm{CASH} / \mathrm{TA}$ & -5.17857 & 0.3112 & -2.41142 & 0.4582 & -1.70842 & 0.5208 & -2.20675 & 0.3914 & -2.08824 & 0.416 \\
\hline $\mathrm{CFO} / \mathrm{NI}$ & -0.00224 & 0.5307 & -0.00203 & 0.5586 & -0.00199 & 0.5649 & -0.00258 & 0.421 & -0.00239 & 0.4342 \\
\hline $\mathrm{CFO} / \mathrm{TA}$ & -0.86027 & 0.6601 & -0.798 & 0.6086 & -0.7857 & 0.6129 & & & & \\
\hline $\mathrm{CFO} / \mathrm{TL}$ & 0.003588 & 0.9916 & & & & & & & & \\
\hline CS/GP & 0.010245 & 0.2745 & 0.009801 & 0.2791 & 0.010077 & 0.2777 & 0.009905 & 0.2478 & 0.011946 & 0.2386 \\
\hline $\mathrm{EQ} / \mathrm{TA}$ & 0.397738 & 0.7086 & 0.648589 & 0.5154 & 0.700843 & 0.4663 & 0.553649 & 0.5501 & & \\
\hline FA/TA & -2.566 & 0.0243 & -2.34894 & 0.032 & -2.33164 & 0.031 & -2.3735 & 0.0282 & -2.20811 & 0.0364 \\
\hline GP/SAL & -0.67312 & 0.7288 & -0.29621 & 0.8472 & & & & & & \\
\hline GP/TA & -2.03929 & 0.5288 & -2.76513 & 0.294 & -3.1218 & 0.1727 & -3.5543 & 0.0944 & -3.68626 & 0.0852 \\
\hline NI/SAL & 0.605417 & 0.6492 & 0.629341 & 0.6279 & 0.546993 & 0.6382 & & & & \\
\hline REC/REV & 0.547439 & 0.1083 & 0.52824 & 0.1112 & 0.51977 & 0.1132 & 0.530325 & 0.1028 & 0.532646 & 0.0949 \\
\hline NI/TA & -4.3188 & 0.2488 & -4.16565 & 0.2495 & -3.92361 & 0.2345 & -2.69176 & 0.1941 & -2.71179 & 0.1941 \\
\hline RST & 1.180019 & 0 & 1.186392 & 0 & 1.17883 & 0 & 1.16331 & 0 & 1.149389 & 0 \\
\hline SAL/COST & -1.94284 & 0.2483 & -2.09273 & 0.1988 & -2.16607 & 0.1606 & -2.24845 & 0.1484 & -2.10506 & 0.1797 \\
\hline SAL/GA & 0.090497 & 0.5105 & 0.09552 & 0.4995 & 0.094849 & 0.4998 & 0.087101 & 0.5202 & & \\
\hline SAL/TA & -0.04882 & 0.878 & & & & & & & & \\
\hline WC/TA & -1.51171 & 0.1784 & -1.83121 & 0.0781 & -1.78028 & 0.0835 & -1.67351 & 0.0983 & -1.3942 & 0.13 \\
\hline Cons & 0.413976 & 0.8142 & 0.475448 & 0.7848 & 0.487822 & 0.7711 & 0.699425 & 0.6746 & 0.838133 & 0.6117 \\
\hline LR stat & \multicolumn{2}{|l|}{107.7088} & \multicolumn{2}{|l|}{107.101} & \multicolumn{2}{|l|}{106.9345} & \multicolumn{2}{|l|}{106.4358} & \multicolumn{2}{|l|}{105.473} \\
\hline Prob > chi 2 & \multicolumn{2}{|l|}{0} & \multicolumn{2}{|l|}{0} & \multicolumn{2}{|l|}{0} & \multicolumn{2}{|l|}{0} & \multicolumn{2}{|l|}{0} \\
\hline Pseudo $\mathrm{R}^{2}$ & \multicolumn{2}{|l|}{0.308853} & \multicolumn{2}{|l|}{0.30711} & \multicolumn{2}{|l|}{0.306633} & \multicolumn{2}{|l|}{0.305203} & \multicolumn{2}{|l|}{0.302442} \\
\hline
\end{tabular}

Bảng 10: Kết quả hồi quy logit mô hình II - bảng 1 


\begin{tabular}{|c|c|c|c|c|c|c|c|c|}
\hline \multirow[b]{2}{*}{ FRAUD } & \multicolumn{2}{|c|}{$\begin{array}{l}\text { Mô hình } 6 \\
\text { Tù̀ mô hình } 5 \text {, loại } \\
\text { CFO/NI) }\end{array}$} & \multicolumn{2}{|c|}{$\begin{array}{l}\text { Mô hình } 7 \\
\text { (từ mô hình 6, loại } \\
\text { CASH/TA) }\end{array}$} & \multicolumn{2}{|c|}{$\begin{array}{l}\text { Mô hình } 8 \\
\text { (từ mô hình 7, loại } \\
\text { CS/GP) }\end{array}$} & \multicolumn{2}{|c|}{$\begin{array}{l}\text { Mô hình } 9 \\
\text { Từ mô hình 8, loạ } \\
\text { AUDREPORT, } \\
\text { SAL/COST) }\end{array}$} \\
\hline & Coef. & $\mathrm{P}>\mathrm{Z}$ & Coef. & $\mathrm{P}>\mathrm{z}$ & Coef. & $\mathrm{P}>\mathrm{z}$ & Coef. & $\mathrm{P}>\mathrm{Z}$ \\
\hline AUDREPORT & 0.716491 & 0.1755 & 0.712005 & 0.1825 & 0.556624 & 0.2911 & & \\
\hline \multicolumn{9}{|l|}{ CASH/CA } \\
\hline \multicolumn{9}{|l|}{$\mathrm{CASH} / \mathrm{CL}$} \\
\hline CASH/TA & -2.36792 & 0.3584 & & & & & & \\
\hline \multicolumn{9}{|l|}{ CFO/NI } \\
\hline \multicolumn{9}{|l|}{$\mathrm{CFO} / \mathrm{TA}$} \\
\hline \multicolumn{9}{|l|}{$\mathrm{CFO} / \mathrm{TL}$} \\
\hline $\mathrm{CS} / \mathrm{GP}$ & 0.01188 & 0.2362 & 0.012299 & 0.2381 & & & & \\
\hline \multicolumn{9}{|l|}{$\mathrm{EQ} / \mathrm{TA}$} \\
\hline FA/TA & -2.28606 & 0.0297 & -2.31807 & 0.0289 & -2.47573 & 0.0185 & -2.47338 & 0.0168 \\
\hline \multicolumn{9}{|l|}{ GP/SAL } \\
\hline GP/TA & -3.85839 & 0.0723 & -4.16342 & 0.0497 & \begin{tabular}{|l|}
-4.21309 \\
\end{tabular} & 0.0429 & -4.04022 & 0.0521 \\
\hline \multicolumn{9}{|l|}{ NI/SAL } \\
\hline REC/REV & 0.531453 & 0.0971 & 0.581869 & 0.071 & 0.537273 & 0.0835 & 0.599168 & 0.052 \\
\hline NI/TA & -2.62583 & 0.2083 & -2.9133 & 0.1573 & -2.81846 & 0.1684 & -3.81147 & 0.0491 \\
\hline RST & 1.130724 & 0 & 1.137879 & 0 & 1.093674 & 0 & 1.103443 & 0 \\
\hline SAL/COST & -2.20981 & 0.1611 & -2.00037 & 0.1945 & -1.7732 & 0.2286 & & \\
\hline \multicolumn{9}{|l|}{ SAL/GA } \\
\hline \multicolumn{9}{|l|}{ SAL/TA } \\
\hline WC/TA & -1.46967 & 0.1083 & -1.62602 & 0.0732 & -1.71857 & 0.0566 & -1.6579 & 0.0616 \\
\hline Cons & 1.026268 & 0.5329 & 0.719278 & 0.6527 & 0.687676 & 0.654 & -1.04751 & 0.0194 \\
\hline LR stat & \multicolumn{2}{|l|}{104.806} & \multicolumn{2}{|l|}{103.8879} & \multicolumn{2}{|l|}{99.2959} & \multicolumn{2}{|l|}{96.69526} \\
\hline Prob > chi2 & \multicolumn{2}{|l|}{0} & \multicolumn{2}{|l|}{0} & \multicolumn{2}{|l|}{0} & \multicolumn{2}{|l|}{0} \\
\hline Pseudo $\mathrm{R}^{2}$ & \multicolumn{2}{|l|}{0.300529} & \multicolumn{2}{|l|}{0.297897} & \multicolumn{2}{|l|}{0.284729} & \multicolumn{2}{|l|}{0.277272} \\
\hline
\end{tabular}

Bảng 11: Kết quả hồi quy logit mô hình II - bảng 2 
Tất cả các mô hình đều có hệ số LR Chi2 cao (từ 96.6953 đến 107.709) với p-value (Prob>chi2) là 0,000 cho thấy các mô hình này là phù hợp để nghiên cứu gian lận. Các hệ số Pseudo R2 cao hơn mức tối thiểu là 0.2 theo yêu cầu của McFadden (1974). Trong bảng trên, mô hình số 9 được xem là tối ưu để dự đoán gian lận vì có ít biến, thuận tiện khi sử dụng, các biến có ý nghĩa thống kê cao.

Phương trình hồi quy logit mô hình 9 được viết lại như sau:

FRAUD=-1.04751-2.473382FA/TA-4.040222GP/TA+0.599168REC/REV-

\subsection{NI/TA-1.6579WC/TA+1.103443RST}

\subsubsection{Lụa chọn giá trị phân biệt p, đối chiếu mẫu ngoài nghiên cứu}

(a) Lựa chọn giá trị phân biệt p

Tương tự mô hình đầu tiên, nhóm nghiên cứu lựa chọn giá trị p sao cho tỉ lệ phân biệt chính xác trung bình cao nhất và có tính đại diện cao nhất.

\begin{tabular}{|c|c|c|c|c|c|}
\hline \multirow{7}{*}{$\begin{array}{l}\text { Mẫu nghiên } \\
\text { cứu }\end{array}$} & & $\mathrm{p}=10 \%$ & $\mathrm{p}=13 \%$ & $\mathrm{p}=16 \%$ & $\mathrm{p}=19 \%$ \\
\hline & $\begin{array}{l}\text { Số dự báo chính xác báo cáo } \\
\text { không gian lận }\end{array}$ & 263 & 296 & 315 & 323 \\
\hline & $\begin{array}{l}\text { Tỉ lệ phần trăm dự báo chính xác } \\
\text { báo cáo không gian lận }\end{array}$ & $70.32 \%$ & $79.14 \%$ & $84.22 \%$ & $86.36 \%$ \\
\hline & $\begin{array}{l}\text { Số dụ báo chính xác báo cáo gian } \\
\text { lận }\end{array}$ & 52 & 48 & 43 & 42 \\
\hline & $\begin{array}{l}\text { Tỉ lệ phần trăm dự báo chính xác } \\
\text { báo cáo gian lận }\end{array}$ & $86.67 \%$ & 80 & $71.67 \%$ & $70 \%$ \\
\hline & Tỉ lệ dự báo chính xác trung bình & $72.58 \%$ & $79.26 \%$ & $82.49 \%$ & $84.1 \%$ \\
\hline & $\mathbf{C V}$ & $7.78 \%$ & $0.37 \%$ & $5.25 \%$ & $6.71 \%$ \\
\hline
\end{tabular}

Bảng 12: Kết quả dụ đoán của mô hình II với mẫu nghiên cứu

Từ bảng 12 nhóm nghiên cứu lựa chọn mức $\mathrm{p}=13 \%$.

(b) Đối chiếu với mẫu ngoài nghiên cứu 


\begin{tabular}{|l|l|l|}
\hline \multirow{4}{*}{$\begin{array}{l}\text { Mẫu ngoài } \\
\text { nghiên cứu }\end{array}$} & Số dụ̂ báo chính xác báo cáo không gian lận & $\mathrm{p}=13 \%$ \\
\cline { 2 - 3 } & Tỉ lệ phần trăm dự báo chính xác báo cáo không gian lận & 68 \\
\cline { 2 - 3 } & Số dự báo chính xác báo cáo gian lận & $75.56 \%$ \\
\cline { 2 - 3 } & Tỉ lệ phần trăm dụ̣ báo chính xác báo cáo gian lận & 20 \\
\cline { 2 - 3 } & Tỉ lệ dự báo chính xác trung bình & $100 \%$ \\
\hline
\end{tabular}

Bảng 13: Kết quả dụ đoán của mô hình II với mẫu ngoài nghiên cứu

Dựa vào kết quả của mô hình đầu tiên, nhóm nghiên cứu loại bỏ các biến không phân

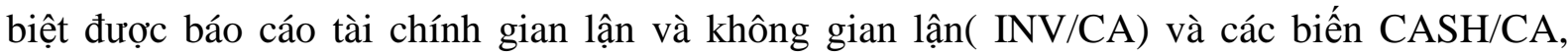
CASH/TA, CASH/CL, GP/SAL,SAL/TA thêm vào các biến (CA - INV)/CL, CA/TL, CFO/CS, CFO/SAL, EBT/TA, EQ/NI, EQ/LA,GP/CS, GP/FA NI/CFO, NI/CS, OP/GP, OP/SAL.

\subsubsection{Mô hình III}

\subsubsection{Phân tích tương quan}

(a) Kiểm tra hệ số tuoong quan

Nhóm nghiên cứu sử dụng phần mềm Eview 8 để kiểm tra phân tích tương quan giữa các biến độc lập với với biến phụ thuộc FRAUD. Các biến có ít tương quan với FRAUD (pvalue $\geq 0.2$ ) đều được loại ra khỏi mô hình. Kết quả phân tích tương quan (Correlation Analysis) cho thấy phần lớn các biến độc lập có tương quan với FRAUD với mức ý nghĩa bé hơn 0.2 (ngoại trừ các biến GP/FA, NI/CFO, CS/GP, EQ/LA)

\section{(b) Kiểm định đa cộng tuyến}

Nhóm nghiên cứu sử dụng phần mềm Eview 8 để kiểm tra phân tích tương quan giữa các biến độc lập với nhau. Các biến có hệ số tương quan $\geq 0.8$ được xem là có đa cộng tuyến cao, ngược lại các biến có hệ số tương quan $<0.8$ được xem là có đa cộng tuyến không đáng kể. Kết quả phân tích cho thấy đa số biến biến đều không có tượng quan cao với nhau (trừ (CA-INV)/CL tương quan cao với $\mathrm{CA} / \mathrm{TL}, \mathrm{CFO} / \mathrm{CS}$ tương quan cao với $\mathrm{CFO} / \mathrm{SAL}, \mathrm{EBT} / \mathrm{TA}$ tương quan cao với NI/TA, NI/CS với NI/SAL, NI/CS với OP/SAL, NI/SAL với OP/SAL). 


\begin{tabular}{|c|c|c|c|c|c|c|}
\hline & \multicolumn{2}{|c|}{ Tương quan với Fraud } & \multicolumn{2}{|l|}{ Jarque-Bera } & \multicolumn{2}{|c|}{ Wilcoxon/Mann-Whitney } \\
\hline & Corr. & P-value & JB & $\operatorname{Pr}>|J \mathbf{J B}|$ & Z-value & $\operatorname{Pr}>|Z|$ \\
\hline$(\mathrm{CA}-\mathrm{INV}) / \mathrm{CL}$ & -0.0747 & 0.1203 & 5783.1330 & 0 & 1.7346 & 0.0828 \\
\hline AUDREPORT & 0.2330 & 0 & 2480.9050 & 0 & 2.1294 & 0.0332 \\
\hline $\mathrm{CA} / \mathrm{TL}$ & -0.1057 & 0.0277 & 16886.630 & 0 & 1.6027 & 0.109 \\
\hline $\mathrm{CFO} / \mathrm{CS}$ & -0.1440 & 0.0026 & 17420.02 & 0 & 3.1550 & 0.0016 \\
\hline $\mathrm{CFO} / \mathrm{NI}$ & -0.0970 & 0.0435 & 280047.8 & 0 & 1.9708 & 0.0487 \\
\hline $\mathrm{CFO} / \mathrm{SAL}$ & -0.1402 & 0.0034 & 18864.1700 & 0 & 2.9288 & 0.0034 \\
\hline $\mathrm{CFO} / \mathrm{TA}$ & -0.1575 & 0.001 & 310.3738 & 0 & 4.0874 & 0 \\
\hline $\mathrm{CFO} / \mathrm{TL}$ & -0.1026 & 0.0327 & 9972.1150 & 0 & 4.4455 & 0 \\
\hline $\mathrm{CS} / \mathrm{GP}$ & 0.0615 & 0.201 & 1915691 & 0 & 2.9565 & 0.0031 \\
\hline $\mathrm{EBT} / \mathrm{TA}$ & -0.2719 & 0 & 4501.5500 & 0 & 8.3029 & 0 \\
\hline $\mathrm{EQ} / \mathrm{LA}$ & -0.0307 & 0.5239 & 1327430 & 0 & 1.2934 & 0.1959 \\
\hline $\mathrm{EQ} / \mathrm{NI}$ & 0.0638 & 0.1849 & 265810.6 & 0 & 5.5687 & 0 \\
\hline $\mathrm{EQ} / \mathrm{TA}$ & -0.1163 & 0.0153 & 12.6915 & 0.0018 & 2.3877 & 0.017 \\
\hline FA/TA & -0.1638 & 0.0006 & 132.8984 & 0 & 4.1750 & 0 \\
\hline GP/CS & -0.1336 & 0.0053 & 6691.8540 & 0 & 3.4532 & 0.0006 \\
\hline GP/FA & 0.0353 & 0.4629 & 40310.7900 & 0 & & \\
\hline GP/TA & -0.2800 & 0 & 200.3026 & 0 & 7.4347 & 0 \\
\hline $\mathrm{NI} / \mathrm{CFO}$ & -0.0398 & 0.408 & 1721496 & 0 & 3.6007 & 0.0003 \\
\hline $\mathrm{NI} / \mathrm{CS}$ & -0.1056 & 0.0278 & 19504.6300 & 0 & 4.9589 & 0 \\
\hline NI/SAL & -0.1455 & 0.0024 & 20589.1800 & 0 & 4.9434 & 0 \\
\hline NI_TA & -0.2619 & 0 & 9912.2190 & 0 & 8.3849 & 0 \\
\hline $\mathrm{OP} / \mathrm{GP}$ & -0.0654 & 0.174 & 1447384 & 0 & 4.3025 & 0 \\
\hline OP/SAL & -0.1761 & 0.0002 & 15388.8300 & 0 & 5.4833 & 0 \\
\hline REC/REV & 0.0058 & 0.904 & 1006.1670 & 0 & & \\
\hline RST & 0.4245 & 0 & 289.1251 & 0 & 6.3077 & 0 \\
\hline SAL/COST & -0.0798 & 0.0968 & 17278.83 & 0 & 1.9342 & 0.0531 \\
\hline SAL/GA & 0.0677 & 0.159 & 261519.3 & 0 & & \\
\hline WC/TA & -0.0829 & 0.0847 & 5.7432 & 0.0566 & 1.6094 & 0.1075 \\
\hline
\end{tabular}

Bảng 14: Kết quả phân tích tương quan, kiểm định Jarque-Bera, kiểm định Wilcoxon/Mann-Whitney

\subsubsection{Kiểm định phân phối của các biến với kiểm đinh khả năng phát hiên}

\section{gian lận của các biến}

(a) Kiểm định phân phối chuẩn

Nhóm nghiên cứu sử dụng phần mềm Eview 8 thực hiện kiểm đinh Jarque-Bera để kiểm tra hai giả thuyết:

- Ho: các biến không tuân theo quy luật phân phối chuẩn $(\mathrm{p}<0.1)$ 
- H1: các biến tuân theo quy luật phân phối chuẩn ( $\mathrm{p} \geq 0.1)$

Kết quả kiểm đinh cho thấy tất cả các các biến đều không tuân theo quy luật phân phối chuẩn.

(b) Kiểm định khả năng phát hiên gian lận của các biến:

Nhóm nghiên cứu sử dụng kiểm định Mann-Whitney U test để kiểm tra khả năng phân biệt các báo cáo gian lận và không gian lận của các biến không tuân theo quy luật phân phối chuẩn:

- Ho: các biến có khả năng phân biệt các báo cáo gian lận và không gian lận (p<0.2).

- H1: các biến không có khả năng phân biệt các báo cáo tài chính gian lận và không gian lận $(\mathrm{p} \geq 0.2)$.

Kết quả kiểm định chó thấy tất cả số các biến đều có khả năng phân biệt các báo cáo tài chính gian lận và không gian lận.

\subsubsection{Hồi quy logit}

Mô hình hồi quy logit 24 biến sau khi đã loại các biến không phù hợp có dạng như sau:

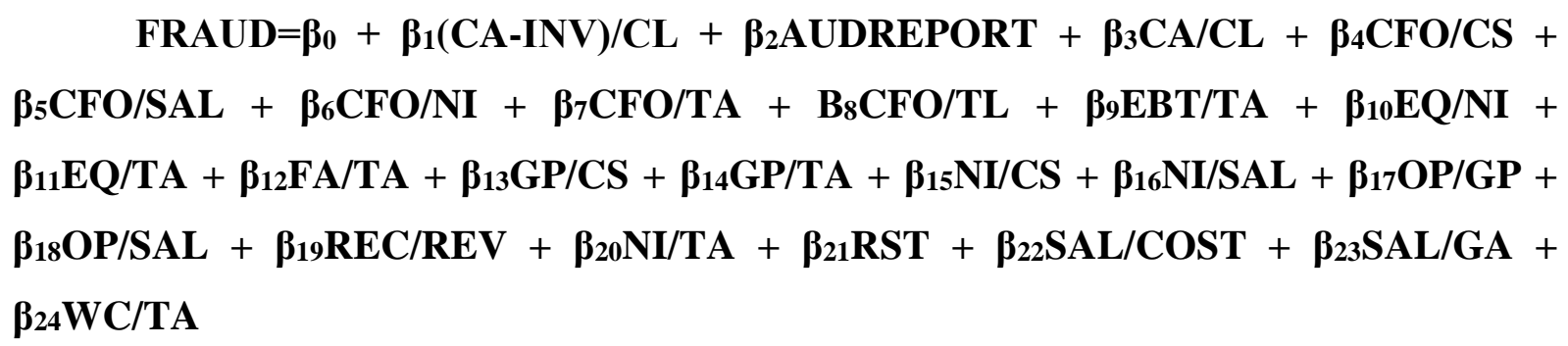

Kết quả hồi quy mô hình theo phương pháp logit được trình bày trong bảng sau: 


\begin{tabular}{|c|c|c|c|c|c|c|c|c|c|c|}
\hline \multirow[b]{2}{*}{ FRAUD } & \multicolumn{2}{|l|}{ Mô hình 1} & \multicolumn{2}{|c|}{$\begin{array}{l}\text { Mô hình } 2 \\
\text { (từ mô hình } 1, \text { loại }(\mathrm{CA} \\
-\quad \text { INV)/CL, CFO/TL, } \\
\text { NI/SAL, } \\
\text { NI/TA) }\end{array}$} & \multicolumn{2}{|c|}{$\begin{array}{l}\text { Mô hình } 3 \\
\text { (từ mô hình 2, loại } \\
\text { EQ/NI, GP/TA) }\end{array}$} & \multicolumn{2}{|c|}{$\begin{array}{l}\text { Mô hình } 4 \\
\text { (từ mô hình 3, loại } \\
\text { CFO/NI, WC/TA) }\end{array}$} & \multicolumn{2}{|c|}{$\begin{array}{l}\text { Mô hình } 5 \\
\text { (từ mô hình 4, loại } \\
\text { SAL/GA) }\end{array}$} \\
\hline & Coef. & $\mathrm{P}>\mathrm{Z}$ & Coef. & $\mathrm{P}>\mathrm{Z}$ & Coef. & $\mathrm{P}>\mathrm{Z}$ & Coef. & $\mathrm{P}>\mathrm{Z}$ & Coef. & $\mathrm{P}>\mathrm{Z}$ \\
\hline$(\mathrm{CA}-\mathrm{INV}) / \mathrm{CL}$ & 0.108272 & 0.2331 & & & & & & & & \\
\hline AUDREPORT & 0.47189 & 0.462 & 0.627242 & 0.2967 & 0.631738 & 0.291 & 0.592889 & 0.3187 & 0.661107 & 0.2573 \\
\hline $\mathrm{CA} / \mathrm{TL}$ & -0.9226 & 0.055 & -0.72351 & 0.0844 & -0.70738 & 0.0575 & -0.60681 & 0.0336 & -0.58349 & 0.0373 \\
\hline $\mathrm{CFO} / \mathrm{CS}$ & 1.061481 & 0.146 & & & & & & & & \\
\hline $\mathrm{CFO} / \mathrm{SAL}$ & -2.08048 & 0.1104 & -0.32779 & 0.4031 & -0.32862 & 0.3876 & -0.29434 & 0.4181 & -0.29347 & 0.4162 \\
\hline $\mathrm{CFO} / \mathrm{NI}$ & 0.003809 & 0.397 & 0.001378 & 0.7237 & 0.001418 & 0.7146 & & & & \\
\hline CFO/TA & -3.04102 & 0.2771 & -3.53498 & 0.1973 & -3.47928 & 0.1646 & -3.08668 & 0.1957 & -2.7906 & 0.232 \\
\hline $\mathrm{CFO} / \mathrm{TL}$ & 1.127128 & 0.1358 & 1.173162 & 0.1189 & 1.178553 & 0.0748 & 1.048087 & 0.0857 & 1.001873 & 0.0955 \\
\hline EBT/TA & -22.1667 & 0.5204 & -12.2837 & 0.0095 & -11.5911 & 0.0008 & -11.468 & 0.0007 & -11.4373 & 0.0008 \\
\hline EQ/NI & -0.0005 & 0.5641 & -0.00011 & 0.901 & & & & & & \\
\hline EQ/TA & 2.49579 & 0.0622 & 2.185398 & 0.0798 & 2.112189 & 0.0772 & 2.041071 & 0.0778 & 1.904095 & 0.0959 \\
\hline FA/TA & -3.05377 & 0.014 & -2.2994 & 0.047 & -2.30117 & 0.0459 & -2.41062 & 0.0268 & -2.43699 & 0.0256 \\
\hline GP/CS & -2.5727 & 0.0249 & -2.39678 & 0.0148 & -2.28339 & 0.0064 & -2.22348 & 0.0078 & -2.26007 & 0.0081 \\
\hline GP/TA & 2.062531 & 0.5301 & 0.675766 & 0.828 & & & & & & \\
\hline $\mathrm{NI} / \mathrm{CS}$ & 5.276098 & 0.0399 & 3.831178 & 0.0013 & 3.68429 & 0.0002 & 3.671626 & 0.0002 & 3.704406 & 0.0003 \\
\hline NI/SAL & 5.101892 & 0.338 & & & & & & & & \\
\hline OP/GP & -1.192 & 0.0004 & -1.11147 & 0.0012 & -1.10931 & 0.0011 & -1.09355 & 0.0011 & -1.10696 & 0.0011 \\
\hline OP/SAL & -7.11675 & 0.0359 & & & & & & & & \\
\hline REC/REV & 0.976172 & 0.0847 & 0.720777 & 0.1482 & 0.683284 & 0.145 & 0.672316 & 0.1475 & 0.678064 & 0.142 \\
\hline NI/TA & 10.03653 & 0.7866 & & & & & & & & \\
\hline RST & 1.414605 & 0 & 1.323007 & 0 & 1.310569 & 0 & 1.318834 & 0 & 1.316055 & 0 \\
\hline SAL/COST & -4.05173 & 0.0642 & -3.7066 & 0.0641 & -3.71428 & 0.0605 & -3.66136 & 0.0619 & -3.47143 & 0.0806 \\
\hline SAL/GA & 0.10121 & 0.5225 & 0.099956 & 0.5063 & 0.098404 & 0.5124 & 0.107 & 0.4912 & & \\
\hline WC/TA & 0.347559 & 0.8286 & 0.571968 & 0.7006 & 0.501266 & 0.715 & & & & \\
\hline Cons & 2.696897 & 0.2522 & 2.2735 & 0.2896 & 2.356655 & 0.258 & 2.297845 & 0.2649 & 2.271198 & 0.2789 \\
\hline LR stat & \multicolumn{2}{|l|}{142.8428} & \multicolumn{2}{|l|}{135.4623} & \multicolumn{2}{|l|}{135.3908} & \multicolumn{2}{|l|}{135.1203} & \multicolumn{2}{|l|}{134.0629} \\
\hline Prob > chi2 & \multicolumn{2}{|l|}{0} & \multicolumn{2}{|l|}{0} & \multicolumn{2}{|l|}{0} & \multicolumn{2}{|l|}{0} & \multicolumn{2}{|l|}{0} \\
\hline Pseudo $\mathrm{R}^{2}$ & \multicolumn{2}{|l|}{0.409599} & \multicolumn{2}{|l|}{0.388436} & \multicolumn{2}{|l|}{0.388231} & \multicolumn{2}{|l|}{0.387455} & \multicolumn{2}{|l|}{0.384423} \\
\hline
\end{tabular}

Bảng 15: Kết quả hồi quy logit mô hình III - bảng 1 


\begin{tabular}{|c|c|c|c|c|}
\hline \multirow[b]{2}{*}{ FRAUD } & \multicolumn{2}{|c|}{$\begin{array}{l}\text { Mô hình } 6 \\
\text { (tù̀ mô hình 5, loại } \\
\text { AUDREPORT) }\end{array}$} & \multicolumn{2}{|c|}{$\begin{array}{l}\text { Mô hình } 7 \\
\text { (từ mô hình 6, loại } \\
\text { CFO/TA) }\end{array}$} \\
\hline & Coef. & $\mathrm{P}>\mathrm{Z}$ & Coef. & $\mathrm{P}>\mathrm{Z}$ \\
\hline \multicolumn{5}{|l|}{$(\mathrm{CA}-\mathrm{INV}) / \mathrm{CL}$} \\
\hline \multicolumn{5}{|l|}{ AUDREPORT } \\
\hline $\mathrm{CA} / \mathrm{TL}$ & -0.5623 & 0.0404 & -0.51474 & 0.0739 \\
\hline \multicolumn{5}{|l|}{$\mathrm{CFO} / \mathrm{CS}$} \\
\hline $\mathrm{CFO} / \mathrm{SAL}$ & -0.3406 & 0.3515 & -0.5345 & 0.1033 \\
\hline \multicolumn{5}{|l|}{$\mathrm{CFO} / \mathrm{NI}$} \\
\hline $\mathrm{CFO} / \mathrm{TA}$ & -2.61471 & 0.2592 & & \\
\hline $\mathrm{CFO} / \mathrm{TL}$ & 0.975043 & 0.1006 & 0.587763 & 0.2112 \\
\hline EBT/TA & -11.8484 & 0.0005 & -11.6231 & 0.0005 \\
\hline \multicolumn{5}{|l|}{$\mathrm{EQ} / \mathrm{NI}$} \\
\hline $\mathrm{EQ} / \mathrm{TA}$ & 1.690455 & 0.1303 & 1.611726 & 0.1654 \\
\hline FA/TA & -2.51897 & 0.0205 & -2.68071 & 0.0141 \\
\hline GP/CS & -2.25898 & 0.0067 & -2.19077 & 0.0081 \\
\hline \multicolumn{5}{|l|}{ GP/TA } \\
\hline $\mathrm{NI} / \mathrm{CS}$ & 3.705919 & 0.0002 & 3.630521 & 0.0003 \\
\hline \multicolumn{5}{|l|}{ NI/SAL } \\
\hline OP/GP & -1.11799 & 0.0009 & -1.09942 & 0.0014 \\
\hline \multicolumn{5}{|l|}{ OP/SAL } \\
\hline REC/REV & 0.740408 & 0.1116 & 0.767205 & 0.103 \\
\hline \multicolumn{5}{|l|}{ NI/TA } \\
\hline RST & 1.359916 & 0 & 1.356324 & 0 \\
\hline SAL/COST & -3.29291 & 0.0945 & -3.53467 & 0.0749 \\
\hline \multicolumn{5}{|l|}{ SAL/GA } \\
\hline \multicolumn{5}{|l|}{$\mathrm{WC} / \mathrm{TA}$} \\
\hline Cons & 2.233285 & 0.2834 & 2.417365 & 0.2497 \\
\hline LR stat & 132.7922 & & 131.4711 & \\
\hline Prob > chi 2 & 0 & & 0 & \\
\hline Pseudo $\mathrm{R}^{2}$ & 0.380779 & & 0.376991 & \\
\hline
\end{tabular}

Bảng 16: Kết quả hồi quy logit mô hình III - bảng 2 
Tất cả các mô hình đều có hệ số LR Chi2 cao (từ 131.4711 đến142.8428) với p-value (Prob>chi2)là 0,000 cho thấy các mô hình này là phù hợp để nghiên cứu gian lận. Các hệ số Pseudo R2 cao hơn mức tối thiểu là 0.2 theo yêu cầu của McFadden (1974). Trong bảng trên, mô hình số 7 được xem là tối ưu để dự đoán gian lận vì có ít biến, thuận tiện khi sử dụng, các biến có ý nghĩa thống kê cao.

Phương trình hồi quy logit mô hình 7 được viết lại như sau:

FRAUD $=2.417365-0.51474 \mathrm{CA} / \mathrm{TL}-0.5345 \mathrm{CFO} / \mathrm{SAL}+0.587763 \mathrm{CFO} / \mathrm{CL}-$ 11.6231 EBT/TA +1.611726 EQ/TA - 2.68071 FA/TA -2.19077 GP/CS + 3.630521 NI/ CS - 1.09942 OP/GP + 0.767205 REC/REV +1.356324 RST - 3.53467 SAL/COST

\subsubsection{Lựa chọn giá trị phân biệt p, đối chiếu mẫu ngoài nghiên cứu}

(a) Lựa chọn giá trị phân biệt $p$

Tương tự mô hình đầu tiên, nhóm nghiên cứu lựa chọn giá trị p sao cho tỉ lệ phân biệt chính xác trung bình cao nhất và có tính đại diện cao nhất.

\begin{tabular}{|c|c|c|c|c|c|}
\hline \multirow{7}{*}{$\begin{array}{l}\text { Mẫu } \\
\text { nghiên cứu }\end{array}$} & & $\mathrm{p}=10 \%$ & $\mathrm{p}=13 \%$ & $\mathrm{p}=16 \%$ & $\mathrm{p}=19 \%$ \\
\hline & $\begin{array}{l}\text { Số dụ báo chính xác báo cáo } \\
\text { không gian lận }\end{array}$ & 297 & 315 & 325 & 327 \\
\hline & $\begin{array}{l}\text { Tỉ lệ phần trăm dụ báo chính xác } \\
\text { báo cáo không gian lận }\end{array}$ & $79.41 \%$ & $84.22 \%$ & $86.9 \%$ & $87.43 \%$ \\
\hline & $\begin{array}{l}\text { Số dụ báo chính xác báo cáo gian } \\
\text { lận }\end{array}$ & 52 & 52 & 48 & 47 \\
\hline & $\begin{array}{l}\text { Tỉ lệ phần trăm dụ báo chính xác } \\
\text { báo cáo gian lận }\end{array}$ & $86.67 \%$ & $86.67 \%$ & $80 \%$ & $78.33 \%$ \\
\hline & Tỉ lệ dụ̣ báo chính xác trung bình & $80.41 \%$ & $84.56 \%$ & 85.94 & $86.18 \%$ \\
\hline & $\mathrm{CV}$ & $3.12 \%$ & $1 \%$ & $2.77 \%$ & $3.64 \%$ \\
\hline
\end{tabular}

Bảng 17: Kết quả dụ đoán của mô hình III với mẫu nghiên cứu 
Từ bảng 17 nhóm nghiên cứu lựa chọn mức $\mathrm{p}=13 \%$

(b) Đối chiếu mẫu ngoài nghiên cưu

\begin{tabular}{|c|c|c|}
\hline \multirow{6}{*}{$\begin{array}{l}\text { Mẫu ngoài } \\
\text { nghiên cứu }\end{array}$} & & $\mathrm{p}=13 \%$ \\
\hline & Số dự báo chính xác báo cáo không gian lận & 77 \\
\hline & Tỉ lệ phần trăm dự báo chính xác báo cáo không gian lận & 85.56 \\
\hline & Số dự báo chính xác báo cáo gian lận & 17 \\
\hline & Tỉ lệ phần trăm dự báo chính xác báo cáo gian lận & $85 \%$ \\
\hline & Tỉ lệ dụ báo chính xác trung bình & $85.45 \%$ \\
\hline
\end{tabular}

Bảng 18: Kết quả dụ đoán của mô hình III với mẫu ngoài nghiên cưu

\subsubsection{Kết hợp các mô hình:}

Từ kết quả hồi quy ba mô hình I, II, III, nhóm nghiên cứu lập mô hình ma trận kết hợp 3 mô hình. Kết quả mô hình ma trận kết hơp được trình bày ở phần phụ lục 1 .

Từ kết quả của mô hình ma trận kết hơp, ta thấy:

Với mô hình I:

Tỉ lệ dự đoán đúng báo cáo gian lận của: $62 / 80=77.5 \%$

Tỉ lệ dự đoán đúng báo cáo không gian lận: 370/464 = 79.741\%

Tỉ lệ dự đoán đúng chung $=(62+370) / 544=79.412 \%$

Với mô hình II:

Tỉ lệ dự đoán đúng báo cáo gian lận: 68/80 = 85\%

Tỉ lệ dự đoán đúng báo cáo không gian lận: 364/464 = 78.448\%

Tỉ lệ dự đoán đúng chung $=(68+364) / 544=79.412 \%$

Với mô hình III:

Tỉ lệ dự đoán đúng báo cáo gian lận: 69/80 = 86.250\%

Tỉ lệ dự đoán đúng báo cáo không gian lận: 392/464 = 84.483\%

Tỉ lệ dự đoán đúng chung $=(69+392) / 544=84.743 \%$

Trong số 80 báo cáo gian lận:

Có 6 báo cáo không bị phát hiện gian lận, tương đương 7.5\%

Có 7 báo cáo chỉ có 1 mô hình có thể phát hiện dấu hiệu gian lận, tương đương $8.75 \%$

Có 9 báo cáo 2 mô hình có thể phát hiện dấu hiệu gian lận, tương đương 11.25\%

Có 58 báo cáo cả 3 mô hình bị phát hiện gian lận, chiếm 72,5\%

Kết hơp 3 mô hình, có 74 báo cáo tài chính bị phát hiện có gian lận trong báo cáo tài chính, tương đương $92.5 \%$

Trong số 464 báo cáo tài chính không gian lận, có 343 báo cáo không bị coi là gian lận khi kết hơp 3 mô hình, tương đương 73.92\%. 


\section{Kết luận chương 4}

Trong chương 4 , nhóm nghiên cứu đã đưa ra quá trình thực hiện và đi đến kết quả nghiên cứu. Từ đưa ra giả thuyết nghiên cứu, kiểm nghiệm giả thuyết bằng dữ liệu và đưa ra kết quả

Dựa trên cơ sở lí luận nêu ra ở chương 2, trong chương 4, nhóm nghiên cứu đã đưa ra giả thuyết đó là các yếu tố của tam giác gian lận (Động cơ/Áp lực, cơ hội, thái độ) có mối tương quan đối với hành vi gian lận, và có thể được sử dụng để dự báo gian lận trên báo cáo tài chính tại Việt Nam. Và đưa ra các chỉ số trên báo cáo tài chính làm đại diện cho các yếu tố này.

Để kiểm nghiệm lý thuyết trên với tổng thể nghiên cứu là các công ty tại Việt Nam, nhóm nghiên cứu đã chọn được mẫu nghiên cứu gồm 434 quan sát đến từ các công ty niêm yết trên sàn HOSE, mẫu ngoài nghiên cứu là 110 quan sát đến từ các công ty trên sàn HOSE. Sau đó thu thập và xử lý số liệu thô.

Nhóm nghiên cứu sử dụng phương pháp định lượng để kiểm định giả thuyết: Phân tích tương quan, kiểm tra đa cộng tuyến, kiểm định Mann U Whitney. Sau đó, nhóm nghiên cứu xây dựng 3 mô hình xác định gian lận bằng hồi quy logit. Cuối cùng là kết hợp ba mô hình trên thành một mô hình ma trận. Kết quả, mô hình ma trận dự đoán chính xác $92.5 \%$ các báo cáo gian lận và $73.92 \%$ các báo cáo không gian lận từ kết quả hồi quy 3 mô hình. Trong tương lai, nhóm nghiên cứu dự kiến sẽ áp dụng các phương pháp thống kê khác như Bayesian (Scutari, 2010; McElreath, 2018) sử dụng chương trình bayesvl trên môi trường $\mathrm{R}$ (La \& Vuong, 2019). 


\section{CHƯƠNG 5: THẢO LUẬn KẾT QUẢ VÀ GIẢI PHÁP PHÒNG CHỐNG GIAN LẬN}

\subsection{Thảo luận về kết quả}

\subsubsection{Mô hình I}

Từ kết quả nghiên cứu mô hình $\mathrm{I}$, nhóm nghiên cứu thấy kết quả phân biệt gian lận của các biến ứng với các nhóm như sau.

\subsubsection{Nhóm yếu tố động co/áp lục:}

Nhóm các biến phản ánh sự ổn định tài chính: Biến GP/SAL, GP/TA, OP/GP, NI/TA có khả năng phân biệt được các công ty gian lận. Các biến này càng thấp thì khả năng gian lận càng cao và ngược lại. Trong khi đó, chỉ số NI/EQ không phân biệt được các báo cáo tài chính gian lận và không gian lận.

Nhóm biến thể hiện cơ cấu tài sản và khả năng tạo doanh thu: FA/TA, SAL/TA, SAL/COST, SAL/GA đều có khả năng phát hiện gian lận. Các báo cáo tài chính có các chỉ số này thấp có khả năng gian lận cao hơn. Trong khi đó,biến SAL/CS, SAL/FA không có khả năng phát hiện gian lận báo cáo tài chính.

Áp lực từ bên thứ 3 , khả năng thanh toán và trả nợ, cơ cấu nguồn vốn : $\mathrm{LEV}, \mathrm{CFO} / \mathrm{CL}$, WC/TA, CA/CL, CA/TL, CASH/TA, CASH/CA, CASH/CL có khả năng phát hiện gian lận. Các báo cáo mà các biến này có giá trị thấp, khả năng gian lận càng cao.Trong khi đó, các biến CL/TL,EQ/TL không có khả năng phát hiện gian lận.

Nhóm biến phản ánh dòng tiền thu được từ kinh doanh: TAc/TA không phân biệt được các báo cáo gian lận và không gian lận.

\subsubsection{Nhóm yếu tố cơ hội}

Nhóm biến phản ánh mức độ quản trị doanh nghiệp BIG4, CEO đều không có ý nghĩa trong phát hiện các báo cáo tài chính gian lận.

Nhóm biến thể hiện đặc điểm của ngành hay các hoạt động của đơn vị của công ty INV/TA, INV/CS không có khả năng phát hiện gian lận báo cáo tài chính. Biến REC/REV có thể phát hiện các công ty gian lận. REV/REC càng cao thi khả năng báo cáo tài chính bị gian lận càng lớn

\subsubsection{Nhóm yếu tố thái độ, đạo đức:}

Nhóm biến thể hiện thái độ và tiền sử gian lận: các biến AUDREPORT, RST đều có khả năng phát hiện các công ty gian lận. Các công ty có gian lận báo cáo tài chính hoặc nhận được ý kiến không chấp nhận toàn phần trong quá khứ có khả năng gian lận cao hơn.

Dựa theo kết quả của mô hình hồi quy logit $\mathrm{I}$, nhóm nghiên cứu thấy rằng tỉ lệ dự đoán chính xác cáo báo cáo tài chính gian lận khá cao $80.88 \%$ với mẫu nghiên cứu và $81.82 \%$ với mẫu ngoài nghiên cứu. 
Mô hình I có thể là một công cụ hữu ích để phát hiện gian lận báo cáo tài chính.

\subsubsection{Mô hình II}

Từ kết quả nghiên cứu mô hình II, nhóm nghiên cứu thấy kết quả phân biệt gian lận của các biến ứng với các nhóm như sau.

\subsubsection{Nhóm yếu tố động cơ/áp lục:}

Nhóm yếu tố phản ánh sự ổn định tài chính: GP/SAL, GP/TA và NI/SAL có ý nghĩ thống kê trong việc phát hiện các công ty gian lận. Các chỉ số này càng thấp thì ham ý rằng khả năng gian lận của các công ty càng cao. Trong khi đó, chỉ số CS/GP, NI/TA, không có ý nghĩa thống kê trong việc phát hiện gian lận.

Nhóm yếu tố chỉ dòng tiền trong doanh nghiệp: $\mathrm{CFO} / \mathrm{NI}, \mathrm{CFO} / \mathrm{TA}$ có ý nghĩa thống kê trong việc phát hiện các công ty gian lận. Các chỉ số này càng thấp thì có nghĩa rằng khả năng gian lận của các công ty càng cao.

Nhóm yếu tố chỉ áp lực từ bên thứ ba: CASH/CA, CASH/CL, CASH/TA, EQ/TA, WC/TA và $\mathrm{CFO} / \mathrm{TL}$ có ý nghĩa thống kê trong việc phát hiện gian lận của các công ty. Các chỉ số này càng thấp thì khả năng gian lận của các công ty càng cao.

Nhóm yếu tố chỉ khả năng tạo ra doanh thu: FA/TA, SAL/TA, SAL/COST, SAL/GA có ý nghĩa thống kê trong việc phát hiện gian lận của các công ty. Các chỉ số này càng thấp thì khả năng gian lận của các công ty càng cao. Bên cạnh đó, các chỉ số như INV/CA không có ý nghĩa thống kê trong việc phát hiện gian lận.

\subsubsection{Nhóm yếu tố cơ hội}

Nhóm yếu tố đặc điểm của ngành hay các hoạt động của đơn vị: REC/REV có ý nghĩa thống kê trong việc phát hiện gian lận của các công ty. Cấc biến này càng cao hàm ý rằng các công ty có khả năng gian lận càng lớn.

\subsubsection{Nhóm yếu tố thái độ}

Các biến AUDREPORT, RST có ý nghĩa thống kê trong việc phát hiện gian lận của các công ty. Các chỉ số này càng cao hàm ý rằng khả năng gian lận của các công ty càng lớn.

Dựa theo kết quả của mô hình hồi quy logit II, nhóm nghiên cứu thấy rằng : tỉ lệ dự đoán chính xác cáo báo cáo tài chính gian lận khá cao $79.26 \%$ với mẫu nghiên cứu và $80 \%$ với mẫu ngoài nghiên cứu.

Mô hình I có thể là một công cụ hữu ích để phát hiện gian lận báo cáo tài chính.

\subsubsection{Mô hình III}

Từ kết quả nghiên cứu mô hình III, nhóm nghiên cứu thấy kết quả phân biệt gian lận của các biến ứng với các nhóm như sau. 


\subsubsection{Nhóm yếu tố động cơ/áp lục:}

Nhóm các biến phản ánh sự ổn định tài chính: Biến OP/SAL, EQ/NI, EBT/TA, NI/CS, GP/TA, OP/GP, NI/SAL có khả năng phân biệt được các công ty gian lận. Trong đó các biến $\mathrm{OP} / \mathrm{SAL}, \mathrm{EQ} / \mathrm{NI}, \mathrm{EBT} / \mathrm{TA}, \mathrm{OP} / \mathrm{GP}$ càng thấp thì khả năng gian lận càng cao và ngược lại. Và các biến NI/CS, GP/TA, NI/SAL càng thấp thì khả năng gian lận càng thấp. Trong khi đó, chỉ số GP/FA, CS/GP, GP/CS không phân biệt được các báo cáo tài chính gian lận và không gian lận.

Nhóm biến liên quan đến dòng tiền trong doanh nghiệp: CFO/CS, CFO/TA, CFO/NI, CFO/SAL có khả năng phát hiện gian lận.Trong đó các báo cáo tài chính có các chỉ số $\mathrm{CFO} / \mathrm{CS}$ và $\mathrm{CFO} / \mathrm{NI}$ này thấp có khả năng gian lận thấp hơn. Còn nếu chỉ số $\mathrm{CFO} / \mathrm{TA}$, CFO/SAL càng thấp thì khả năng gian lận càng cao. Trong khi đó, biến NI/CFO không có khả năng phát hiện gian lận báo cáo tài chính.

Áp lực từ bên thứ 3 , khả năng thanh toán và trả nợ, cơ cấu nguồn vốn: WC/TA, $\mathrm{CA} / \mathrm{TL}, \mathrm{CFO} / \mathrm{TL}, \mathrm{EQ} / \mathrm{TA},(\mathrm{CA}-\mathrm{INV}) / \mathrm{CL}$ có khả năng phát hiện gian lận. Các báo cáo mà các biến này có giá trị WC/TA, $\mathrm{CFO} / \mathrm{TL}, \mathrm{EQ} / \mathrm{TA},(\mathrm{CA}-\mathrm{INV}) / \mathrm{CL}$ càng thấp, khả năng gian lận càng thấp. Còn nếu biến $\mathrm{CA} / \mathrm{TL}$ càng thấp thì khả năng gian lận càng cao. Trong khi đó, các biến EQ/LA không có khả năng phát hiện gian lận.

Nhóm biến phản ánh khả năng tạo doanh thu: Các biến FA/TA, SAL/COST, SAL/GA đều có khả năng phát hiện gian lận. Trong đó nếu FA/TA và SAL/GA càng thấp thì khả năng gian lận càng cao. Còn nếu $\mathrm{SAL} / \mathrm{COST}$ càng thấp thì khả năng gian lận càng thấp.

\subsubsection{Nhóm yếu tố co hội}

Nhóm biến phản ánh mức độ quản trị doanh nghiệp BIG4, CEO đều không có ý nghĩa trong phát hiện các báo cáo tài chính gian lận

Nhóm biến thể hiện đặc điểm của ngành hay các hoạt động của đơn vị INV/CA không có khả năng phát hiện gian lận báo cáo tài chính. Biến REC/REV có thể phát hiện các công ty gian lận. REV/REC càng cao thi khả năng báo cáo tài chính bị gian lận càng lớn

\subsubsection{Nhóm yếu tố thái độ, đạo đức}

Nhóm biến thể hiện thái độ và tiền sử gian lận: các biến AUDREPORT, RST đều có khả năng phát hiện các công ty gian lận. Các công ty có gian lận báo cáo tài chính hoặc nhận được ý kiến không chấp nhận toàn phần trong quá khứ có khả năng gian lận cao hơn.

Dựa theo kết quả của mô hình hồi quy logit III, nhóm nghiên cứu thấy rằng : tỉ lệ dự đoán chính xác cáo báo cáo tài chính gian lận khá cao :84.56\% với mẫu nghiên cứu và $85.45 \%$ với mẫu ngoài nghiên cứu. 
Mô hình III có thể là một công cụ hữu ích để phát hiện gian lận báo cáo tài chính hiện gian lận báo cáo tài chính

\subsubsection{Mô hình ma trận kết hợp}

Mô hình này có thể dự đoán chính xác báo cáo gian lận với tỉ lệ cao $92.5 \%$ trong khi vẫn giữ được tỉ lệ dự báo chính xác báo cáo tài chính không gian lận ở mức cao $73.92 \%$, nên mô hình phù hợp cho những nhà đầu tư không muốn đầu tư vào các công ty gian lận báo cáo tài chính.

\section{2. Đề xuất}

\subsubsection{Giải pháp nhận diện gian lận}

Từ những kết quả nghiên cứu của mô hình I, II, III và mô hình kết hợp, nhóm nghiên cứu đề xuất một số giải pháp nhằm nâng cao khả năng phát hiện báo cáo tài chính gian lận:

Với các yếu tố động cơ, áp lực, kiểm toán viên cần quan tâm đến các chỉ số thể hiện khả năng sinh lợi nhuận của công ty, khả năng tạo doanh thu của công ty và dòng tiền thực tế hình thành từ hoạt động sản xuất kinh doanh của công ty. Kiểm toán viên thực hiện phân tích chỉ số này dựa trên cơ sở sánh với mức bình quân chung hoặc so sánh với chính số liệu đã kiểm toán năm trước của công ty. Sự biến động bất thường của các chỉ số này là dấu hiệu cho thấy sự không ổn định về tình hình tài chính của công ty, dẫn đến khả năng xảy ra gian lận báo cáo tài chính cao hơn.

Với các nhân tố cơ hội, kiểm toán viên cần xem xét tỉ lệ nợ phải thu trên doanh thu. Nếu tỉ lệ này cao hơn mức trung bình chung thì công ty này có khả năng thổi phồng doanh thu thông qua các khoản nợ phải thu hoặc không ghi các khoản dự phòng.

Với yếu tố thái độ, kiểm toán viên có thể dựa vào kết quả của các cuộc kiểm toán trong quá khứ để đánh giá thái độ và đạo đức của ban giám đốc, nếu có dấu hiệu cho thấy ban giám đốc không chính trực (đã từng bị phát hiện gian lận lợi nhuận trước đây, đã từng phải nhận ý kiến không chấp nhận toàn phần của kiểm toán viên), thì khả năng có gian lận trong báo cáo tài chính cao hơn.

\subsubsection{Giải pháp ngăn chặn gian lận báo cáo tài chính}

Tội phạm kinh tế nói chung và gian lận báo cáo nói riêng ngày càng phát triên tinh vi cùng với sự phát triển của xã hội, và đem lại những hậu quả kinh tế khó lường. Cũng như các quốc gia trên thế giới,trong các công ty ở Việt Nam cũng tiềm ẩn khả năng xảy ra gian lận cao, do đó cần phải có những biện pháp hiệu quả để ngăn chặn, phòng ngừa gian lận

\section{- Đối với công ty}

- Có các chương trình đào tạo: "Đạo đức kinh doanh và tuân thủ”. 
- Xây dựng hệ thống kiểm soát nội bộ hữu hiệu, có các quy định chặt chẽ, phân công rõ ràng về quyền hạn và nghĩa vụ của kiểm soát nội bộ.

- Ngoài ra, để phát hiện gian lận, doanh nghiệp cần sử dụng các biện pháp khác như là thành lập bộ phận kiểm toán nội bộ, hay thiết lập đường dây nóng để thu nhận các thông tin nhanh chóng nhất.

- Đối với kiểm toán viên

- Tăng cường trách nhiệm của kiểm toán đối với gian lận trong kiểm toán báo cáo tài chính.

- Yêu cầu kiểm toán viên phải gữi thái độ nghi ngờ tính chân thực của báo cáo tài chính, giữ đúng đạo đức nghề kiểm toán.

- Nâng cao khả năng phát hiện gian lận, để ý tới các dấu hiệu bất thường của công ty trong sản xuất kinh doanh.

- Đối với nhà đầu tur

- Cần có thêm hiểu biết về kinh tế, tài chính và cả kế toán, tìm hiểu kỹ về công ty.

- Có các kỹ năng phân tích báo cáo tài chính, kết hợp, xâu chuỗi, đối chiếu so sánh với báo cáo tài chính năm trước và so sánh với mức trung bình chung của toàn bộ hệ thống doanh nghiệp.

- Hãy thận trọng với những “chiêu” làm đẹp sổ sách của các công ty mẹ, công ty con.

- Đa dạng hóa danh mục đầu tư để giảm thiểu rủi ro.

- Đối với quản lý nhà nước

- Cần tăng cường xử phạt gian lận báo cáo tài chính. Bộ Tài chính đã lường trước tất cả các hành vi vi phạm trong việc lập báo cáo tài chính có thể xảy ra trong thực tế và đều quy định mức phạt cụ thể, nhưng tính răn đe không cao.

- Hoàn hiện hệ thống pháp lý về kế toán, kiểm toán, công bố thông tin theo chuẩn mực và thông lệ quốc tế.

- Đẩy mạnh hoạt động thanh tra, kiểm tra báo cáo tài chính, nâng cao năng lực quản lý của nhà quản trị.

- Cần lưu ý các yếu tố văn hóa, xã hội tại Việt Nam vì đây là gốc rễ sâu xa của tâm lý và hành vi gian lận (Hoang \& Dung, 2009; Vuong et al., 2018).

\section{Kết luận chương 5}

Từ kết quả của chương 4 , trong chương 5 , nhóm nghiên cứu đưa ra kết quả và thảo luận về kết quả. Từ đó nhóm nghiên cứu đưa ra một số đề xuất. Nhóm nghiên cứu chỉ ra các 
biến có khả năng phân biệt gian lận. Chỉ ra mức độ hiệu quả của mô hình ma trận trong việc đánh giá gian lận.Từ kết quả được đưa ra, nhóm nghiên cứu đề xuất hai nhóm giải pháp. Thứ nhất là nhóm giải pháp giúp nhận diện gian lận và thứ hai là nhóm giải pháp giúp giúp ngăn chặn gian lận. 


\section{CHƯONG 6: KẾT LUẬN}

\subsection{Kết luận về các kết quả đã nghiên cứu}

Gian lận báo cáo tài chính trên thế giới và ở Việt Nam ngày càng phức tạp, tinh vi và gây ra nhiều hậu quả nghiêm trọng cho các các nhân, tổ chức và cả nền kinh tế, do đó cần phải có những biện pháp hữu hiệu để phát hiện, ngăn chặn gian lận báo cáo tài chính.

Trong bài nghiên cứu, nhóm nghiên cứu chú trọng đến việc tìm hiểu đến những động cơ dựa trên các tiêu chuẩn kiểm toán của Việt Nam về đánh giá gian lận. Nội dung đưa ra những lý thuyết gian lận và từ đó đề ra những dấu hiệu nhận biết công ty này đang gian lận trên báo cáo tài chính.

Nghiên cứu đóng góp cho quá trình thực nghiệm những lý thuyết nền tảng về gian lận bằng việc tiến hành những điều tra vào những đặc điêm của các công ty vi phạm những tiêu chuẩn kế toán và sai sót trong quá trình công bố những thông tin trung thực. Sau quá trình này, nghiên cứu đã đưa ra những bằng chứng quan sát khách quan về quá trình cung cấp báo cáo tài chính của các công ty có khả năng gian lận.

Nhóm nghiên cứu đã sử dụng những lý thuyết giải thích hành vi gian lận trên thế giới kết hợp với chuẩn mực VSA 240 của bộ tài chính để đưa ra lý thuyết tổng hợp về hành vi gian lận, qua đó tạo cơ sở để xây dựng, kiểm định và tìm ra các chỉ số tài chính có khả năng nhận diện gian lận, từ đó kết hợp các chỉ số , sử dụng hồi quy logit tạo ra mô hình nhận diện gian lận.Nhóm nghiên cứu đã xây dựng được 3 mô hình có khả năng nhận diện gian lận cao và đã xây dựng 1 mô hình ma trận kết hợp để loại bỏ được đa số các công ty gian lận. Từ những kết quả này, nhóm nghiên cứu tiến hành phân tích và đề ra những ý kiến đóng góp để nâng cao khả năng phát hiện gian lận đối với cả nhà đầu tư và nhà quản lí.

\section{2. Đóng góp của nghiên cứu}

Nghiên cứu đã xây dựng được nền tảng lý thuyết vững chắc dựa trên lý thuyết tam giác gian lận để áp dụng vào gian lận báo cáo tài chính, xây dựng các mô hình với số quan sát lớn, có tính đại diện cao. Bài nghiên cứu đã xây dựng thành công 3 mô hình nhận diện gian lận với độ chính xác cao, xây dựng mô hình ma trận kết hợp nhận diện được hầu hết báo cáo tài chính gian lận trong khi tỉ lệ dự đoán chính xác các công ty không gian lận vẫn ở mức cao, đồng thời đề xuất một số ý kiến nhằm nâng cao khả năng nhận diện gian lận báo cáo tài chính. Bản thân quá trình thực nghiên cứu và sản phẩm đầu ra cũng cho thấy các sinh viên đại học, với sự sự hướng dẫn đúng đắn có đủ khả năng mang đến các công trình học thuật đủ phẩm chất, với chi phí tối thiểu, và kết quả có giá trị (Vuong, 2018).

\subsection{Hạn chế của nghiên cứu và hướng khắc phục}

Dưới đây là một số hạn chế của nghiên cứu. 
Nghiên cứu mới chỉ thực hiện dựa trên dữ liệu của các công ty trên sàn HOSE, trong giai đoạn 2016-2018 nên chưa phản ánh được một cách tổng quát các công ty được niêm yết trên sàn chứng khoán, chứa phản ánh được tình trạng gian lận báo cáo tài chính trong giai đoạn trước năm 2016.

Các biến đại diện cho tam giác gian lận có hạn chế. Các biến đại diện cho các yếu tố cơ hội thực hiện hành vi gian lận ít và chỉ có biến REC/REV có thể phân biệt được hành vi gian lận, chưa có các biến đại diện cho phương thức gian lận thông qua hàng tồn kho, không ghi chi phí,... có thể phân biệt được các báo cáo tài chính gian lận và không gian lận. Chưa có các biến đại diện cho chất lượng của kiểm soát nội bộ. Các biến đại diện cho yếu tố thái độ, đao đức còn thiếu các biến như: trình độ giáo dục của ban giám đốc, năng lực điều hành của giám đốc... Do đó, cần các nghiên cứu tiếp theo xây dựng hệ thống các biến đại diện cho các yếu tố được nêu ra trong VSA 240

Trong các mô hình của nhóm nghiên cứu không có các biến đại diện cho những tài sản mà giá trị của nó ít thuộc tầm kiểm soát của của doanh nghiệp như các loại chứng khoán ngắn hạn, dài hạn do doanh nghiệp nắm giữ, các khoản đầu tư tài chính ngắn hạn, dài hạn; thiếu các biến đại diện cho hoạt động đánh giá lại giá trị tài sản của doạn nghiệp, chênh lệch tỉ giá, thanh lý tài sản của doanh nghiệp. Đây cũng là một trong những phương thức gian lận chủ yếu những chưa được thể hiện thông qua các biến của mô hình.

Các quan sát trong mẫu nghiên cứu và mẫu ngoài nghiên cứu đều là các báo cáo tài chính của các doanh nghiệp không hoạt động trong lĩnh vực tài chính.

Nhóm nghiên cứu đề xuất một số phương pháp để khắc phục hạn chế. Cần những nghiên cứu với quy mô rộng hơn, mẫu nghiên cứu lớn chứa báo cáo tài chính của các công ty niêm yết trên các sàn chứng khoán khác nhau, nghiên cứu trong nhiều thời kỳ kinh tế để có những đánh giá tổng quan về gian lận, tìm thêm các biến khác nhau thể hiện phương thức gian lận, theo dõi các thông tin trên sàn chứng khoán để đưa ra các biến về những tài sản như chứng khoán ngắn hạn, dài hạn... của doanh nghiệp, nghiên cứu sâu hơn về thái độ, đạo đức của giám đốc, từ đó tìm ra các biến thích hợp đại diện cho yếu tố thái độ. 


\section{PHỤ LỤC: BẢNG KẾT QUẢ MÔ HİNH MA TRẬN}

Trong cột FRAUD: 0: báo cáo tài chính thực tế không gian lận, 1 báo cáo tài chính thực tế gian lận

Trong 4 cột dự báo của mô hình I, dự báo của mô hình II, dự báo của mô hình III, dự báo của mô hình ma trận kết hơp: 0 : báo cáo được xác đinh là không gian lận dựa vào mô hình; 1: báo cáo được xác định là gian lận dựa vào mô hình

\begin{tabular}{|c|c|c|c|c|c|c|}
\hline $\mathrm{T}$ & Mã CK & $\begin{array}{l}\text { FRAUD } \\
2018\end{array}$ & $\begin{array}{l}\text { Dự báo của } \\
\text { mô hình ma } \\
\text { trận }\end{array}$ & $\begin{array}{l}\text { Dự báo của } \\
\text { mô hình I }\end{array}$ & $\begin{array}{l}\text { Dự báo của } \\
\text { mô hình II }\end{array}$ & $\begin{array}{l}\text { Dự báo của } \\
\text { mô hình III }\end{array}$ \\
\hline 2018 & AAA & 0 & 0 & 0 & 0 & 0 \\
\hline 2018 & AAM & 0 & 1 & 1 & 0 & 0 \\
\hline 2018 & ACL & 0 & 0 & 0 & 0 & 0 \\
\hline 2018 & CAV & 0 & 0 & 0 & 0 & 0 \\
\hline 2018 & $\mathrm{CCI}$ & 0 & 0 & 0 & 0 & 0 \\
\hline 2018 & CCL & 0 & 1 & 1 & 1 & 0 \\
\hline 2018 & CHP & 0 & 1 & 0 & 0 & 1 \\
\hline 2018 & CII & 0 & 1 & 0 & 1 & 0 \\
\hline 2018 & CLC & 0 & 0 & 0 & 0 & 0 \\
\hline 2018 & CLL & 0 & 0 & 0 & 0 & 0 \\
\hline 2018 & CLW & 0 & 0 & 0 & 0 & 0 \\
\hline 2018 & $\mathrm{COM}$ & 0 & 0 & 0 & 0 & 0 \\
\hline 2018 & CSM & 0 & 0 & 0 & 0 & 0 \\
\hline 2018 & CTD & 0 & 0 & 0 & 0 & 0 \\
\hline 2018 & D2D & 0 & 0 & 0 & 0 & 0 \\
\hline 2018 & DBD & 0 & 0 & 0 & 0 & 0 \\
\hline 2018 & DCL & 0 & 1 & 1 & 0 & 0 \\
\hline 2018 & $\mathrm{DCM}$ & 0 & 0 & 0 & 0 & 0 \\
\hline 2018 & DGW & 0 & 0 & 0 & 0 & 0 \\
\hline 2018 & DHA & 0 & 0 & 0 & 0 & 0 \\
\hline 2018 & $\mathrm{DHG}$ & 0 & 0 & 0 & 0 & 0 \\
\hline 2018 & DHM & 0 & 1 & 1 & 1 & 1 \\
\hline 2018 & DMC & 0 & 0 & 0 & 0 & 0 \\
\hline
\end{tabular}




\begin{tabular}{|c|c|c|c|c|c|c|}
\hline 2018 & DPM & 0 & 0 & 0 & 0 & 0 \\
\hline 2018 & DRL & 0 & 0 & 0 & 0 & 0 \\
\hline 2018 & DSN & 0 & 0 & 0 & 0 & 0 \\
\hline 2018 & DVP & 0 & 0 & 0 & 0 & 0 \\
\hline 2018 & DXG & 0 & 0 & 0 & 0 & 0 \\
\hline 2018 & DXV & 0 & 1 & 1 & 0 & 1 \\
\hline 2018 & FCM & 0 & 0 & 0 & 0 & 0 \\
\hline 2018 & FIT & 0 & 1 & 1 & 0 & 1 \\
\hline 2018 & FPT & 0 & 0 & 0 & 0 & 0 \\
\hline 2018 & GDT & 0 & 0 & 0 & 0 & 0 \\
\hline 2018 & GSP & 0 & 0 & 0 & 0 & 0 \\
\hline 2018 & GTA & 0 & 1 & 1 & 1 & 0 \\
\hline 2018 & HAH & 0 & 0 & 0 & 0 & 0 \\
\hline 2018 & HAP & 0 & 0 & 0 & 0 & 0 \\
\hline 2018 & HAS & 0 & 1 & 1 & 0 & 0 \\
\hline 2018 & HAX & 0 & 0 & 0 & 0 & 0 \\
\hline 2018 & HBC & 0 & 1 & 0 & 1 & 0 \\
\hline 2018 & HDC & 0 & 0 & 0 & 0 & 0 \\
\hline 2018 & HHS & 0 & 0 & 0 & 0 & 0 \\
\hline 2018 & HII & 0 & 1 & 1 & 1 & 1 \\
\hline 2018 & HNG & 0 & 1 & 1 & 1 & 0 \\
\hline 2018 & HOT & 0 & 0 & 0 & 0 & 0 \\
\hline 2018 & HPG & 0 & 0 & 0 & 0 & 0 \\
\hline 2018 & HTI & 0 & 0 & 0 & 0 & 0 \\
\hline 2018 & HTV & 0 & 0 & 0 & 0 & 0 \\
\hline 2018 & HVX & 0 & 1 & 1 & 1 & 1 \\
\hline 2018 & IMP & 0 & 0 & 0 & 0 & 0 \\
\hline 2018 & ITC & 0 & 1 & 1 & 1 & 1 \\
\hline 2018 & KSB & 0 & 0 & 0 & 0 & 0 \\
\hline 2018 & L10 & 0 & 1 & 1 & 1 & 0 \\
\hline 2018 & LAF & 0 & 1 & 1 & 1 & 1 \\
\hline 2018 & LBM & 0 & 0 & 0 & 0 & 0 \\
\hline 2018 & LDG & 0 & 0 & 0 & 0 & 0 \\
\hline
\end{tabular}




\begin{tabular}{|c|c|c|c|c|c|c|}
\hline 2018 & LIX & 0 & 0 & 0 & 0 & 0 \\
\hline 2018 & MCP & 0 & 0 & 0 & 0 & 0 \\
\hline 2018 & MHC & 0 & 0 & 0 & 0 & 0 \\
\hline 2018 & NT2 & 0 & 0 & 0 & 0 & 0 \\
\hline 2018 & NVL & 0 & 0 & 0 & 0 & 0 \\
\hline 2018 & OPC & 0 & 0 & 0 & 0 & 0 \\
\hline 2018 & PAN & 0 & 0 & 0 & 0 & 0 \\
\hline 2018 & PC1 & 0 & 0 & 0 & 0 & 0 \\
\hline 2018 & PDN & 0 & 0 & 0 & 0 & 0 \\
\hline 2018 & PET & 0 & 0 & 0 & 0 & 0 \\
\hline 2018 & PGD & 0 & 0 & 0 & 0 & 0 \\
\hline 2018 & PHC & 0 & 1 & 1 & 1 & 1 \\
\hline 2018 & PHR & 0 & 0 & 0 & 0 & 0 \\
\hline 2018 & PJT & 0 & 0 & 0 & 0 & 0 \\
\hline 2018 & PNC & 0 & 0 & 0 & 0 & 0 \\
\hline 2018 & PNJ & 0 & 0 & 0 & 0 & 0 \\
\hline 2018 & POM & 0 & 1 & 0 & 1 & 0 \\
\hline 2018 & PPC & 0 & 0 & 0 & 0 & 0 \\
\hline 2018 & PXS & 0 & 1 & 1 & 1 & 1 \\
\hline 2018 & RAL & 0 & 0 & 0 & 0 & 0 \\
\hline 2018 & REE & 0 & 0 & 0 & 0 & 0 \\
\hline 2018 & S4A & 0 & 0 & 0 & 0 & 0 \\
\hline 2018 & SAV & 0 & 0 & 0 & 0 & 0 \\
\hline 2018 & SBA & 0 & 0 & 0 & 0 & 0 \\
\hline 2018 & SC5 & 0 & 1 & 1 & 1 & 0 \\
\hline 2018 & SFC & 0 & 0 & 0 & 0 & 0 \\
\hline 2018 & SFG & 0 & 0 & 0 & 0 & 0 \\
\hline 2018 & SGN & 0 & 0 & 0 & 0 & 0 \\
\hline 2018 & SHA & 0 & 0 & 0 & 0 & 0 \\
\hline 2018 & SII & 0 & 1 & 0 & 1 & 0 \\
\hline 2018 & SJD & 0 & 0 & 0 & 0 & 0 \\
\hline 2018 & SKG & 0 & 0 & 0 & 0 & 0 \\
\hline 2018 & SMA & 0 & 0 & 0 & 0 & 0 \\
\hline
\end{tabular}




\begin{tabular}{|c|c|c|c|c|c|c|}
\hline 2018 & SMB & 0 & 0 & 0 & 0 & 0 \\
\hline 2018 & SMC & 0 & 0 & 0 & 0 & 0 \\
\hline 2018 & SRC & 0 & 1 & 0 & 0 & 1 \\
\hline 2018 & SRF & 0 & 1 & 0 & 1 & 0 \\
\hline 2018 & ST8 & 0 & 0 & 0 & 0 & 0 \\
\hline 2018 & TCO & 0 & 0 & 0 & 0 & 0 \\
\hline 2018 & THG & 0 & 0 & 0 & 0 & 0 \\
\hline 2018 & THI & 0 & 0 & 0 & 0 & 0 \\
\hline 2018 & TIP & 0 & 0 & 0 & 0 & 0 \\
\hline 2018 & TMS & 0 & 0 & 0 & 0 & 0 \\
\hline 2018 & TNC & 0 & 0 & 0 & 0 & 0 \\
\hline 2018 & TPC & 0 & 0 & 0 & 0 & 0 \\
\hline 2018 & TRA & 0 & 0 & 0 & 0 & 0 \\
\hline 2018 & TSC & 0 & 1 & 1 & 1 & 1 \\
\hline 2018 & TYA & 0 & 0 & 0 & 0 & 0 \\
\hline 2018 & VAF & 0 & 0 & 0 & 0 & 0 \\
\hline 2018 & VCF & 0 & 0 & 0 & 0 & 0 \\
\hline 2018 & VFG & 0 & 0 & 0 & 0 & 0 \\
\hline 2018 & VHC & 0 & 0 & 0 & 0 & 0 \\
\hline 2018 & VIC & 0 & 1 & 1 & 1 & 1 \\
\hline 2018 & VIP & 0 & 0 & 0 & 0 & 0 \\
\hline 2018 & VIS & 0 & 1 & 0 & 1 & 0 \\
\hline 2018 & VNG & 0 & 0 & 0 & 0 & 0 \\
\hline 2018 & VNL & 0 & 0 & 0 & 0 & 0 \\
\hline 2018 & VNM & 0 & 0 & 0 & 0 & 0 \\
\hline 2018 & VOS & 0 & 1 & 1 & 0 & 1 \\
\hline 2018 & VPD & 0 & 0 & 0 & 0 & 0 \\
\hline 2018 & VPS & 0 & 0 & 0 & 0 & 0 \\
\hline 2018 & VSC & 0 & 0 & 0 & 0 & 0 \\
\hline 2018 & \begin{tabular}{|l|l|} 
VTO \\
\end{tabular} & 0 & 0 & 0 & 0 & 0 \\
\hline 2017 & AAA & 0 & 0 & 0 & 0 & 0 \\
\hline 2017 & AAM & 0 & 1 & 1 & 1 & 0 \\
\hline 2017 & ACC & 0 & 0 & 0 & 0 & 0 \\
\hline
\end{tabular}




\begin{tabular}{|c|c|c|c|c|c|c|}
\hline 2017 & BTT & 0 & 0 & 0 & 0 & 0 \\
\hline 2017 & CAV & 0 & 0 & 0 & 0 & 0 \\
\hline 2017 & CCI & 0 & 0 & 0 & 0 & 0 \\
\hline 2017 & CCL & 0 & 1 & 1 & 1 & 1 \\
\hline 2017 & $\mathrm{CDC}$ & 0 & 1 & 1 & 1 & 0 \\
\hline 2017 & CHP & 0 & 0 & 0 & 0 & 0 \\
\hline 2017 & CII & 0 & 0 & 0 & 0 & 0 \\
\hline 2017 & CLC & 0 & 0 & 0 & 0 & 0 \\
\hline 2017 & CLL & 0 & 0 & 0 & 0 & 0 \\
\hline 2017 & CLW & 0 & 0 & 0 & 0 & 0 \\
\hline 2017 & CMT & 0 & 0 & 0 & 0 & 0 \\
\hline 2017 & CMV & 0 & 0 & 0 & 0 & 0 \\
\hline 2017 & $\mathrm{COM}$ & 0 & 0 & 0 & 0 & 0 \\
\hline 2017 & CSM & 0 & 0 & 0 & 0 & 0 \\
\hline 2017 & CTD & 0 & 0 & 0 & 0 & 0 \\
\hline 2017 & CTI & 0 & 1 & 1 & 1 & 1 \\
\hline 2017 & CVT & 0 & 0 & 0 & 0 & 0 \\
\hline 2017 & D2D & 0 & 0 & 0 & 0 & 0 \\
\hline 2017 & DAG & 0 & 0 & 0 & 0 & 0 \\
\hline 2017 & DCL & 0 & 0 & 0 & 0 & 0 \\
\hline 2017 & DGW & 0 & 0 & 0 & 0 & 0 \\
\hline 2017 & DHA & 0 & 0 & 0 & 0 & 0 \\
\hline 2017 & DHG & 0 & 0 & 0 & 0 & 0 \\
\hline 2017 & DMC & 0 & 0 & 0 & 0 & 0 \\
\hline 2017 & DPM & 0 & 0 & 0 & 0 & 0 \\
\hline 2017 & DQC & 0 & 0 & 0 & 0 & 0 \\
\hline 2017 & DRL & 0 & 0 & 0 & 0 & 0 \\
\hline 2017 & DTT & 0 & 1 & 1 & 1 & 1 \\
\hline 2017 & DVP & 0 & 0 & 0 & 0 & 0 \\
\hline 2017 & DXG & 0 & 0 & 0 & 0 & 0 \\
\hline 2017 & EVE & 0 & 0 & 0 & 0 & 0 \\
\hline 2017 & FCM & 0 & 0 & 0 & 0 & 0 \\
\hline 2017 & FIT & 0 & 0 & 0 & 0 & 0 \\
\hline
\end{tabular}




\begin{tabular}{|c|c|c|c|c|c|c|}
\hline 2017 & FPT & 0 & 0 & 0 & 0 & 0 \\
\hline 2017 & GAS & 0 & 0 & 0 & 0 & 0 \\
\hline 2017 & GDT & 0 & 0 & 0 & 0 & 0 \\
\hline 2017 & GIL & 0 & 0 & 0 & 0 & 0 \\
\hline 2017 & GMC & 0 & 0 & 0 & 0 & 0 \\
\hline 2017 & GMD & 0 & 0 & 0 & 0 & 0 \\
\hline 2017 & GSP & 0 & 0 & 0 & 0 & 0 \\
\hline 2017 & GTA & 0 & 0 & 0 & 0 & 0 \\
\hline 2017 & HAH & 0 & 0 & 0 & 0 & 0 \\
\hline 2017 & HAP & 0 & 1 & 1 & 1 & 1 \\
\hline 2017 & HAS & 0 & 1 & 1 & 0 & 0 \\
\hline 2017 & HAX & 0 & 1 & 1 & 0 & 0 \\
\hline 2017 & HDC & 0 & 1 & 1 & 0 & 0 \\
\hline 2017 & HLG & 0 & 0 & 0 & 0 & 0 \\
\hline 2017 & HOT & 0 & 0 & 0 & 0 & 0 \\
\hline 2017 & HPG & 0 & 0 & 0 & 0 & 0 \\
\hline 2017 & HRC & 0 & 1 & 0 & 1 & 1 \\
\hline 2017 & HT1 & 0 & 0 & 0 & 0 & 0 \\
\hline 2017 & HTV & 0 & 0 & 0 & 0 & 0 \\
\hline 2017 & IJC & 0 & 1 & 1 & 1 & 1 \\
\hline 2017 & IMP & 0 & 0 & 0 & 0 & 0 \\
\hline 2017 & ITC & 0 & 1 & 1 & 1 & 1 \\
\hline 2017 & KDC & 0 & 1 & 1 & 1 & 1 \\
\hline 2017 & KSB & 0 & 0 & 0 & 0 & 0 \\
\hline 2017 & L10 & 0 & 0 & 0 & 0 & 0 \\
\hline 2017 & LBM & 0 & 0 & 0 & 0 & 0 \\
\hline 2017 & LCG & 0 & 1 & 1 & 1 & 1 \\
\hline 2017 & LCM & 0 & 1 & 0 & 1 & 0 \\
\hline 2017 & LHG & 0 & 1 & 1 & 1 & 1 \\
\hline 2017 & LIX & 0 & 0 & 0 & 0 & 0 \\
\hline 2017 & MCG & 0 & 1 & 1 & 1 & 1 \\
\hline 2017 & MCP & 0 & 0 & 0 & 0 & 0 \\
\hline 2017 & MHC & 0 & 1 & 1 & 1 & 0 \\
\hline
\end{tabular}




\begin{tabular}{|c|c|c|c|c|c|c|}
\hline 2017 & MSN & 0 & 0 & 0 & 0 & 0 \\
\hline 2017 & MWG & 0 & 0 & 0 & 0 & 0 \\
\hline 2017 & NAV & 0 & 1 & 1 & 1 & 1 \\
\hline 2017 & NBB & 0 & 1 & 0 & 1 & 0 \\
\hline 2017 & NCT & 0 & 0 & 0 & 0 & 0 \\
\hline 2017 & NKG & 0 & 0 & 0 & 0 & 0 \\
\hline 2017 & NLG & 0 & 0 & 0 & 0 & 0 \\
\hline 2017 & NNC & 0 & 0 & 0 & 0 & 0 \\
\hline 2017 & NSC & 0 & 0 & 0 & 0 & 0 \\
\hline 2017 & NTL & 0 & 1 & 1 & 1 & 1 \\
\hline 2017 & NVT & 0 & 1 & 1 & 1 & 0 \\
\hline 2017 & OGC & 0 & 0 & 0 & 0 & 0 \\
\hline 2017 & OPC & 0 & 0 & 0 & 0 & 0 \\
\hline 2017 & PAN & 0 & 0 & 0 & 0 & 0 \\
\hline 2017 & PDR & 0 & 1 & 1 & 0 & 0 \\
\hline 2017 & PET & 0 & 0 & 0 & 0 & 0 \\
\hline 2017 & PGC & 0 & 0 & 0 & 0 & 0 \\
\hline 2017 & PGD & 0 & 0 & 0 & 0 & 0 \\
\hline 2017 & PHC & 0 & 1 & 1 & 1 & 1 \\
\hline 2017 & PHR & 0 & 0 & 0 & 0 & 0 \\
\hline 2017 & PIT & 0 & 1 & 1 & 1 & 1 \\
\hline 2017 & PJT & 0 & 0 & 0 & 0 & 0 \\
\hline 2017 & PNC & 0 & 1 & 0 & 1 & 1 \\
\hline 2017 & PNJ & 0 & 0 & 0 & 0 & 0 \\
\hline 2017 & PPC & 0 & 1 & 1 & 1 & 0 \\
\hline 2017 & PTB & 0 & 0 & 0 & 0 & 0 \\
\hline 2017 & PXI & 0 & 1 & 0 & 1 & 0 \\
\hline 2017 & PXT & 0 & 1 & 1 & 1 & 1 \\
\hline 2017 & QBS & 0 & 1 & 1 & 1 & 1 \\
\hline 2017 & SFG & 0 & 0 & 0 & 0 & 0 \\
\hline 2017 & SHA & 0 & 0 & 0 & 0 & 0 \\
\hline 2017 & SHI & 0 & 0 & 0 & 0 & 0 \\
\hline 2017 & SJD & 0 & 0 & 0 & 0 & 0 \\
\hline
\end{tabular}




\begin{tabular}{|c|c|c|c|c|c|c|}
\hline 2017 & SMA & 0 & 0 & 0 & 0 & 0 \\
\hline 2017 & SMB & 0 & 0 & 0 & 0 & 0 \\
\hline 2017 & SMC & 0 & 0 & 0 & 0 & 0 \\
\hline 2017 & SPM & 0 & 1 & 1 & 1 & 1 \\
\hline 2017 & SRC & 0 & 0 & 0 & 0 & 0 \\
\hline 2017 & SRF & 0 & 1 & 1 & 1 & 0 \\
\hline 2017 & ST8 & 0 & 0 & 0 & 0 & 0 \\
\hline 2017 & STG & 0 & 0 & 0 & 0 & 0 \\
\hline 2017 & SVC & 0 & 1 & 0 & 0 & 1 \\
\hline 2017 & SVI & 0 & 0 & 0 & 0 & 0 \\
\hline 2017 & SZC & 0 & 1 & 1 & 1 & 1 \\
\hline 2017 & SZL & 0 & 0 & 0 & 0 & 0 \\
\hline 2017 & TAC & 0 & 0 & 0 & 0 & 0 \\
\hline 2017 & TBC & 0 & 0 & 0 & 0 & 0 \\
\hline 2017 & TCL & 0 & 1 & 1 & 1 & 1 \\
\hline 2017 & TCM & 0 & 0 & 0 & 0 & 0 \\
\hline 2017 & TIP & 0 & 1 & 1 & 0 & 0 \\
\hline 2017 & TLG & 0 & 0 & 0 & 0 & 0 \\
\hline 2017 & TLH & 0 & 0 & 0 & 0 & 0 \\
\hline 2017 & TMP & 0 & 0 & 0 & 0 & 0 \\
\hline 2017 & TMS & 0 & 0 & 0 & 0 & 0 \\
\hline 2017 & TTB & 0 & 0 & 0 & 0 & 0 \\
\hline 2017 & TYA & 0 & 0 & 0 & 0 & 0 \\
\hline 2017 & VAF & 0 & 0 & 0 & 0 & 0 \\
\hline 2017 & VFG & 0 & 0 & 0 & 0 & 0 \\
\hline 2017 & VHC & 0 & 0 & 0 & 0 & 0 \\
\hline 2017 & VIC & 0 & 1 & 1 & 1 & 1 \\
\hline 2017 & VNE & 0 & 1 & 1 & 1 & 1 \\
\hline 2017 & VNG & 0 & 0 & 0 & 0 & 0 \\
\hline 2017 & VNL & 0 & 0 & 0 & 0 & 0 \\
\hline 2017 & VNM & 0 & 0 & 0 & 0 & 0 \\
\hline 2017 & VNS & 0 & 0 & 0 & 0 & 0 \\
\hline 2016 & ACC & 0 & 0 & 0 & 0 & 0 \\
\hline
\end{tabular}




\begin{tabular}{|c|c|c|c|c|c|c|}
\hline 2016 & ANV & 0 & 1 & 1 & 1 & 1 \\
\hline 2016 & APC & 0 & 0 & 0 & 0 & 0 \\
\hline 2016 & BBC & 0 & 0 & 0 & 0 & 0 \\
\hline 2016 & BMC & 0 & 0 & 0 & 0 & 0 \\
\hline 2016 & BMP & 0 & 0 & 0 & 0 & 0 \\
\hline 2016 & BTP & 0 & 1 & 1 & 1 & 1 \\
\hline 2016 & BTT & 0 & 0 & 0 & 0 & 0 \\
\hline 2016 & CAV & 0 & 0 & 0 & 0 & 0 \\
\hline 2016 & $\mathrm{CCI}$ & 0 & 0 & 0 & 0 & 0 \\
\hline 2016 & CCL & 0 & 1 & 1 & 1 & 1 \\
\hline 2016 & $\mathrm{CDC}$ & 0 & 1 & 1 & 1 & 0 \\
\hline 2016 & CHP & 0 & 0 & 0 & 0 & 0 \\
\hline 2016 & CII & 0 & 1 & 0 & 1 & 1 \\
\hline 2016 & CLC & 0 & 0 & 0 & 0 & 0 \\
\hline 2016 & CLL & 0 & 0 & 0 & 0 & 0 \\
\hline 2016 & CLW & 0 & 1 & 0 & 1 & 1 \\
\hline 2016 & CMT & 0 & 1 & 1 & 0 & 1 \\
\hline 2016 & CMV & 0 & 0 & 0 & 0 & 0 \\
\hline 2016 & $\mathrm{COM}$ & 0 & 0 & 0 & 0 & 0 \\
\hline 2016 & CSM & 0 & 0 & 0 & 0 & 0 \\
\hline 2016 & DMC & 0 & 0 & 0 & 0 & 0 \\
\hline 2016 & DPM & 0 & 0 & 0 & 0 & 0 \\
\hline 2016 & DQC & 0 & 0 & 0 & 0 & 0 \\
\hline 2016 & DRL & 0 & 0 & 0 & 0 & 0 \\
\hline 2016 & DTA & 0 & 1 & 1 & 1 & 1 \\
\hline 2016 & DVP & 0 & 0 & 0 & 0 & 0 \\
\hline 2016 & DXG & 0 & 0 & 0 & 0 & 0 \\
\hline 2016 & EVE & 0 & 0 & 0 & 0 & 0 \\
\hline 2016 & FCM & 0 & 0 & 0 & 0 & 0 \\
\hline 2016 & FIT & 0 & 1 & 1 & 0 & 0 \\
\hline 2016 & FPT & 0 & 0 & 0 & 0 & 0 \\
\hline 2016 & GAS & 0 & 0 & 0 & 0 & 0 \\
\hline 2016 & GDT & 0 & 0 & 0 & 0 & 0 \\
\hline
\end{tabular}




\begin{tabular}{|c|c|c|c|c|c|c|}
\hline 2016 & GIL & 0 & 0 & 0 & 0 & 0 \\
\hline 2016 & HAH & 0 & 0 & 0 & 0 & 0 \\
\hline 2016 & HAP & 0 & 1 & 1 & 1 & 1 \\
\hline 2016 & HAS & 0 & 1 & 1 & 1 & 1 \\
\hline 2016 & HAX & 0 & 0 & 0 & 0 & 0 \\
\hline 2016 & HHS & 0 & 0 & 0 & 0 & 0 \\
\hline 2016 & HLG & 0 & 0 & 0 & 0 & 0 \\
\hline 2016 & HMC & 0 & 1 & 1 & 1 & 1 \\
\hline 2016 & HOT & 0 & 0 & 0 & 0 & 0 \\
\hline 2016 & HPG & 0 & 0 & 0 & 0 & 0 \\
\hline 2016 & HRC & 0 & 1 & 1 & 1 & 1 \\
\hline 2016 & HT1 & 0 & 0 & 0 & 0 & 0 \\
\hline 2016 & HTI & 0 & 0 & 0 & 0 & 0 \\
\hline 2016 & HTL & 0 & 0 & 0 & 0 & 0 \\
\hline 2016 & HTV & 0 & 0 & 0 & 0 & 0 \\
\hline 2016 & HVX & 0 & 1 & 1 & 1 & 1 \\
\hline 2016 & IMP & 0 & 0 & 0 & 0 & 0 \\
\hline 2016 & KDC & 0 & 0 & 0 & 0 & 0 \\
\hline 2016 & KSB & 0 & 0 & 0 & 0 & 0 \\
\hline 2016 & L10 & 0 & 1 & 1 & 0 & 0 \\
\hline 2016 & LAF & 0 & 0 & 0 & 0 & 0 \\
\hline 2016 & LBM & 0 & 0 & 0 & 0 & 0 \\
\hline 2016 & MSN & 0 & 0 & 0 & 0 & 0 \\
\hline 2016 & MWG & 0 & 0 & 0 & 0 & 0 \\
\hline 2016 & NBB & 0 & 1 & 0 & 1 & 0 \\
\hline 2016 & NCT & 0 & 0 & 0 & 0 & 0 \\
\hline 2016 & NKG & 0 & 0 & 0 & 0 & 0 \\
\hline 2016 & NLG & 0 & 0 & 0 & 0 & 0 \\
\hline 2016 & $\mathrm{NNC}$ & 0 & 0 & 0 & 0 & 0 \\
\hline 2016 & NSC & 0 & 0 & 0 & 0 & 0 \\
\hline 2016 & NT2 & 0 & 1 & 1 & 1 & 0 \\
\hline 2016 & NTL & 0 & 0 & 0 & 0 & 0 \\
\hline 2016 & NVT & 0 & 1 & 0 & 1 & 0 \\
\hline
\end{tabular}




\begin{tabular}{|c|c|c|c|c|c|c|}
\hline 2016 & OGC & 0 & 1 & 1 & 1 & 0 \\
\hline 2016 & OPC & 0 & 0 & 0 & 0 & 0 \\
\hline 2016 & PAN & 0 & 0 & 0 & 0 & 0 \\
\hline 2016 & PDN & 0 & 0 & 0 & 0 & 0 \\
\hline 2016 & PDR & 0 & 1 & 1 & 0 & 0 \\
\hline 2016 & PET & 0 & 0 & 0 & 0 & 0 \\
\hline 2016 & PGC & 0 & 0 & 0 & 0 & 0 \\
\hline 2016 & PGD & 0 & 0 & 0 & 0 & 0 \\
\hline 2016 & PHR & 0 & 0 & 0 & 0 & 0 \\
\hline 2016 & PPC & 0 & 1 & 1 & 1 & 1 \\
\hline 2016 & PTB & 0 & 0 & 0 & 0 & 0 \\
\hline 2016 & PVD & 0 & 0 & 0 & 0 & 0 \\
\hline 2016 & PVT & 0 & 0 & 0 & 0 & 0 \\
\hline 2016 & PXS & 0 & 0 & 0 & 0 & 0 \\
\hline 2016 & PXT & 0 & 1 & 1 & 1 & 1 \\
\hline 2016 & RAL & 0 & 0 & 0 & 0 & 0 \\
\hline 2016 & RDP & 0 & 0 & 0 & 0 & 0 \\
\hline 2016 & REE & 0 & 0 & 0 & 0 & 0 \\
\hline 2016 & RIC & 0 & 1 & 1 & 1 & 0 \\
\hline 2016 & SAV & 0 & 1 & 1 & 1 & 1 \\
\hline 2016 & SBA & 0 & 0 & 0 & 0 & 0 \\
\hline 2016 & SBT & 0 & 0 & 0 & 0 & 0 \\
\hline 2016 & SC5 & 0 & 1 & 1 & 1 & 0 \\
\hline 2016 & SCR & 0 & 1 & 0 & 1 & 0 \\
\hline 2016 & SFC & 0 & 0 & 0 & 0 & 0 \\
\hline 2016 & SJD & 0 & 0 & 0 & 0 & 0 \\
\hline 2016 & SVC & 0 & 0 & 0 & 0 & 0 \\
\hline 2016 & SVI & 0 & 0 & 0 & 0 & 0 \\
\hline 2016 & SZC & 0 & 1 & 0 & 1 & 1 \\
\hline 2016 & SZL & 0 & 0 & 0 & 0 & 0 \\
\hline 2016 & TAC & 0 & 0 & 0 & 0 & 0 \\
\hline 2016 & TCL & 0 & 0 & 0 & 0 & 0 \\
\hline 2016 & TCM & 0 & 0 & 0 & 0 & 0 \\
\hline
\end{tabular}




\begin{tabular}{|c|c|c|c|c|c|c|}
\hline 2016 & TCO & 0 & 0 & 0 & 0 & 0 \\
\hline 2016 & TCR & 0 & 1 & 0 & 0 & 1 \\
\hline 2016 & TCT & 0 & 0 & 0 & 0 & 0 \\
\hline 2016 & TDW & 0 & 0 & 0 & 0 & 0 \\
\hline 2016 & THG & 0 & 0 & 0 & 0 & 0 \\
\hline 2016 & TLG & 0 & 0 & 0 & 0 & 0 \\
\hline 2016 & TLH & 0 & 0 & 0 & 0 & 0 \\
\hline 2016 & TMS & 0 & 0 & 0 & 0 & 0 \\
\hline 2016 & TMT & 0 & 0 & 0 & 0 & 0 \\
\hline 2016 & TNA & 0 & 0 & 0 & 0 & 0 \\
\hline 2016 & TNC & 0 & 0 & 0 & 0 & 0 \\
\hline 2016 & TNT & 0 & 1 & 1 & 1 & 1 \\
\hline 2016 & TPC & 0 & 0 & 0 & 0 & 0 \\
\hline 2016 & TRA & 0 & 0 & 0 & 0 & 0 \\
\hline 2016 & TSC & 0 & 1 & 1 & 1 & 1 \\
\hline 2016 & TYA & 0 & 0 & 0 & 0 & 0 \\
\hline 2016 & VCF & 0 & 0 & 0 & 0 & 0 \\
\hline 2016 & VFG & 0 & 0 & 0 & 0 & 0 \\
\hline 2016 & VPK & 0 & 1 & 1 & 1 & 1 \\
\hline 2016 & VSC & 0 & 0 & 0 & 0 & 0 \\
\hline 2016 & VSH & 0 & 1 & 1 & 0 & 1 \\
\hline 2018 & AGM & 0 & 1 & 0 & 0 & 1 \\
\hline 2018 & ANV & 0 & 0 & 0 & 0 & 0 \\
\hline 2018 & BFC & 0 & 0 & 0 & 0 & 0 \\
\hline 2018 & $\mathrm{BMC}$ & 0 & 0 & 0 & 0 & 0 \\
\hline 2018 & BMP & 0 & 0 & 0 & 0 & 0 \\
\hline 2018 & BRC & 0 & 0 & 0 & 0 & 0 \\
\hline 2018 & BTT & 0 & 0 & 0 & 0 & 0 \\
\hline 2018 & MSH & 0 & 0 & 0 & 0 & 0 \\
\hline 2018 & MSN & 0 & 0 & 0 & 0 & 0 \\
\hline 2018 & MWG & 0 & 0 & 0 & 0 & 0 \\
\hline 2018 & NAV & 0 & 1 & 1 & 1 & 0 \\
\hline 2018 & NBB & 0 & 1 & 0 & 1 & 0 \\
\hline
\end{tabular}




\begin{tabular}{|c|c|c|c|c|c|c|}
\hline 2018 & NCT & 0 & 0 & 0 & 0 & 0 \\
\hline 2018 & NLG & 0 & 0 & 0 & 0 & 0 \\
\hline 2018 & NNC & 0 & 0 & 0 & 0 & 0 \\
\hline 2018 & NSC & 0 & 0 & 0 & 0 & 0 \\
\hline 2018 & STK & 0 & 0 & 0 & 0 & 0 \\
\hline 2018 & SVC & 0 & 0 & 0 & 0 & 0 \\
\hline 2018 & SVI & 0 & 0 & 0 & 0 & 0 \\
\hline 2018 & SZC & 0 & 1 & 0 & 1 & 0 \\
\hline 2018 & SZL & 0 & 0 & 0 & 0 & 0 \\
\hline 2018 & TBC & 0 & 0 & 0 & 0 & 0 \\
\hline 2018 & TCL & 0 & 0 & 0 & 0 & 0 \\
\hline 2017 & ASP & 0 & 1 & 1 & 1 & 1 \\
\hline 2017 & BBC & 0 & 0 & 0 & 0 & 0 \\
\hline 2017 & BCG & 0 & 1 & 1 & 1 & 1 \\
\hline 2017 & BFC & 0 & 0 & 0 & 0 & 0 \\
\hline 2017 & BMC & 0 & 0 & 0 & 0 & 0 \\
\hline 2017 & BMP & 0 & 0 & 0 & 0 & 0 \\
\hline 2017 & RAL & 0 & 0 & 0 & 0 & 0 \\
\hline 2017 & REE & 0 & 0 & 0 & 0 & 0 \\
\hline 2017 & SAV & 0 & 0 & 0 & 0 & 0 \\
\hline 2017 & SBA & 0 & 0 & 0 & 0 & 0 \\
\hline 2017 & SBT & 0 & 0 & 0 & 0 & 0 \\
\hline 2017 & SC5 & 0 & 1 & 1 & 1 & 0 \\
\hline 2017 & SCR & 0 & 1 & 1 & 1 & 0 \\
\hline 2017 & SFC & 0 & 0 & 0 & 0 & 0 \\
\hline 2016 & CTD & 0 & 0 & 0 & 0 & 0 \\
\hline 2016 & CVT & 0 & 0 & 0 & 0 & 0 \\
\hline 2016 & D2D & 0 & 1 & 1 & 0 & 0 \\
\hline 2016 & DAG & 0 & 0 & 0 & 0 & 0 \\
\hline 2016 & DCL & 0 & 0 & 0 & 0 & 0 \\
\hline 2016 & DHA & 0 & 0 & 0 & 0 & 0 \\
\hline 2016 & DHG & 0 & 0 & 0 & 0 & 0 \\
\hline 2016 & GMC & 0 & 0 & 0 & 0 & 0 \\
\hline
\end{tabular}




\begin{tabular}{|c|c|c|c|c|c|c|}
\hline 2016 & GMD & 0 & 0 & 0 & 0 & 0 \\
\hline 2016 & GSP & 0 & 0 & 0 & 0 & 0 \\
\hline 2016 & GTA & 0 & 0 & 0 & 0 & 0 \\
\hline 2016 & LHG & 0 & 1 & 0 & 1 & 0 \\
\hline 2016 & LIX & 0 & 0 & 0 & 0 & 0 \\
\hline 2016 & MCG & 0 & 1 & 1 & 1 & 1 \\
\hline 2016 & MCP & 0 & 0 & 0 & 0 & 0 \\
\hline 2016 & MHC & 0 & 0 & 0 & 0 & 0 \\
\hline 2016 & PIT & 0 & 0 & 0 & 0 & 0 \\
\hline 2016 & PJT & 0 & 0 & 0 & 0 & 0 \\
\hline 2016 & PNC & 0 & 1 & 1 & 1 & 1 \\
\hline 2016 & PNJ & 0 & 0 & 0 & 0 & 0 \\
\hline 2016 & POM & 0 & 1 & 1 & 1 & 1 \\
\hline 2016 & SFG & 0 & 0 & 0 & 0 & 0 \\
\hline 2016 & SFI & 0 & 0 & 0 & 0 & 0 \\
\hline 2016 & SHA & 0 & 0 & 0 & 0 & 0 \\
\hline 2016 & SHI & 0 & 0 & 0 & 0 & 0 \\
\hline 2016 & SHP & 0 & 0 & 0 & 0 & 0 \\
\hline 2016 & SKG & 0 & 0 & 0 & 0 & 0 \\
\hline 2016 & SMC & 0 & 1 & 1 & 1 & 0 \\
\hline 2016 & SPM & 0 & 1 & 1 & 1 & 1 \\
\hline 2016 & SRC & 0 & 0 & 0 & 0 & 0 \\
\hline 2016 & ST8 & 0 & 0 & 0 & 0 & 0 \\
\hline 2016 & VIS & 0 & 1 & 0 & 1 & 0 \\
\hline 2016 & VNG & 0 & 1 & 1 & 1 & 1 \\
\hline 2016 & VNL & 0 & 0 & 0 & 0 & 0 \\
\hline 2016 & VNM & 0 & 0 & 0 & 0 & 0 \\
\hline 2016 & VNS & 0 & 0 & 0 & 0 & 0 \\
\hline 2016 & VOS & 0 & 0 & 0 & 0 & 0 \\
\hline 2017 & VOS & 0 & 0 & 0 & 0 & 0 \\
\hline 2017 & VPH & 0 & 1 & 1 & 1 & 0 \\
\hline 2017 & VPK & 0 & 0 & 0 & 0 & 0 \\
\hline 2017 & VSC & 0 & 0 & 0 & 0 & 0 \\
\hline
\end{tabular}




\begin{tabular}{|c|c|c|c|c|c|c|}
\hline 2017 & VSH & 0 & 1 & 0 & 1 & 1 \\
\hline 2016 & AAA & 0 & 0 & 0 & 0 & 0 \\
\hline 2016 & $\mathrm{ABT}$ & 0 & 1 & 1 & 1 & 1 \\
\hline 2017 & TMT & 0 & 1 & 1 & 1 & 1 \\
\hline 2017 & TNA & 0 & 0 & 0 & 0 & 0 \\
\hline 2017 & TNT & 0 & 1 & 1 & 1 & 1 \\
\hline 2017 & TPC & 0 & 0 & 0 & 0 & 0 \\
\hline 2017 & TRA & 0 & 0 & 0 & 0 & 0 \\
\hline 2017 & TSC & 0 & 1 & 1 & 1 & 1 \\
\hline 2017 & TCO & 0 & 0 & 0 & 0 & 0 \\
\hline 2017 & TCT & 0 & 0 & 0 & 0 & 0 \\
\hline 2017 & TDC & 0 & 1 & 1 & 1 & 0 \\
\hline 2018 & HMC & 1 & 0 & 0 & 0 & 0 \\
\hline 2018 & PIT & 1 & 1 & 0 & 0 & 1 \\
\hline 2018 & PXI & 1 & 1 & 1 & 1 & 1 \\
\hline 2018 & RDP & 1 & 1 & 1 & 1 & 1 \\
\hline 2018 & TCR & 1 & 1 & 1 & 0 & 1 \\
\hline 2018 & TDM & 1 & 1 & 0 & 0 & 1 \\
\hline 2018 & TNT & 1 & 1 & 1 & 1 & 1 \\
\hline 2017 & CIG & 1 & 1 & 1 & 1 & 1 \\
\hline 2017 & CLG & 1 & 1 & 1 & 1 & 1 \\
\hline 2017 & DHM & 1 & 1 & 1 & 1 & 1 \\
\hline 2017 & DIG & 1 & 1 & 1 & 1 & 1 \\
\hline 2017 & DLG & 1 & 1 & 1 & 1 & 1 \\
\hline 2017 & GTN & 1 & 1 & 1 & 1 & 1 \\
\hline 2017 & HAG & 1 & 1 & 1 & 1 & 1 \\
\hline 2017 & HAI & 1 & 1 & 1 & 1 & 1 \\
\hline 2017 & HAR & 1 & 1 & 1 & 1 & 1 \\
\hline 2017 & HQC & 1 & 1 & 1 & 1 & 1 \\
\hline 2017 & HVX & 1 & 1 & 1 & 1 & 1 \\
\hline 2017 & KAC & 1 & 1 & 1 & 1 & 1 \\
\hline 2017 & KSH & 1 & 1 & 1 & 1 & 1 \\
\hline 2017 & LGL & 1 & 1 & 1 & 1 & 1 \\
\hline
\end{tabular}




\begin{tabular}{|c|c|c|c|c|c|c|}
\hline 2017 & PTC & 1 & 1 & 1 & 1 & 1 \\
\hline 2017 & PTL & 1 & 1 & 1 & 1 & 1 \\
\hline 2017 & PXS & 1 & 1 & 1 & 1 & 1 \\
\hline 2017 & TTF & 1 & 1 & 1 & 1 & 1 \\
\hline 2016 & AGM & 1 & 1 & 0 & 0 & 1 \\
\hline 2016 & ASP & 1 & 1 & 1 & 1 & 1 \\
\hline 2016 & BCE & 1 & 1 & 1 & 1 & 1 \\
\hline 2016 & CIG & 1 & 1 & 1 & 1 & 1 \\
\hline 2016 & CLG & 1 & 1 & 1 & 1 & 1 \\
\hline 2016 & DLG & 1 & 1 & 1 & 1 & 1 \\
\hline 2016 & DTT & 1 & 1 & 1 & 1 & 1 \\
\hline 2016 & FDC & 1 & 1 & 1 & 1 & 1 \\
\hline 2016 & HAG & 1 & 1 & 1 & 1 & 1 \\
\hline 2016 & HAR & 1 & 1 & 0 & 0 & 1 \\
\hline 2016 & HU1 & 1 & 1 & 1 & 1 & 1 \\
\hline 2016 & IJC & 1 & 1 & 1 & 1 & 1 \\
\hline 2016 & ITC & 1 & 1 & 1 & 1 & 1 \\
\hline 2016 & KAC & 1 & 1 & 1 & 1 & 1 \\
\hline 2016 & KDH & 1 & 0 & 0 & 0 & 0 \\
\hline 2016 & KSH & 1 & 1 & 1 & 1 & 1 \\
\hline 2016 & LCG & 1 & 1 & 1 & 1 & 1 \\
\hline 2016 & NAV & 1 & 1 & 1 & 1 & 1 \\
\hline 2016 & PAC & 1 & 0 & 0 & 0 & 0 \\
\hline 2016 & PHC & 1 & 1 & 1 & 1 & 1 \\
\hline 2016 & PTC & 1 & 1 & 1 & 1 & 1 \\
\hline 2016 & PTL & 1 & 1 & 1 & 1 & 1 \\
\hline 2016 & PXI & 1 & 1 & 1 & 1 & 1 \\
\hline 2016 & QBS & 1 & 1 & 1 & 1 & 1 \\
\hline 2016 & QCG & 1 & 1 & 1 & 1 & 1 \\
\hline 2016 & STG & 1 & 1 & 1 & 1 & 1 \\
\hline 2016 & SVT & 1 & 1 & 1 & 1 & 1 \\
\hline 2016 & TIE & 1 & 1 & 0 & 1 & 0 \\
\hline 2016 & TMP & 1 & 0 & 0 & 0 & 0 \\
\hline
\end{tabular}




\begin{tabular}{|l|l|l|l|l|l|l|}
\hline 2016 & TTF & 1 & 1 & 1 & 1 & 1 \\
\hline 2016 & VIC & 1 & 1 & 0 & 1 & 0 \\
\hline 2016 & VPH & 1 & 1 & 1 & 0 & 1 \\
\hline 2016 & VRC & 1 & 1 & 1 & 1 & 1 \\
\hline 2017 & TDW & 1 & 0 & 0 & 0 & 0 \\
\hline 2017 & THG & 1 & 0 & 0 & 0 & 0 \\
\hline 2018 & SVT & 1 & 1 & 1 & 1 & 0 \\
\hline 2017 & ANV & 1 & 1 & 1 & 1 & 1 \\
\hline 2017 & BCE & 1 & 1 & 1 & 1 & 1 \\
\hline 2016 & DHM & 1 & 1 & 1 & 1 & 1 \\
\hline 2016 & DIG & 1 & 1 & 1 & 1 & 1 \\
\hline 2016 & LGL & 1 & 1 & 1 & 1 & 1 \\
\hline 2016 & SII & 1 & 1 & 1 & 1 & 1 \\
\hline 2016 & VMD & 1 & 1 & 1 & 1 & 1 \\
\hline 2016 & VNE & 1 & 1 & 1 & 1 & 1 \\
\hline 2017 & VRC & 1 & 1 & 0 & 1 & 1 \\
\hline 2017 & TS4 & 1 & 1 & 1 & 1 & 1 \\
\hline 2017 & PPI & 1 & 1 & 1 & 1 & 1 \\
\hline 2017 & SVT & 1 & 1 & 1 & 1 & 0 \\
\hline 2017 & ANV & 1 & 1 & 0 & 1 & 1 \\
\hline 2017 & BCE & 1 & 1 & 1 & 1 & 1 \\
\hline 2016 & PPI & 1 & 1 & 1 & 1 & 1 \\
\hline 2016 & SII & 1 & 1 & 0 & 1 & 1 \\
\hline 2016 & TIE & 1 & 1 & 0 & 1 & 0 \\
\hline 2016 & VMD & 1 & 1 & 0 & 1 & 1 \\
\hline 2016 & VNE & 1 & 1 & 0 & 1 & 1 \\
\hline & & & & & 1 & \\
\hline
\end{tabular}




\section{References:}

Abbott, L. J., Park, Y., \& Parker, S. (2000). The effects of audit committee activity and independence on corporate fraud. Managerial Finance, 26(11), 55-68.

ACFE. (2012). Report to the nations on occupational fraud and abuse 2012. Association of $\begin{array}{llll}\text { Certified Fraud } & \text { Examiners. } & \text { Retrieved }\end{array}$ https://www.acfe.com/uploadedfiles/acfe_website/content/rttn/2012-report-tonations.pdf

Beasley, M. S. (1996). An empirical analysis of the relation between the board of director composition \& financial statement fraud. Accounting Review, 71(4), 443-465.

Beneish, M. D. (1997). Detecting GAAP violation: Implications for assessing earnings management among firms with extreme financial performance. Journal of Accounting \& Public Policy, 16(3), 271-309.

Beneish, M.D. (1999). The detection of earnings manipulation. Financial Analysts Journal, 5, $24-36$

Beneish, M.D., \& Press, E. (1993). Costs of technical violation of accounting-based debt covenants. The Accounting Review, 68(2), 233-257.

Cressey, D. R. (1953). Other People's Money: A Study in the Social Psychology of Embezzlement. Glencoe, Ill: Free Press.

Dechow, P. M., Ge, W., Larson, C. R., \& Sloan, R. G. (2011). Predicting material accounting misstatements. Contemporary Accounting Research, 28(1), 17-82

Dechow, P. M., Sloan, R. G., \& Sweeney, A. P. (1996). Causes and consequences of earnings manipulation: An analysis of firms subject to enforcement actions by the SEC. Contemporary Accounting Research, 13(1), 1-36.

Hien, N. A., \& Trung, P. T. (2015). Kiểm định và Nhân diện Mô hình nghiên cứu hành viên điều chỉnh lợi nhuận của các công ty niêm yết tại Việt Nam. Tạp chí Phát triển Khoa hoc \& Công nghẹ, 18(3), 7-17

Hoang, V. Q., \& Dung, T. T. (2009). The cultural dimensions of the Vietnamese private entrepreneurship. IUP Journal of Entrepreneurship Development, VI(3-4), 54-78.

Jensen, M. C., \& Meckling, W. H. (1976). Theory of the firm: Managerial behavior, agency costs \& ownership structure. Journal of Financial Economics, 3(4), 305-360.

Jones, J. (1991). Earnings management during import relief investigations. Journal of Accounting Research, 29, 193-228. 
Kanapickiene, R., \& Grudien, Z. (2015), The model of fraud detection in financial statements by means of financial ratios. Procedia - Social and Behavioral Sciences, 213, 321 327

Kothari, S.P., Leone, A.J., \& Wasley, C.E. (2005). Performance matched discretionary accrual measures. Journal of Accounting and Economics, 39, 163-197

La, V. P., \& Vuong, Q. H. (2019). bayesvl: Visually Learning the Graphical Structure of Bayesian Networks and Performing MCMC with 'Stan'. The Comprehensive $R$ Archive Network (CRAN). Retrieved from <https://cran.rproject.org/web/packages/bayesvl/index.html>; version 0.8.5.

Leonard, M. J., \& Alam, P. (2009), An historical perpective on fraud detection: From bankruptcy models to most effective indincators of fraud in recent incidents. Journal of Forensic \& Investigative Acccounting, 1(1), 3-11

Loebbecke, J. K., Eining, M. M., \& Willingham, J. J. (1989). Auditors' experience with material irregularities: Frequency, nature and detectability. Auditing: A Journal of Practice \& Theory, 9(1), 1-28.

Lou, Y.-I., \& Wang, M.-L. (2011). Fraud risk factor of the fraud triangle assessing the likelihood of fraudulent financial reporting. Journal of Business \& Economics Research (JBER), 7(2).

Marinakis, P. (2011). An investigation in earnings management and earnings manipulation in UK (PhD Thesis). University of Nottingham, Nottingham, UK. URL: http://eprints.nottingham.ac.uk/id/eprint/12874.

McElreath, R. (2018). Statistical Rethinking: A Bayesian Course with Examples in $R$ and Stan. London, UK: Chapman and Hall/CRC.

McFadden, D. (1974). Conditional logit analysis of qualitative choice behavior. In P. Zarembka (Ed.), Frontiers in Econometrics. New York, NY: Academic Press.

MOF. (2001). Chuẩn mực kiểm toán Việt Nam số 400 - Kiểm toán. Ministry of Finance. Retrieved from https://thuvienphapluat.vn/van-ban/Ke-toan-Kiem-toan/Quyet-dinh143-2001-QD-BTC-sau-chuan-muc-kiem-toan-Viet-Nam-dot-3-240-300-400-530540-610-49397.aspx

MOF. (2012). Chuẩn mực kiểm toán Việt Nam số 240 - Trách nhiệm của kiểm toán viên đối với gian lận trong kiểm toán báo cáo tài chính. Ministry of Finance. Retrieved from https://www.kreston.vn/vbpl/kiem-toan/chuan-muc-kiem-toan/vsa-240/

Persons, O. (1995). Using financial statement data to identify factors ssociated with fraudulent financing reporting. Journal of Applied Business Research, 11, 38-46 
Phương, N. C., \& Trân, N. T. N. (2014). Mô hình Beneish dự đoán sai sót trọng yếu trong báo cáo tài chính. Tạp chí Kinh tế \& Phát triển, 206(8), 54 - 60.

PwC. (2018). Khảo sát về tội phạm kinh tế và gian lận toàn cầu 2018 - Đưa hành vi gian lận ra ánh sang - Góc nhìn Việt Nam. PwC. Retrieved from https://www.pwc.com/vn/vn/publications/vietnam-publications/economic-crimefraud-survey-2018.html

Scutari, M. (2010). Learning Bayesian Networks with the bnlearn R Package. Journal of Statistical Software, 35(3), 1-22. doi:10.18637/jss.v035.i03

Skousen, C. J., Smith, K. R., \& Wright, C. J. (2009). Detecting \& predicting financial statement fraud: The effectiveness of the fraud triangle \& SAS No. 99. Advances in Financial Economics, 13, 53-81.

Tân, T. T. G, Tri, N. T., Tú, Đ. N., Hiệp, H. T., \& Uyên, N. Đ. H. (2014). Đánh giá rủi ro gian lận của các công ty niêm yết tại Việt Nam. Tạp chí Phát triển kinh tế, 26(1), 74-94.

Vu, T. H., Nguyen, V. D., Ho, M. T., \& Vuong, Q. H. (2019). Determinants of Vietnamese listed firm performance: Competition, wage, CEO, firm size, age, and international trade. Journal of Risk and Financial Management, 12(2), 62, DOI: $10.3390 / \mathrm{jrfm} 12020062$.

Vuong, Q. H. (2018). The (ir)rational consideration of the cost of science in transition economies. Nature Human Behaviour, 2(1), 5, DOI: 10.1038/s41562-017-0281-4.

Vuong, Q. H., La, V. P., Vuong, T. T., Nguyen, V. H., Ho, M. T., Nguyen, T. H. K., Bui, Q. K., \& Ho, M. T.. (2018). Cultural additivity: Behavioural insights from the interaction of Confucianism, Buddhism, and Taoism in folktales. Palgrave Communications, 4 , 143, DOI: $10.1057 / \mathrm{s} 41599-018-0189-2$. 